\title{
Copyright
}

by

Haryanto Adiguna

2012 
The Thesis Committee for Haryanto Adiguna Certifies that this is the approved version of the following thesis:

\section{Comparative Study for the Interpretation of Mineral Concentrations, Total Porosity, and TOC in Hydrocarbon-Bearing Shale from Conventional Well Logs}

APPROVED BY
SUPERVISING COMMITTEE:

Supervisor:

Carlos Torres-Verdín

Matthew Balhoff 
Comparative Study for the Interpretation of Mineral Concentrations, Total Porosity, and TOC in Hydrocarbon-Bearing Shale from Conventional Well Logs

\author{
by \\ Haryanto Adiguna, B.S.M.E.; M.S. \\ Thesis \\ Presented to the Faculty of the Graduate School of \\ The University of Texas at Austin \\ in Partial Fulfillment \\ of the Requirements \\ for the Degree of
}

Master of Science in Engineering

The University of Texas at Austin

December 2012 


\section{Dedication}

To my wife, Silviago. 


\section{Acknowledgements}

First and foremost, I would like to thank my advisor, Dr. Carlos Torres-Verdín for his guidance and support throughout this research. It was an honor to have been a part of his formation evaluation research group looking beyond conventional wisdom. I would also like to thank Dr. Matthew Balhoff, the second reader of this thesis.

I am deeply grateful to be surrounded by people who have been very supportive and helpful: Dr. Zoya Heidari for her endless patience in explaining and answering questions on the inversion algorithm, Ben Voss for his quick responses about UTAPWeLS software, Paul Linden for reviewing and suggesting corrections for this thesis, and all my colleagues in the UT FE research group for making my study here a productive and enjoyable experience.

I would like to thank Dr. Ursula Hammes for our technical discussions about the geology of Haynesville shale and Dr. Stephen Ruppel for his lectures and our discussions of the Barnett shale and mudrock mineralogy. I am grateful to Christopher Skelt for his insight on the nuclear capture gamma-ray spectroscopy log and our discussions on the interpretation of Haynesville shale. I am also thankful for the technical and administrative assistance from Rey Casanova, Roger Terzian, and Frankie Hart.

Thanks are due to BG, BP, Chevron, ConocoPhillips, and Marathon Oil for providing the data sets used in the research. The work reported in this thesis was funded by the University of Texas at Austin's Research Consortium on Formation Evaluation, jointly sponsored by Anadarko, Apache, Aramco, Baker-Hughes, BG, BHP Billiton, BP, Chevron, China Oilfield Services, LTD., ConocoPhillips, ENI, ExxonMobil, Halliburton, Hess, Maersk, Marathon Oil Corporation, Mexican Institute for Petroleum, Nexen, 
ONGC, Petrobras, Repsol, RWE, Schlumberger, Shell, Statoil, Total, Weatherford and Woodside Petroleum Limited. 


\begin{abstract}
Comparative Study for the Interpretation of Mineral Concentrations, Total Porosity, and TOC in Hydrocarbon-Bearing Shale from Conventional Well Logs
\end{abstract}

\author{
Haryanto Adiguna, M.S.E. \\ The University of Texas at Austin, 2012
}

Supervisor: Carlos Torres-Verdín

The estimation of porosity, water saturation, kerogen concentration, and mineral composition is an integral part of unconventional shale reservoir formation evaluation. Porosity, water saturation, and kerogen content determine the amount of hydrocarbon-inplace while mineral composition affects hydro-fracture generation and propagation. Effective hydraulic fracturing is a basic requirement for economically viable flow of gas in very-low permeability shales. Brittle shales are favorable for initiation and propagation of hydraulic fracture because they require marginal or no plastic deformation. By contrast, ductile shales tend to oppose fracture propagation and can heal hydraulic fractures. Silica and carbonate-rich shales often exhibit brittle behavior while clay-rich shales tend to be ductile.

Many operating companies have turned their attention to neutron capture gammaray spectroscopy (NCS) logs for assessing in-situ mineral composition. The NCS tool converts the energy spectrum of neutron-induced captured gamma-rays into relative vii 
elemental yields and subsequently transforms them to dry-weight elemental fractions. However, NCS logs are not usually included in a well-logging suite due to cost, tool availability, and borehole conditions. Conventional well logs are typically acquired as a minimum logging program because they provide geologists and petrophysicists with the basic elements for tops identification, stratigraphic correlation, and net-pay determination. Most petrophysical interpretation techniques commonly used to quantify mineral composition from conventional well logs are based on the assumption that lithology is dominated by one or two minerals. In organic shale formations, these techniques are ineffective because all well logs are affected by large variations of mineralogy and pore structure. Even though it is difficult to separate the contribution from each mineral and fluid component on well logs using conventional interpretation methods, well logs still bear essential petrophysical properties that can be estimated using an inversion method.

This thesis introduces an inversion-based workflow to estimate mineral and fluid concentrations of shale gas formations using conventional well logs. The workflow starts with the construction and calibration of a mineral model based on core analysis of crushed samples and X-Ray Diffraction (XRD). We implement a mineral grouping approach that reduces the number of unknowns to be estimated by the inversion without loss of accuracy in the representation of the main minerals. The second step examines various methods that can provide good initial values for the inversion. For example, a reliable prediction of kerogen concentration can be obtained using the $\Delta \log R$ method (Passey et al., 1990) as well as an empirical correlation with gamma-ray or uranium logs. After the mineral model is constructed and a set of initial values are established, nonlinear joint inversion estimates mineral and fluid concentrations from conventional well logs. An iterative refinement of the mineral model can be necessary depending on viii 
formation complexity and data quality. The final step of the workflow is to perform rock classification to identify favorable production zones. These zones are selected based on their hydrocarbon potential inferred from inverted petrophysical properties.

Two synthetic examples with known mineral compositions and petrophysical properties are described to illustrate the application of inversion. The impact of shoulderbed effects on inverted properties is examined for the two inversion modes: depth-bydepth and layer-by-layer. This thesis also documents several case studies from Haynesville and Barnett shales where the proposed workflow was successfully implemented and is in good agreement with core measurements and NCS logs. The field examples confirm the accuracy and reliability of nonlinear inversion to estimate porosity, water saturation, kerogen concentration, and mineral composition. 


\section{Table of Contents}

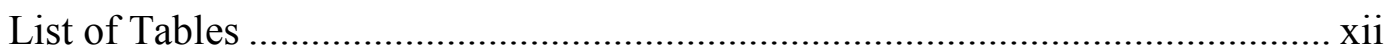

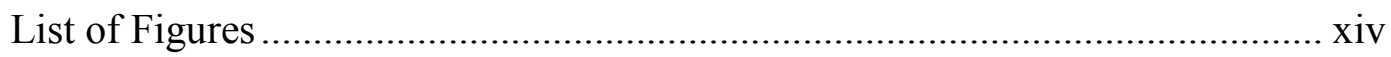

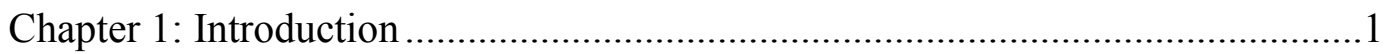

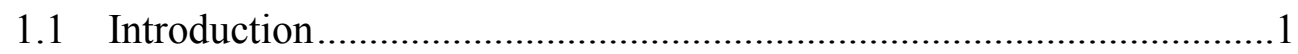

1.2 Objectives and Scope .................................................................

Chapter 2: Petrophysical Model for Gas Shales ......................................................6

2.1 Petrophysical Properties and Mineral Compositions ..............................6

2.2 Integration of Core Measurements......................................................12

2.3 Well-Log Responses in Shale-Gas Formations .................................16

Chapter 3: Application of Nonlinear Inversion of Well Logs to Estimate Mineral

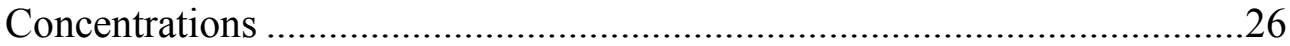

3.1 Construction of the Mineral Model....................................................26

3.2 Estimation of TOC and Kerogen Concentration....................................31

3.3 Calibration of Mineral Model and Petrophysical Properties .................37

3.4 Nonlinear Joint Inversion of Conventional Well Logs ..........................38

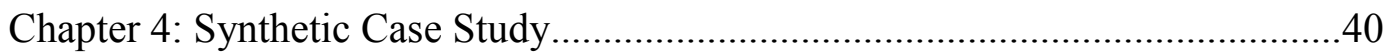

4.1 Construction of the Synthetic Model and Simulated Well Logs .........40

$4.2 \quad$ Synthetic Case 1 ..................................................................................41

4.3 Synthetic Case 2 ............................................................................4

Chapter 5: Haynesville Shale Case Study ............................................................48

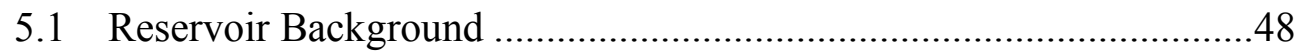

5.2 Mineral Model and Associated Parameters ..........................................51

5.3 Inversion Results and Discussion .......................................................

Chapter 6: Barnett Shale Case Study ..............................................................62

6.1 Reservoir Background ..................................................................62

6.2 Mineral Model and Associated Parameters ...........................................65 


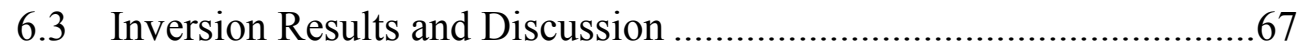

Chapter 7: Summary and Conclusions.............................................................

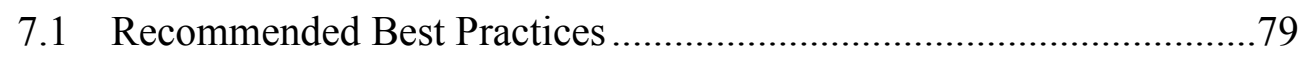

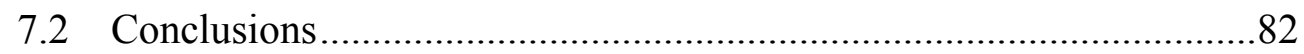

7.3 Applications and Suggestions for Future Research ..............................85

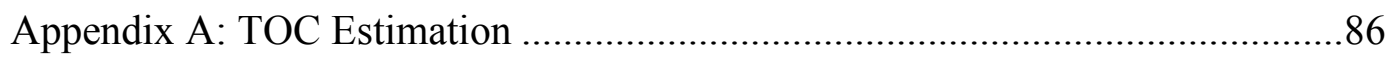

Appendix B: Geochemical Analysis of Kerogen from RockEval Pyrolysis .......100

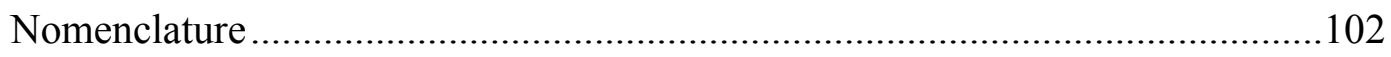

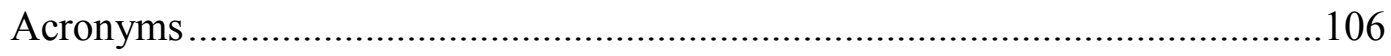

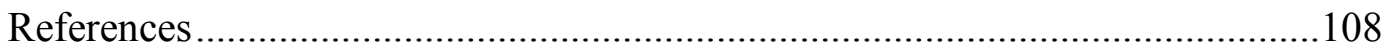




\section{List of Tables}

Table 2.1: Average petrophysical properties of Haynesville and Barnett shales based on GRI analysis performed in 8 wells with core samples. The range value for each property is given between parentheses, next to the corresponding average values.

Table 2.2: Average volumetric concentrations (in fraction of solid volume) of various minerals from XRD analysis performed in 8 wells with core samples in the Haynesville and Barnett shales. Main minerals are present in the form of $V_{\text {quartz }}, V_{p \text {-feldspar }}, V_{\text {calcite }}, V_{\text {illite, }}, V_{\text {chlorite }}, V_{m i x}$, and $V_{\text {kaolinite. }}$. Accessory minerals include $V_{k \text {-feldspar }}, V_{\text {dolomite }}, V_{\text {ankerite }}, V_{\text {pyrite, }}$, and

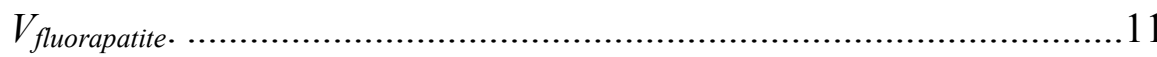

Table 3.1: List of unknowns and inputs of the original system of equations used to estimate mineral concentrations

Table 3.2: Average solid volumetric concentrations of grouped minerals measured with XRD analysis of core samples from 8 wells in the Haynesville and Barnett organic shales.

Table 4.1: Assumed mineral and fluid constituents for Synthetic Case 1. The multi-layer formation is comprised of these two layers alternating with different thickness, ranging from 0.5 to $10 \mathrm{ft}$. 42

Table 4.2: Synthetic Case 1: Summary of assumed Archie's parameters, and matrix, fluid, and formation properties

Table 4.3: Summary of assumed Archie's parameters, and matrix, fluid, and formation properties for Synthetic Case 2 . 
Table 4.4: Comparison of the arithmetic mean percent error of petrophysical properties and mineral volumetric concentrations estimated from depthby-depth and layer-by-layer inversions for Synthetic Case 2...........45

Table 5.1: Description of the mineral model for the Haynesville shale..............52

Table 6.1: Description of the mineral model for the Barnett shale.....................66 


\section{List of Figures}

Figure 2.1: Schematic of typical mineral and fluid constituents of a shale gas formation. Volume of the rock consists of solid matrix, hydrocarbon, and water. The solid matrix is composed of dry clay mineral $\left(V_{\text {clay }}\right)$, kerogen $\left(V_{\text {kerogen }}\right)$, and other non-clay minerals such as quartz $\left(V_{\text {quartz }}\right)$, calcite $\left(V_{\text {calcite }}\right)$, plagioclase feldspar $\left(V_{p \text {-feldspar }}\right)$, potassium feldspar $\left(V_{k \text { - }}\right.$ feldspar $)$, dolomite $\left(V_{\text {dolomite }}\right)$, ankerite $\left(V_{\text {ankerite }}\right)$, pyrite $\left(V_{\text {pyrite }}\right)$, fluorapatite ( $\left.V_{\text {fluorapatite }}\right)$. Water is present in the matrix $\left(V_{W-\text { matrix }}\right)$, as clay bound $\left(V_{W-}\right.$ clay $)$, while hydrocarbon is present in matrix pore $\left(V_{H C-\text { matrix }}\right)$ and kerogen

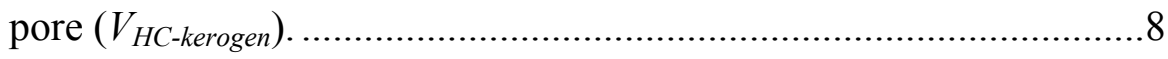

Figure 2.2: Ternary plot representation of mineral composition based on XRD analysis of core samples from a total of 8 wells in (a) Haynesville, and (b) Barnett shales. 12

Figure 2.3: Correlation of core Total Organic Carbon (TOC) in weight percent to (a) gamma ray, (b) apparent resistivity, (c) photoelectric factor, (d) bulk density, and (e) neutron porosity (in limestone matrix) in the Haynesville (to the left), and Barnett shales (to the right). 18

Figure 2.4: Correlation of PEF log with weight concentration of mineral groups estimated from NCS logs in the Haynesville (left), and Barnett shales (right): (a) quartz, feldspar, and mica $\left(W_{Q F M}\right)$, (b) carbonate $\left(W_{C A R}\right)$, (c) clay $\left(W_{C L A}\right)$, and (d) pyrite $\left(W_{\text {pyrite }}\right)$ 22 
Figure 2.5: Example of shoulder-bed effects on apparent resistivity induction logs originating from thin conductive beds. Track 1: Relative depth. Track 2: Gamma ray and caliper logs. Track 3: Electrical micro-resistivity image logs. Track 4: Electrical micro-resistivity. Track 5: Apparent resistivity induction logs. Track 6: Standard-resolution and high-resolution PEF logs. Track 7: Neutron porosity (limestone matrix), standard-resolution bulk density, and high-resolution bulk density logs. .25

Figure 3.1: Schematic of the grouped mineral model. Three mineral groups are considered: (1) $V_{Q F}$ consisting of quartz $\left(V_{\text {quartz }}\right)$, plagioclase feldspar $\left(V_{p \text {-feldspar }}\right)$, and potassium feldspar $\left(V_{k \text {-feldspar }}\right)$; (2) $V_{C A R}$ consisting of calcite $\left(V_{\text {calcite }}\right)$, dolomite $\left(V_{\text {dolomite }}\right)$, and ankerite $\left(V_{\text {ankerite }}\right)$; (3) $V_{C L A}$ consisting of clay $\left(V_{\text {clay }}\right)$, pyrite $\left(V_{\text {pyrite }}\right)$, and fluorapatite $\left(V_{\text {fluorapatite }}\right)$. Remaining constituents are (4) solid kerogen $\left(V_{\text {kerogen }}\right),(5)$ water $\left(V_{W}\right)$,

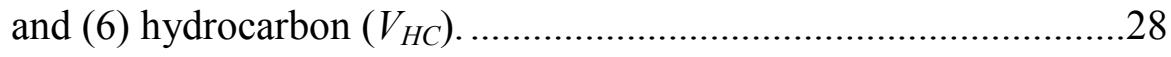

Figure 3.2: Comparison of measured and calculated bulk density $\left(\rho_{b}\right)$ and grain $\operatorname{density}\left(\rho_{g}\right)$ based on the original and grouped mineral models for (a) Haynesville, and (b) Barnett shales 30

Figure 3.3: Measured (in green) and calculated (in orange) Vitrinite reflectance values $\left(R_{o}\right)$ based on core samples from a total of 5 wells in (a) Haynesville, and (b) Barnett shales.

Figure 3.4: Determination of $L O M$ from $S_{2}$ vs. TOC cross-plot obtained from RockEval pyrolysis measurements of core samples in (a) Haynesville, and (b) Barnett shales. The cross-plot is adapted from Passey et al. (1990) 
Figure 3.5: Comparison of various $T O C$ estimation methods and core data for a Barnett shale field example. Track 1: Relative depth. Track 2: Gammaray and caliper logs. Track 3: TOC estimated from the gamma-ray log. Track 4: $T O C$ calculated with the sonic/resistivity $\triangle \log R$ method. Track 5: $T O C$ calculated with the bulk density/resistivity $\triangle \log R$ method. Track 6: $T O C$ calculated with the neutron porosity/resistivity $\Delta \log R$ method.

Figure 3.6: Comparison between estimated initial clay volumetric concentration $\left(V_{\text {clay }}\right)$ and clay weight concentration $\left(W_{\text {clay }}\right)$ from NCS logs for field examples in (a) Haynesville, and (b) Barnett shales. 39

Figure 4.1: Cross-plot of log bulk density $\left(\rho_{b}\right)$ and kerogen volumetric concentration $\left(V_{\text {kerogen }}\right)$ for Synthetic Case 2.

Figure 4.2: Synthetic Case 1. Track 1: Relative depth. Track 2: Gamma-ray log. Track 3: Array-induction apparent resistivity logs. Track 4: PEF, bulk density, and neutron (limestone matrix) porosity logs. Track 5: Earth model and inverted porosity. Track 6: Earth model and inverted water saturation. Track 7: Earth model and inverted kerogen volumetric concentration. Track 8: Earth model mineral compositions. Track 9: Mineral compositions obtained from depth-by-depth inversion. Track 10: Mineral compositions obtained from layer-by-layer inversion. .46 
Figure 4.3: Synthetic Case 2. Track 1: Relative depth. Track 2: Gamma-ray log. Track 3: Array-induction apparent resistivity logs. Track 4: PEF, bulk density, and neutron (limestone matrix) porosity logs. Track 5: Earth model and inverted porosity. Track 6: Earth model and inverted water saturation. Track 7: Earth model and inverted kerogen volumetric concentration. Track 8: Earth model mineral compositions. Track 9: Mineral compositions obtained from depth-by-depth inversion. Track 10: Mineral compositions obtained from layer-by-layer inversion. .47

Figure 5.1: Map of Haynesville shale showing surrounding basins and main structural elements during the time of deposition. Haynesville shale productive areas are highlighted with red stripes (Hammes et al., 2011, (C) AAPG 2011, reprinted by permission of the AAPG, whose permission is required for further use).

Figure 5.2: Haynesville shale stratigraphic column. The right-most track shows the geological age in million years. $\mathrm{LST}=$ lowstand systems tract, $\mathrm{TST}=$ transgressive systems tract, $\mathrm{HST}=$ highstand systems tract, MFS = maximum flooding surface. (Hammes et al., 2011, (C) AAPG 2011, reprinted by permission of the AAPG, whose permission is required for further use)

Figure 5.3: Ternary diagram showing the Haynesville shale mineral distribution estimated from NCS log mineral weight concentrations (left), and mineral group weight concentrations obtained from inversion of well logs (right): (a) Well H1, (b) Well H2, (c) Well H3, (d) Well H4, and (e) Well H5 .56 
Figure 5.4: Case study in well H1. Track 1: Relative depth. Track 2: PEF quality control flag. Track 3: Gamma-ray and caliper logs. Track 4: Arrayinduction apparent resistivity logs. Track 5: PEF, bulk density, and neutron (limestone matrix) porosity logs. Track 6: Core and inverted porosity. Track 7: Core and inverted water saturation. Track 8: Core and inverted kerogen volumetric concentration. Track 9: XRD mineral compositions. Track 10: NCS log mineral compositions. Track 11: Mineral compositions obtained from depth-by-depth inversion. Track 12: Mineral compositions obtained from layer-by-layer inversion. .57

Figure 5.5: Case study in well H2. Track 1: Relative depth. Track 2: Gamma-ray and caliper logs. Track 3: Array-induction apparent resistivity logs. Track 4: PEF, bulk density, and neutron (limestone matrix) porosity logs. Track 5 Core and inverted porosity. Track 6: Core and inverted water saturation. Track 7: Core and inverted kerogen volumetric concentration. Track 8: XRD mineral compositions. Track 9: NCS log mineral compositions. Track 10: Mineral compositions obtained from depth-by-depth inversion. Track 11: Mineral compositions obtained

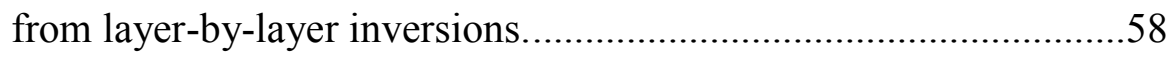


Figure 5.6: Case study in well H3. Track 1: Relative depth. Track 2: Gamma-ray and caliper logs. Track 3: Array-induction apparent resistivity logs. Track 4: PEF, bulk density, and neutron (limestone matrix) porosity logs. Track 5 Core and inverted porosity. Track 6: Core and inverted water saturation. Track 7: Core and inverted kerogen volumetric concentration. Track 8: XRD mineral compositions. Track 9: NCS log mineral compositions. Track 10: Mineral compositions obtained from depth-by-depth inversion. Track 11: Mineral compositions obtained from layer-by-layer inversion .59

Figure 5.7: Case study in well H4. Track 1: Relative depth. Track 2: Gamma-ray and caliper logs. Track 3: Array-induction apparent resistivity logs. Track 4: PEF, bulk density, and neutron (limestone matrix) porosity logs. Track 5 Core and inverted porosity. Track 6: Core and inverted water saturation. Track 7: Core and inverted kerogen volumetric concentration. Track 8: XRD mineral compositions. Track 9: NCS log mineral compositions. Track 10: Mineral compositions obtained from depth-by-depth inversion. 60

Figure 5.8: Case study in well H5. Track 1: Relative depth. Track 2: Gamma-ray and caliper logs. Track 3: Array-induction apparent resistivity logs. Track 4: PEF, bulk density, and neutron (limestone matrix) porosity logs. Track 5 Core and inverted porosity. Track 6: Core and inverted water saturation. Track 7: Core and inverted kerogen volumetric concentration. Track 8: XRD mineral compositions. Track 9: Mineral compositions obtained from depth-by-depth inversion. 
Figure 6.1: Map of the Barnett shale showing contour lines drawn from top of the Ellenburger formation. Newark East field, one of the main producing areas, is shaded in gray (Montgomery et al., 2005, () AAPG 2005, reprinted by permission of the AAPG, whose permission is required for further use).

Figure 6.2: Stratigraphic column of the Fort Worth basin. The expanded section shows interpreted stratigraphic variations across the basin in the SW-NE orientation (Montgomery et al., 2005, C AAPG 2005, reprinted by permission of the AAPG, whose permission is required for further use).

Figure 6.3: Ternary diagram showing the Barnett shale mineral distribution estimated from NCS log mineral weight concentrations (left), and mineral group weight concentrations obtained from inversion (right): (a) Well B1, (b) Well B2, (c) Well B3, (d) Well B4, (e) Well B5 upper Barnett section, and (e) Well B5 lower Barnett section...................72

Figure 6.4: Case study in well B1. Track 1: Relative depth. Track 2: Gamma-ray and caliper logs. Track 3: Array-induction apparent resistivity logs. Track 4: PEF, bulk density, and neutron (limestone matrix) porosity logs. Track 5: Core and inverted porosity. Track 6: Core and inverted water saturation. Track 7: Core and inverted kerogen volumetric concentration. Track 8: XRD mineral compositions. Track 9: NCS log mineral compositions. Track 10: Mineral compositions obtained from depth-by-depth inversion. Track 11: Mineral compositions obtained from layer-by-layer inversion. .73 
Figure 6.5: Case study in well B2. Track 1: Relative depth. Track 2: Gamma-ray and caliper logs. Track 3: Array-induction apparent resistivity logs. Track 4: PEF, bulk density, and neutron (limestone matrix) porosity logs. Track 5: Core and inverted porosity. Track 6: Core and inverted water saturation. Track 7: Core and inverted kerogen volumetric concentration. Track 8: XRD mineral compositions. Track 9: NCS log mineral compositions. Track 10: Mineral compositions obtained from depth-by-depth inversion. Track 11: Mineral compositions obtained from layer-by-layer inversion. .74

Figure 6.6: Case study in well B3. Track 1: Relative depth. Track 2: Gamma-ray and caliper logs. Track 3: Array-induction apparent resistivity logs. Track 4: PEF, bulk density, and neutron (limestone matrix) porosity logs. Track 5: Inverted porosity. Track 6: Inverted water saturation. Track 7: Inverted kerogen volumetric concentration. Track 8: NCS log mineral compositions. Track 9: Mineral compositions obtained from depth-by-depth inversion. Track 10: Mineral compositions obtained from layer-by-layer inversion. .75

Figure 6.7: Case study in well B4. Track 1: Relative depth. Track 2: Gamma-ray and caliper logs. Track 3: Array-induction apparent resistivity logs. Track 4: PEF, bulk density, and neutron (limestone matrix) porosity logs. Track 5: Inverted porosity. Track 6: Inverted water saturation. Track 7: Inverted kerogen volumetric concentration. Track 8: Mineral compositions obtained from depth-by-depth inversion. .76 
Figure 6.8: Case study in well B5, upper Barnett section. Track 1: Relative depth. Track 2: Gamma-ray and caliper logs. Track 3: Array-induction apparent resistivity logs. Track 4: PEF, bulk density, and neutron (limestone matrix) porosity logs. Track 5: Core and inverted porosity. Track 6: Core and inverted water saturation. Track 7: Core and inverted kerogen volumetric concentration. Track 8: XRD mineral compositions. Track 9: NCS log mineral compositions. Track 10: Mineral compositions obtained from depth-by-depth inversion .77

Figure 6.9: Case study in well B5, lower Barnett section. Track 1: Relative depth. Track 2: Gamma-ray and caliper logs. Track 3: Array-induction apparent resistivity logs. Track 4: PEF, bulk density, and neutron (limestone matrix) porosity logs. Track 5: Core and inverted porosity. Track 6: Core and inverted water saturation. Track 7: Core and inverted kerogen volumetric concentration. Track 8: XRD mineral compositions. Track 9: NCS log mineral compositions. Track 10: Mineral compositions obtained from depth-by-depth inversion......................................78

Figure 7.1: Flow chart describing our recommended best practices for interpretation of conventional well logs acquired in organic shale

Figure A.1: Correlation of core Total Organic Carbon (TOC) in weight percent to (a) gamma-ray log and (b) uranium log in the Haynesville (to the left), and Barnett shales (to the right). 89 
Figure A.2: Comparison of various TOC estimation methods in well H1. Track 1: Relative depth. Track 2: Gamma-ray and caliper logs. Track 3: Arrayinduction apparent resistivity logs. Track 4: PEF, bulk density, and neutron (limestone matrix) porosity logs. Track 5: TOC from core and estimated from gamma-ray log. Track 6: TOC from core and estimated from uranium log. Track 7: TOC from core and $\triangle \log R$ estimation using the sonic log. Track 8: TOC from core and $\triangle \log R$ estimation using the bulk density log. Track 9: TOC from core and $\Delta \log R$ estimation using

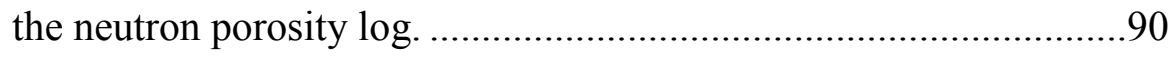

Figure A.3: Comparison of various TOC estimation methods in well H2. Track 1: Relative depth. Track 2: Gamma-ray and caliper logs. Track 3: Arrayinduction apparent resistivity logs. Track 4: PEF, bulk density, and neutron (limestone matrix) porosity logs. Track 5: TOC from core and estimated from gamma-ray log. Track 6: TOC from core and $\triangle \log R$ estimation using the sonic log. Track 7: TOC from core and $\triangle \log R$ estimation using the bulk density log. Track 8: TOC from core and $\Delta \log R$ estimation using the neutron porosity log. . .91 
Figure A.4: Comparison of various TOC estimation methods in well H3. Track 1: Relative depth. Track 2: Gamma-ray and caliper logs. Track 3: Arrayinduction apparent resistivity logs. Track 4: PEF, bulk density, and neutron (limestone matrix) porosity logs. Track 5: TOC from core and estimated from gamma-ray log. Track 6: TOC from core and estimated from uranium log. Track 7: TOC from core and $\triangle \log R$ estimation using the sonic log. Track 8: TOC from core and $\triangle \log R$ estimation using the bulk density log. Track 9: TOC from core and $\triangle \log R$ estimation using

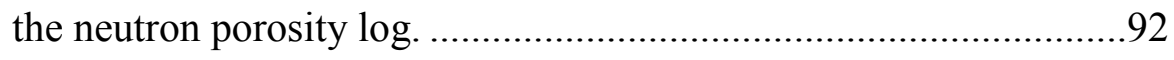

Figure A.5: Comparison of various TOC estimation methods in well H4. Track 1: Relative depth. Track 2: Gamma-ray and caliper logs. Track 3: Arrayinduction apparent resistivity logs. Track 4: PEF, bulk density, and neutron (limestone matrix) porosity logs. Track 5: TOC from core and estimated from gamma-ray log. Track 6: TOC from core and estimated from uranium $\log$. Track 7: TOC from core and $\triangle \log R$ estimation using the sonic $\log$. Track 8: TOC from core and $\triangle \log R$ estimation using the bulk density log. Track 9: TOC from core and $\triangle \log R$ estimation using the neutron porosity $\log$. .93 
Figure A.6: Comparison of various TOC estimation methods in well H5. Track 1:

Relative depth. Track 2: Gamma-ray and caliper logs. Track 3: Arrayinduction apparent resistivity logs. Track 4: PEF, bulk density, and neutron (limestone matrix) porosity logs. Track 5: TOC from core and estimated from gamma-ray log. Track 6: TOC from core and $\triangle \log R$ estimation using the sonic log. Track 7: TOC from core and $\triangle \log R$ estimation using the bulk density log. Track 8: TOC from core and $\triangle \log R$ estimation using the neutron porosity log. 94

Figure A.7: Comparison of various TOC estimation methods in well B1. Track 1: Relative depth. Track 2: Gamma-ray and caliper logs. Track 3: Arrayinduction apparent resistivity logs. Track 4: PEF, bulk density, and neutron (limestone matrix) porosity logs. Track 5: TOC from core and estimated from gamma-ray log. Track 6: TOC from core and $\triangle \log R$ estimation using the sonic $\log$. Track 7: TOC from core and $\triangle \log R$ estimation using the bulk density log. Track 8: TOC from core and $\Delta \log R$ estimation using the neutron porosity log. 95

Figure A.8: Comparison of various TOC estimation methods in well B2. Track 1: Relative depth. Track 2: Gamma-ray and caliper logs. Track 3: Arrayinduction apparent resistivity logs. Track 4: PEF, bulk density, and neutron (limestone matrix) porosity logs. Track 5: TOC from core and estimated from gamma-ray log. Track 6: TOC from core and $\triangle \log R$ estimation using the sonic $\log$. Track 7: TOC from core and $\triangle \log R$ estimation using the bulk density log. Track 8: TOC from core and $\Delta \log R$ estimation using the neutron porosity $\log$. 
Figure A.9: Comparison of various TOC estimation methods in well B3. Track 1:

Relative depth. Track 2: Gamma-ray and caliper logs. Track 3: Arrayinduction apparent resistivity logs. Track 4: PEF, bulk density, and neutron (limestone matrix) porosity logs. Track 5: TOC estimated from gamma-ray log. Track 6: TOC from $\triangle \log R$ estimation using the sonic log. Track 7: TOC from $\triangle \log R$ estimation using the bulk density log. Track 8: TOC from $\triangle \log R$ estimation using the neutron porosity log.97

Figure A.10: Comparison of various TOC estimation methods in well B4. Track 1: Relative depth. Track 2: Gamma-ray and caliper logs. Track 3: Arrayinduction apparent resistivity logs. Track 4: PEF, bulk density, and neutron (limestone matrix) porosity logs. Track 5: TOC estimated from gamma-ray log. Track 6: $T O C$ from $\triangle \log R$ estimation using the bulk density $\log$. Track 7: TOC from $\triangle \log R$ estimation using the neutron porosity $\log$. .98

Figure A.11: Comparison of various TOC estimation methods in well B5. Track 1: Relative depth. Track 2: Gamma-ray and caliper logs. Track 3: Arrayinduction apparent resistivity logs. Track 4: PEF, bulk density, and neutron (limestone matrix) porosity logs. Track 5: TOC from core and estimated from gamma-ray log. Track 6: TOC from core and estimated from uranium log. Track 7: TOC from core and $\triangle \log R$ estimation using the sonic log. Track 8: TOC from core and $\triangle \log R$ estimation using the bulk density log. Track 9: TOC from core and $\Delta \log R$ estimation using the neutron porosity log. .99 
Figure B.1: Pseudo-Van Krevelen diagram constructed from RockEval

measurements of core samples for: (a) Haynesville, and (b) Barnett

shales. Figure is adapted from Espitalie et al. (1977)...................101

xxvii 


\section{Chapter 1: Introduction}

Low-permeability, organic-rich shale formations have recently become an economical source of energy due to advances in drilling and completion technology-in particular, horizontal drilling and hydraulic fracturing. Among unconventional reservoirs, shale gas has gained considerable attention from the oil and gas industry in the United States because of its abundance and lower levels of greenhouse gas emissions compared to other fossil fuels. In 2011, the U.S. Energy Information Administration (EIA) estimated that technically recoverable shale gas resources in the United States amount to 750 trillion cubic feet (tcf) (U.S. Energy Information Administration, 2011). Among all shale gas plays in the U.S., the largest fields are Marcellus (410 tcf), Haynesville/Bossier (75 tcf), and Barnett (43 tcf).

\subsection{INTRODUCTION}

To optimize production from a shale reservoir, operating companies need to determine the most favorable zones for well placement, perforation, and hydraulic fracturing. Favorable production zones depend on the rock's hydrocarbon potential and flow capacity. Unlike in conventional reservoirs, the hydrocarbon potential of shale-gas formations is a combination of the amount of free gas and adsorbed gas. In petrophysical terms, the gas potential is governed by porosity, water saturation, total organic carbon content (TOC), and kerogen type and thermal maturity (Vitrinite reflection). These properties were studied extensively when organic-rich shales were evaluated as source rocks, but they need to be revisited as sources of hydrocarbons. Evaluation of gas flow capacity in shale formations is a more recent research subject that prompted significant research and development attention when multi-stage hydraulic fracturing made these 
reservoirs economically tractable. It is a complicated subject that is difficult to simulate in a laboratory setting. Without assistance of hydraulic fractures, the ability of gas to flow in low-permeability shale depends on its matrix permeability, pore pressure, and existing fracture systems.

Because economical flow can only be established by means of hydraulic fracturing, fracturability (which is a measure of how easily a fracture can be generated and propagated in a rock) becomes an important factor. Fracturability depends on the rock's elastic properties such as compressive and tensile strength, Young's modulus, and Poisson's ratio (Britt and Schoeffler, 2009; King, 2010; Mba and Prasad, 2010). These properties are normally measured from core laboratory tests or estimated using acoustic well logs. Shale fracturability has also been associated with brittleness. When stress is applied, brittle rocks are more likely to fail and to stay open, while ductile rocks tend to stop fracture propagation and can close existing fractures. Even though the complexity of shales has made it difficult to associate shale mineral composition with fracturability, it has been widely accepted that silica and carbonate-rich rocks are more brittle than clayrich rocks. Several authors have remarked about the correlation between mineralogy and brittleness (Jarvie et al., 2007; Parker et al., 2009) and used log-based mineral concentration ratios to calculate a Brittleness Index (Sondergeld et al., 2010; Slatt, 2011). Although the brittleness index disregards several factors such as in-situ stress, pore structure, $T O C$, and maturity of organic matter, it has been observed to correlate well with brittleness estimated with acoustic logs (Sondergeld et al., 2010).

Organic shales were found to be more heterogeneous than they were originally considered. They consist of a large number of minerals whose concentrations vary considerably with depth. Three main minerals are most commonly found in shales: quartz, calcite, and clays. Their concentrations vary with depth and differ widely from 
one formation to another. In addition to these main minerals, potassium feldspar, plagioclase feldspar, dolomite, ankerite, pyrite, and fluorapatite are usually present in smaller concentrations.

To determine mineral concentrations in formations with complex lithology, many companies have turned their attention to neutron-capture spectroscopy (NCS) logs. The NCS tool uses a neutron source and measures the spectrum of gamma-ray generated by the capture of thermal neutrons. Elemental relative yields obtained from the gamma-ray spectrum are separated into elemental dry weight fractions using an oxide closure model (Ellis and Singer, 2007), and are subsequently transformed into mineral concentrations using empirical correlations. NCS logs also have limitations: they do not take kerogen into account (Passey et al., 2010), and their prediction accuracy depends on the accuracy of the oxide closure model and empirical correlations used to transform elements into dry weight minerals (Ellis and Singer, 2007). More importantly, NCS logs are not usually included in a logging program due to cost, tool availability, and borehole conditions. Conventional well logs, often referred to as triple combo logs, consisting of natural gamma ray, resistivity, photoelectric factor, bulk density, and neutron porosity, are commonly acquired in most wells. However, they are not designed to evaluate unconventional reservoirs, and currently there is no complete and accepted petrophysical interpretation workflow for gas shales.

Conventional well log-based mineralogy characterization techniques have been limited to one or two dominant minerals. Assumptions made by conventional interpretation methods are often not valid in hydrocarbon-bearing shales. In addition, well $\log$ responses to petrophysical properties are masked by the effect of heavy minerals, clay minerals, organic matter, micro and nano pore sizes, and complex pore structures. Calculation of porosity from neutron $\operatorname{logs}$ is hindered by the presence of clay and 
kerogen. Similarly, computing porosity from bulk density is not straightforward because of varying mineral compositions and kerogen concentration. There is currently no existing water saturation model available for organic-rich shales; existing models do not take kerogen into consideration. Despite all complexities present in shale gas formations, conventional well logs still respond to many important petrophysical properties that can be estimated using an iterative inversion technique.

\subsection{OBJECTIVES AND SCOPE}

The main purpose of this thesis is to develop a reliable and accurate petrophysical model and workflow for best practices to estimate mineral and fluid concentrations in organic shale from conventional well logs. An improved estimation of porosity and kerogen concentration allows more reliable predictions of the volume of gas-in-place. This workflow also provides reliable mineral concentrations in the absence of core samples or NCS logs. The greatest challenge in extracting important petrophysical properties from formations with complex mineralogy is the under-determined nature of the problem. Because the number of unknowns to be solved is greater than the number of inputs and constraints, there is no unique solution. In our proposed workflow, we first examine mineral compositions based on core XRD analysis and carefully select a mineral model to effectively reduce the number of unknowns. Secondly, we describe the approaches taken to optimize the use of the joint nonlinear inversion developed by the University of Texas at Austin (Heidari et al., 2012).

We detail two synthetic cases to assess the reliability and accuracy of the inversion in a controlled environment where all petrophysical and mineral properties are known. Petrophysical properties and mineral compositions are carefully selected to 
replicate actual field conditions in the Haynesville and Barnett shales. These synthetic cases also serve to compare and examine the accuracy of the two inversion modes: depthby-depth and layer-by-layer.

We appraise the reliability of field applications of inversion with several case studies from the Haynesville and Barnett shales. The proposed workflow is implemented on conventional well logs from these wells and compared against core measurements and NCS logs. Log quality and its effect on estimated properties are examined in detail. Additionaly, we explore abnormal well-log responses and other unaccounted formation properties that could contribute to error in the assessment of porosity, water saturation, $T O C$, and mineral concentrations. 


\section{Chapter 2: Petrophysical Model for Gas Shales}

The estimation of hydrocarbon-in-place and productivity of organic-rich shale reservoirs depends on the accurate estimation of petrophysical properties from well logs. In this chapter, we discuss variations of petrophysical properties and mineral compositions in the Haynesville and Barnett shales. We explore core analyses to enable integration of these measurements into the developed petrophysical interpretation workflow. The sensitivity of well logs to a number of important petrophysical properties is also examined in shale gas formations.

\subsection{Petrophysical Properties and Mineral Compositions}

Figure 2.1 is a schematic of the petrophysical properties of a typical shale gas formation. The solid part of the rock consists of clay minerals $\left(V_{\text {clay }}\right)$, non-clay minerals $\left(V_{n c}\right)$, and kerogen $\left(V_{\text {kerogen }}\right)$. Fluid component consists of hydrocarbon in the matrix pore $\left(V_{H C-m a t r i x}\right)$, hydrocarbon in organic matter pore $\left(V_{H C-k e r o g e n}\right)$, water in the matrix pore $\left(V_{W-}\right.$ matrix $)$, and clay-bound water $\left(V_{W-c l a y}\right) ; V_{H C-m a t r i x}$ is free hydrocarbon that is expelled from kerogen and fills up the matrix pore space, while $V_{H C-k e r o g e n}$ is hydrocarbon-filled pore space created when kerogen matures and is converted into hydrocarbon. Matrix grains are usually water-wet while kerogen has been observed to be oil-wet (Wang and Reed, 2009). Most shale gas reservoirs do not produce water, thus $V_{W-m a t r i x}$ is associated with capillary-bound water; $V_{W-c l a y}$ is associated with the layer of water held on the surface of dry clay minerals and depends on cation-exhange capacity.

Due to the low-porosity nature of shale gas reservoirs, clay-bound water occupies a significant portion of the pores. When comparing log-derived porosity to core-measured porosity, a common question asked is whether core-measured porosity includes all clay- 
bound water, partial, or none. Luffel and Guidry (1992) reported that the Gas Research Institute (GRI) method, which involves crushing and extended drying, removes all water, including clay-bound water. We assume that the porosity measured from core is total porosity $\left(\phi_{t}\right)$, which includes all fluid components. Clay density $\left(\rho_{\text {clay }}\right)$ that is reported in this thesis is the dry clay density, whereas kerogen density ( $\left.\rho_{\text {kerogen }}\right)$ refers to solid kerogen density. Table 2.1 shows average values, along with the range between parentheses, of petrophysical properties in the Haynesville and Barnett shales measured from crushed rock core analysis following the GRI method.

Recent innovations in combining focused-ion beam (FIB) milling and backscattered Scanning Electron Micro-imaging (SEM) have yielded better understanding of gas-shale pore structures (Loucks et al., 2009; Wang and Reed, 2009; Zhang and Klimentidis, 2011). Conventional mechanical cutting and polishing techniques for preparing core for imaging purposes are found to be inadequate because they produce artifacts due to material surface heterogeneities (Loucks et al., 2009). The focused ion beam (FIB) milling technique is used to slice the core to improve surface smoothness of the sample. Wang and Reed (2009) performed shale pore structure analysis of the Barnett shale using SEM. They categorized porosity into four types: non-organic matrix, organic matter, natural fractures, and hydraulic fractures. An important finding from the FIB/SEM study is that nano pores make up a large part of kerogen; these pores are oilwet and their abundance depends on kerogen maturity. FIB/SEM imaging has also been extended from two to three dimensions by incrementally milling thin slices and alternately capturing SEM images (Zhang and Klimentidis, 2011). This technique includes an innovative method to measure core porosity accurately and provides insight to pore connectivity and permeability. 

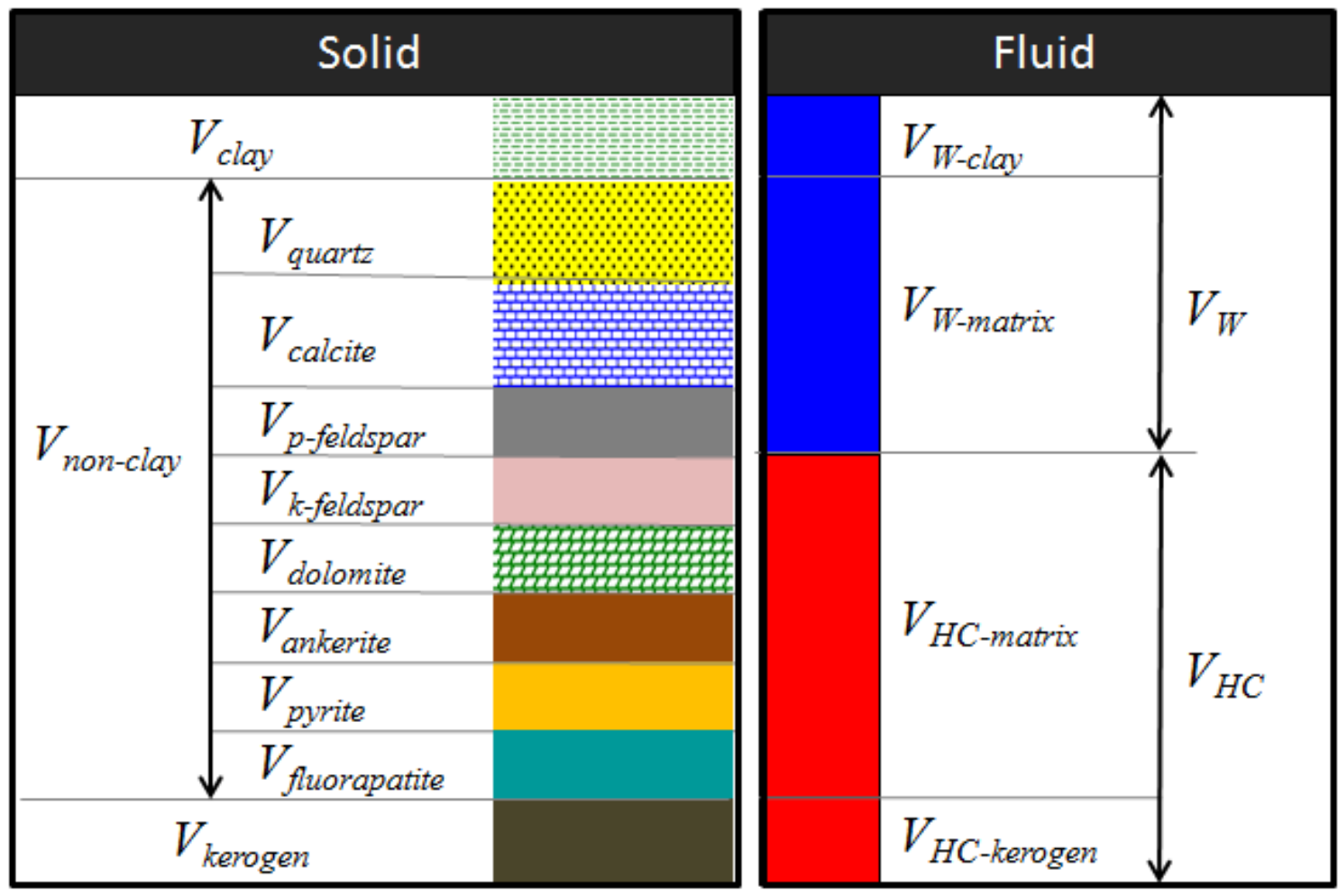

Figure 2.1: Schematic of typical mineral and fluid constituents of a shale gas formation. Volume of the rock consists of solid matrix, hydrocarbon, and water. The solid matrix is composed of dry clay mineral $\left(V_{\text {clay }}\right)$, kerogen $\left(V_{\text {kerogen }}\right)$, and other non-clay minerals such as quartz $\left(V_{\text {quartz }}\right)$, calcite $\left(V_{\text {calcite }}\right)$, plagioclase feldspar $\left(V_{p \text {-feldspar }}\right)$, potassium feldspar $\left(V_{k \text {-feldspar }}\right)$, dolomite $\left(V_{\text {dolomite }}\right)$, ankerite $\left(V_{\text {ankerite }}\right)$, pyrite $\left(V_{\text {pyrite }}\right)$, fluorapatite $\left(V_{\text {fluorapatite }}\right)$. Water is present in the matrix $\left(V_{W \text {-matrix }}\right)$, as clay bound $\left(V_{W \text {-clay }}\right)$, while hydrocarbon is present in matrix pore $\left(V_{H C-m a t r i x}\right)$ and kerogen pore $\left(V_{H C \text {-kerogen }}\right)$. 


\begin{tabular}{lccc}
\hline Petrophysical Property & Units & Haynesville Shale & Barnett Shale \\
\hline Total porosity $\left(\phi_{t}\right)$ & {[]} & $0.073(0.01-0.14)$ & $0.057(0.01-0.11)$ \\
Total water saturation $\left(S_{w t}\right)$ & {[]} & $0.31(0.09-0.73)$ & $0.30(0.00-0.73)$ \\
Gas saturation $\left(S_{g}\right)$ & {[]} & $0.68(0.27-0.91)$ & $0.53(0.07-1.00)$ \\
Oil saturation $\left(S_{o}\right)$ & {[]} & $0.01(0.00-0.05)$ & $0.16(0.00-0.28)$ \\
Bulk density $\left(\rho_{b}\right)$ & $\mathrm{g} / \mathrm{cc}$ & $2.52(2.35-2.69)$ & $2.52(2.41-2.69)$ \\
Grain density $\left(\rho_{g}\right)$ & $\mathrm{g} / \mathrm{cc}$ & $2.69(2.63-2.80)$ & $2.63(2.52-2.76)$ \\
\hline
\end{tabular}

Table 2.1: Average petrophysical properties of Haynesville and Barnett shales based on GRI analysis performed in 8 wells with core samples. The range value for each property is given between parentheses, next to the corresponding average values.

The solid part of organic-rich shale is composed of predominantly silt and claysize minerals and organic matter. Because of low sedimentation rates and low water velocity, many of the associated sedimentary structures are in the form of very fine laminations (Wignall, 1994). Major mineral constituents are quartz, plagioclase feldspar, calcite, and various clays. Clay is composed of mainly illite, mixed layer illite/smectite and chlorite. Table 2.2 shows average volumetric concentrations of various minerals from XRD analysis of Haynesville and Barnett shale core samples. Even though there are a large number of minerals, a great fraction of solid components includes only five distinct members: quartz, plagioclase feldspar, calcite, clay minerals, and kerogen. The sum of these four dominant minerals, referred to as main minerals in Table 2.2, and kerogen amounts to 0.93 and 0.89 of the solid volumetric fractions in Haynesville and Barnett shales, respectively.

One approach used to graphically describe mineral distribution trends is to plot concentrations of the three main mineral groups on a ternary diagram. Based on the mineral grouping performed in this study, we choose the following groups of minerals as 
the vertices: (1) quartz and feldspars (plagioclase and potassium feldspars), (2) carbonates (calcite, dolomite, and ankerite), and (3) clay (illite, chlorite, mixed layer illite/smectite, and kaolinite) and heavy minerals (pyrite and apatite). The XRD mineralogy plotted in Figure 2.2 shows how minerals are distributed in the Haynesville and Barnett shales. A continuous variation from a silica and clay-rich layer to an almost pure carbonate layer can be observed in the Haynesville shale. On the other hand, Barnett shale's mineral distributions are concentrated in the silica-rich layers, with smaller concentrations of clay and carbonate minerals than in the Haynesville shale. 


\begin{tabular}{lcc}
\hline Mineral & Haynesville Shale & Barnett Shale \\
\hline Quartz $\left(V_{\text {quartz }}\right)$ & 0.268 & 0.369 \\
Potassium feldspar $\left(V_{\text {k-feldspar }}\right)$ & 0.004 & 0.021 \\
Plagioclase feldspar $\left(V_{p \text {-feldspar }}\right)$ & 0.073 & 0.050 \\
Calcite $\left(V_{\text {calcite }}\right)$ & 0.203 & 0.131 \\
Dolomite $\left(V_{\text {dolomite }}\right)$ & 0.013 & 0.031 \\
Ankerite $\left(V_{\text {ankerite }}\right)$ & 0.013 & 0.012 \\
Pyrite $\left(V_{\text {pyrite }}\right)$ & 0.020 & 0.031 \\
Fluorapatite $\left(V_{\text {fluorapatite }}\right)$ & 0.018 & 0.015 \\
Kerogen $\left(V_{\text {kerogen }}\right)$ & 0.055 & 0.086 \\
Illite $\left(V_{\text {illite }}\right)$ & 0.233 & 0.092 \\
Chlorite $\left(V_{\text {chlorite }}\right)$ & 0.055 & 0.048 \\
Mixed layer illite $/$ smectite $\left(V_{\text {mix }}\right)$ & 0.035 & 0.110 \\
Kaolinite $\left(V_{\text {kaolinite }}\right)$ & 0.010 & 0.004 \\
\hline Main minerals & 0.877 & 0.804 \\
Accessory minerals & 0.068 & 0.110 \\
Kerogen $\left(V_{\text {kerogen }}\right)$ & 0.055 & 0.086 \\
\hline
\end{tabular}

Table 2.2: Average volumetric concentrations (in fraction of solid volume) of various minerals from XRD analysis performed in 8 wells with core samples in the Haynesville and Barnett shales. Main minerals are present in the form of $V_{\text {quartz }}, V_{p \text {-feldspar }}, V_{\text {calcite, }}, V_{\text {illite }}, V_{\text {chlorite }}, V_{\text {mix }}$, and $V_{\text {kaolinite. }}$ Accessory minerals include $V_{k \text {-feldspar }}, V_{\text {dolomite, }}, V_{\text {ankerite }}, V_{\text {pyrite }}$, and $V_{\text {fluorapatite. }}$ 
(a)

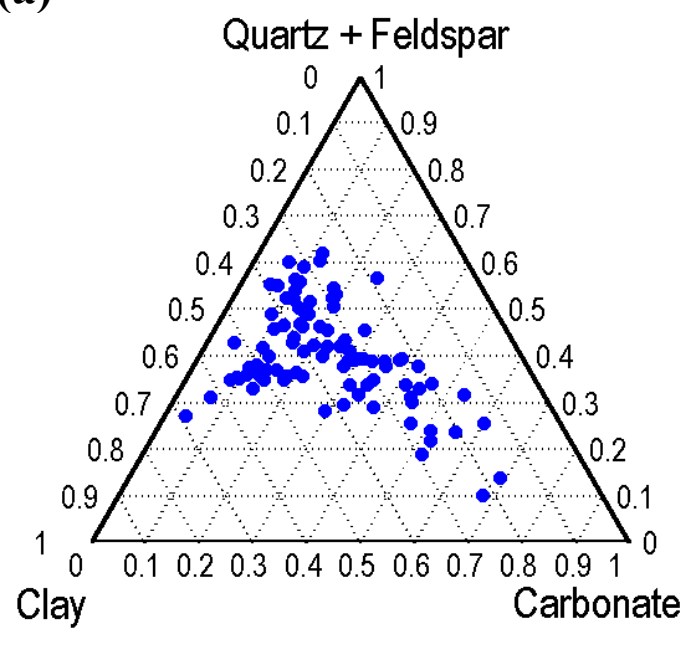

(b)

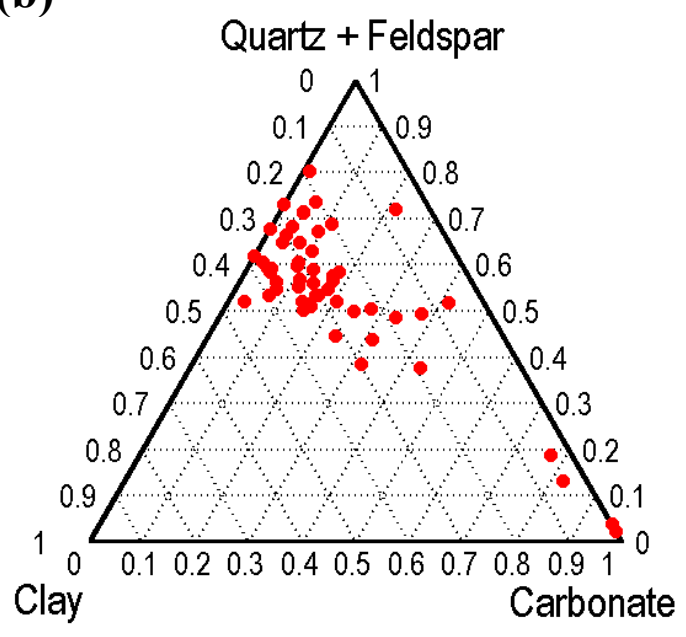

Figure 2.2: Ternary plot representation of mineral composition based on XRD analysis of core samples from a total of 8 wells in (a) Haynesville, and (b) Barnett shales.

\subsection{INTEGRATION OF CORE MEASUREMENTS}

In developing an accurate shale gas petrophysical interpretation method, the integration of core measurements is crucial to calibrate and evaluate interpreted results. Conventional routine core analysis cannot be employed on shale samples due to their very fine grain and micro pores. The Gas Research Institute (GRI) pioneered core analysis methods based on crushed rock samples to measure grain density, porosity, and fluid saturation (Luffel and Guidry, 1992). On biscuit-shaped core samples, the "asreceived" bulk density is initially measured using a mercury immersion technique and the "as-received" grain density is measured with helium using a Boyle's law porosimeter. Core samples are then crushed to a specified mesh size in order to access the pore space. Volumes of water and oil are then measured from crushed samples using a retort or Dean-Stark distillation method. Mass balance is enforced to calculate gas volume, from 
which, porosity and fluid saturation are calculated. Finally, crushed samples are dried at a higher temperature and a longer period of time to remove clay-bound water.

The GRI method has been adopted by several commercial laboratories; however, the procedures have been modified and exact methods are not published, thereby resulting in inconsistencies when core data originate from a number of commercial laboratories. For example, we often observe sizable variations in the porosity measured by different laboratories, as reported elsewhere (Passey et al., 2010; Sondergeld et al., 2010). Some laboratories consider porosity measured with Dean-Stark's method as the total porosity, which includes clay bound water $\left(V_{W \text {-clay }}\right)$ while others consider it effective porosity and measure clay-bound water separately over an extended drying time. In this study, we assume that core-measured porosity provided by all core laboratories is total porosity $\left(\phi_{t}\right)$, which includes hydrocarbon in the matrix pore $\left(V_{H C-m a t r i x}\right)$, hydrocarbon within kerogen $\left(V_{H C \text {-kerogen }}\right)$, water in matrix pore $\left(V_{W \text {-matrix }}\right)$, and clay-bound water $\left(V_{W \text { - }}\right.$ clay). Water saturation reported from GRI core analysis is assumed to be total water saturation $\left(S_{w t}\right)$, which is the sum of all water components $\left(V_{W}\right)$ divided by total porosity $\left(\phi_{t}\right)$

We found larger inconsistencies in permeability measurements performed by different core laboratories. The permeability measurement technique commonly used for these very low permeability shales is the pressure-pulse-decay method (Dicker and Smits, 1988; Jones, 1997). This test was originally implemented on core plugs, but had also been applied to rock cuttings and crushed samples (Luffel et al., 1993). Permeability measured on crushed samples has been observed to be considerably lower than measured on core plugs (Wang and Reed, 2009). We do not have records describing the type of permeability measurement applied to these core data, but suspect that variations in 
measurement procedures are the cause of the large differences observed of core permeability data used in this thesis.

Core mineral identification considered in this thesis is performed by the X-Ray Diffraction (XRD) method, which uses the diffraction patterns of X-Ray interaction with powder samples. Other core mineralogy identification techniques used to analyze shale gas formations include X-Ray Fluorescence (XRF) (Hammes et al., 2011) and Fourier Transform Infrared Transmission Spectroscopy (FTIR) (Sondergeld et al., 2010). One major assumption made when comparing core-measured mineralogy to log-derived mineralogy is that the same volume of rock is measured in both cases; this condition is only true when the rock is homogeneous because core-based mineral composition is taken from a very small sample, while the volume of investigation of logging tools is considerably larger. Another important difference between the two mineral estimation methods is that XRD analysis provides mineral weight concentrations while logging tools yield volumetric concentrations; XRD data must then be converted from weight fraction to volumetric fraction by assuming the density of each mineral. For example, the weight fraction of quartz is transformed to volumetric fraction using the relationship

$$
V_{\text {quartz }}=\frac{\rho_{b}}{\rho_{\text {quartz }}} W_{\text {quartz }},
$$

where $V_{\text {quartz }}$ is quartz volumetric fraction, $\rho_{b}$ is rock bulk density, $\rho_{\text {quartz }}$ is quartz density, and $W_{\text {quartz }}$ is quartz weight fraction.

Additionaly, XRD analysis does not measure kerogen concentration. The current practice applied by many (Guidry et al., 1990; Herron and Le Tendre, 1990; Quirein et al., 2010) is to estimate kerogen weight fraction from Total Organic Carbon (TOC) 
obtained from Leco or RockEval Pyrolysis measurements and then convert it to volumetric fraction; TOC contains all the organic carbon including free hydrocarbons. To estimate kerogen weight fraction from measured TOC in shale gas formations, the following relationship is used:

$$
W_{\text {kerogen }}=\frac{T O C}{C_{k}}
$$

where $W_{\text {kerogen }}$ is kerogen weight fraction, $T O C$ is total organic carbon, and $C_{k}$ is the carbon weight fraction of kerogen. Guidry et al. (1990) used $C_{k}=0.75$ for Devonian shale and Herron and Le Tendre (1990) used $C_{k}=0.8$ for Toarcian shale in the Paris Basin. Subsequently, kerogen volumetric fraction is obtained from kerogen volume fraction by assuming kerogen density $\left(\rho_{\text {kerogen }}\right)$ and using the relationship

$$
V_{\text {kerogen }}=\frac{\rho_{b}}{\rho_{\text {kerogen }}} W_{\text {kerogen }},
$$

where $V_{\text {kerogen }}$ is kerogen volumetric fraction, $\rho_{b}$ is rock bulk density, $\rho_{\text {kerogen }}$ is kerogen density, and $W_{\text {kerogen }}$ is kerogen weight fraction.

Geochemical analysis of organic matter in shale gas formations is still largely based on studies of source rock. Typical tests conducted for that purpose are Leco, RockEval Pyrolysis, and Vitrinite Reflectance; TOC from Leco or RockEval quantify the amount of organic carbon from the rock sample. RockEval Pyrolysis provides an indication of hydrocarbon producing potential of kerogen from the $S_{1}$ value (quantity of free hydrocarbon) and $S_{2}$ value (quantity of hydrocarbon produced by cracking the kerogen) (Espitalie et al., 1977). It also estimates maturity based on temperature of the 
second peak $\left(T_{\max }\right)$. Vitrinite reflectance $\left(R_{o}\right)$ provides another indicator of kerogen maturity from light reflection off the vitrinite maceral. RockEval pyrolysis data from Haynesville and Barnett shales studied in this thesis were plotted using the Pseudo-Van Krevelen diagram and appeared to be at the overmature stage; the corresponding plots are described in Appendix B.

\subsection{Well-Log ReSPONSES IN SHALE-Gas Formations}

Most of the effort spent understanding conventional well logs in organic-rich shale has focused to estimating TOC and porosity. To obtain mineral concentrations, most studies rely on multi-mineral solvers included in commercial petrophysical software. Analysis of natural gamma-ray and spectral gamma-ray log responses in organic-rich shale has been published extensively in the open technical literature (Fertl, 1979; Fertl and Rieke, 1980; Schmoker, 1981; Fertl and Chilingar, 1988; Lüning and Kolonic, 2003). Natural gamma ray logs respond primarily to clay, which commonly exhibits high potassium $(K)$ and Thorium $(T h)$, and to $T O C$, which very often has very high uranium $(U)$ concentration. Even though high uranium concentration has been a good indicator of source rocks, no universal relationship has been successfully established to quantify TOC. The U/TOC relationship varies significantly from one reservoir to another, and is often nonlinear. Another complicating factor is that not all uranium comes from organic matter. Wignall (1994) also pointed out that in order to obtain reliable correlations between uranium counts and TOC, the contribution from detrital uranium has to be removed from total uranium counts because only uranium from authigenic origin is related to organic carbon preservation. 
(a)
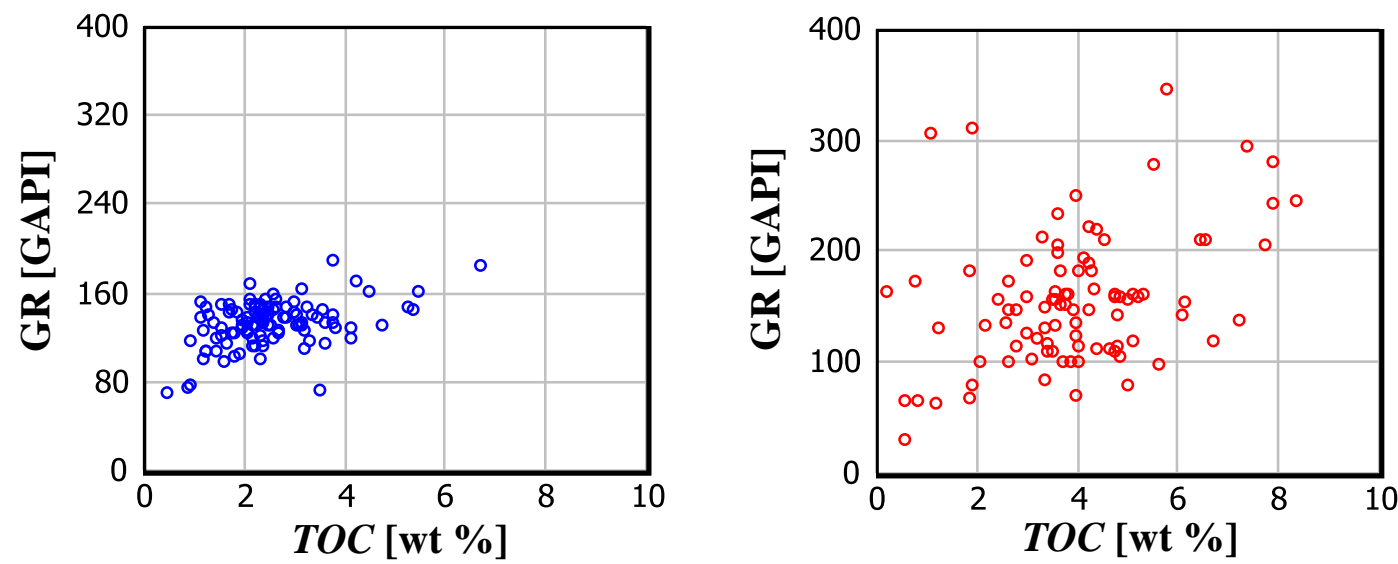

(b)
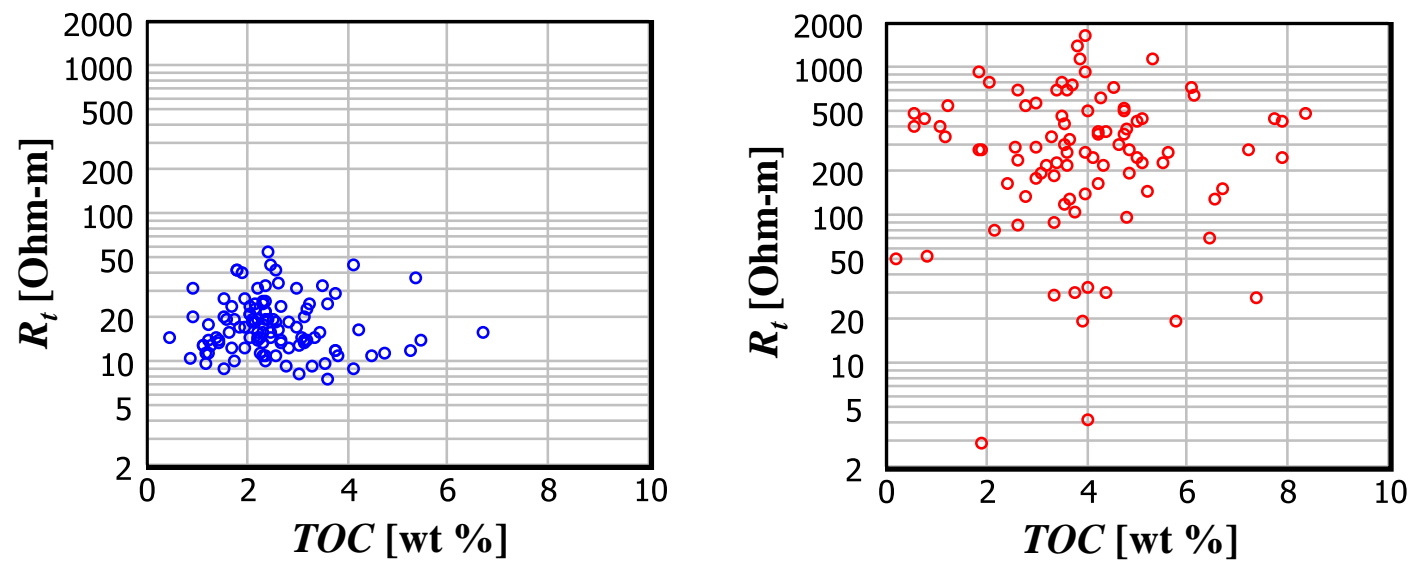

(c)
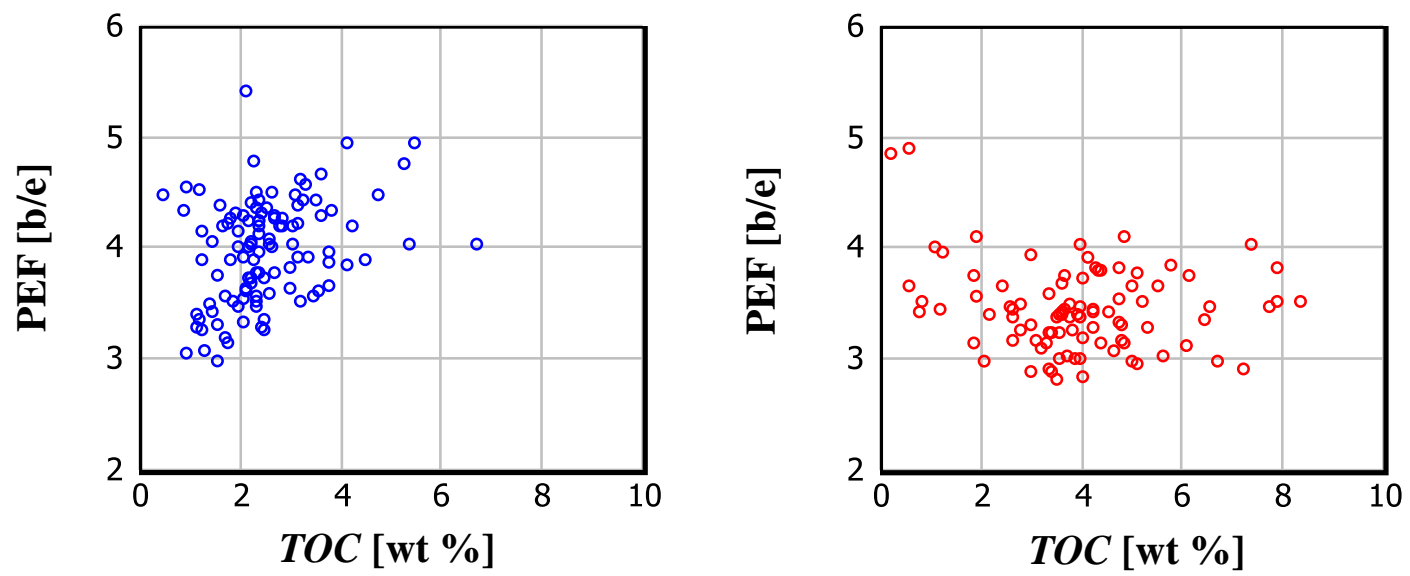
(d)
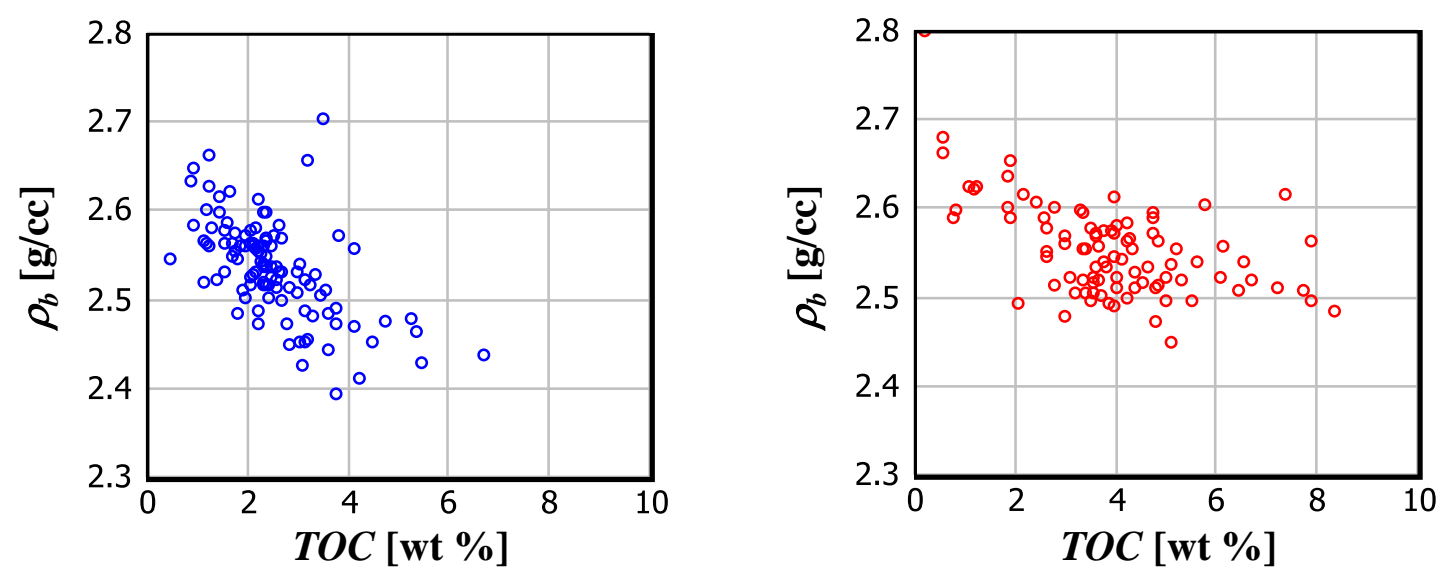

(e)
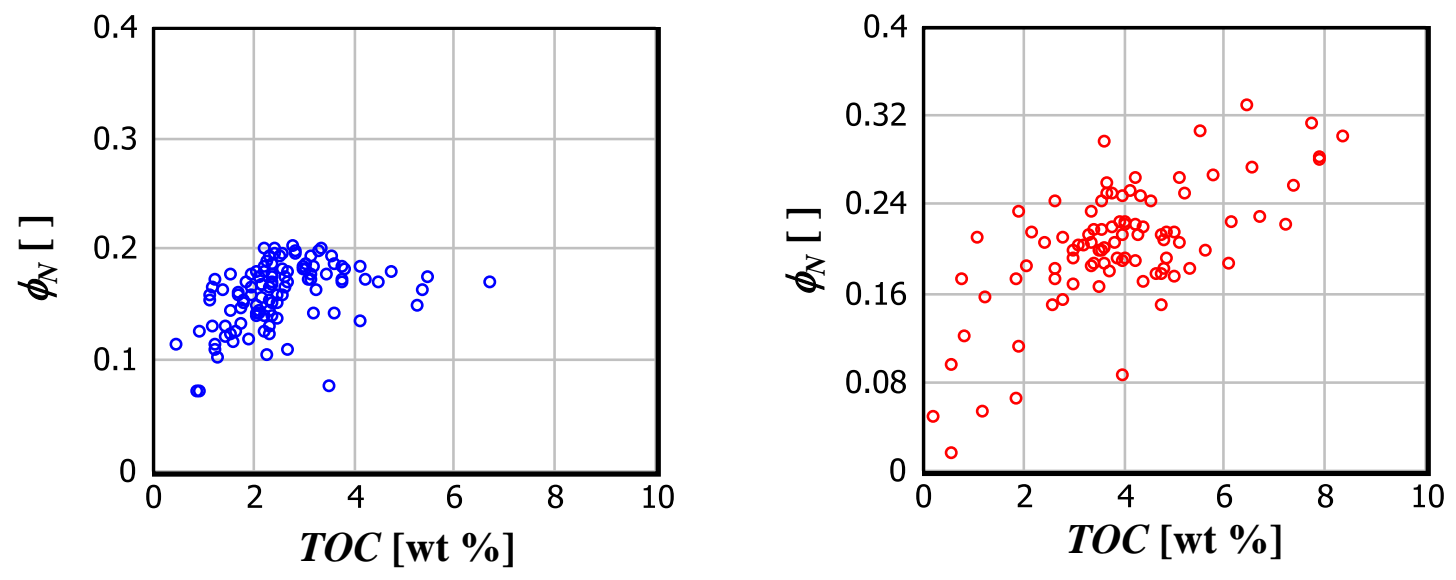

Figure 2.3: Correlation of core Total Organic Carbon (TOC) in weight percent to (a) gamma ray, (b) apparent resistivity, (c) photoelectric factor, (d) bulk density, and (e) neutron porosity (in limestone matrix) in the Haynesville (to the left), and Barnett shales (to the right). 
Figure 2.3 shows the correlation of TOC with various conventional well logs. The bulk density $\log$ has been reported to exhibit the best correlation with TOC (Schmoker, 1979; Passey et al., 2010; Quirein et al., 2010). This correlation, however, is only accurate when variations in grain density, porosity, and water saturation with depth are small. Even though it appears that porosity and water saturation are relatively constant over most depth intervals, mineral compositions vary significantly and so does grain density. Bulk density is described mathematically with the relationship

$$
\rho_{b}=\sum_{i=1}^{n} V_{i} \rho_{i}+V_{\text {kerogen }} \rho_{\text {kerogen }}+S_{w t} \phi_{t} \rho_{W}+\left(1-S_{w t}\right) \phi_{t} \rho_{H C}
$$

where $\rho_{b}$ is bulk density, $V_{i}$ is volumetric fraction of the corresponding $i^{\text {th }}$ mineral, $\rho_{i}$ is density of the corresponding $i^{\text {th }}$ mineral, $V_{\text {kerogen }}$ is volumetric concentration of kerogen, $\rho_{\text {kerogen }}$ is density of kerogen, $S_{w t}$ is total water saturation, $\phi_{t}$ is total porosity, $\rho_{W}$ is density of water, and $\rho_{H C}$ is density of hydrocarbon.

The photoelectric factor log (PEF) has been considered a very good lithology indicator; nevertheless, it is rarely used to quantify mineral concentration other than via lithology cross-plot charts such as the bulk density $\left(\rho_{b}\right)$ vs. photoelectric factor (PEF) chart or apparent grain density $\left(\rho_{\text {maa }}\right)$ vs. apparent matrix volumetric photoelectric factor $\left(U_{\text {maa }}\right)$ chart (Schlumberger, 2009). Practical applications of the lithology cross-plots have been limited to three minerals (quartz, calcite, and dolomite) and they fail whenever clay is present. Figure 2.4 shows cross-plots of PEF and weight fraction for the main mineral groups from NCS logs acquired in Haynesville and Barnett shales. PEF indicates a nonlinear correlation with the carbonate group and anti-correlation with the QFM (Quartz, Feldspar, and Mica) group. The QFM group appears to set the lower PEF end- 
point while the carbonate (CAR) group sets the upper PEF end-point; PEF does not appear to correlate with pyrite, which has the highest PEF value among all minerals, even though the NCS logs show substantial amounts of pyrite (up to approximately $10 \mathrm{wt} \%$ ). These plots also indicate that barite affects the quality of PEF values in the Haynesville shale, where the correlation between PEF and mineral concentrations is not as obvious as in the case with the Barnett shale. 
(a)
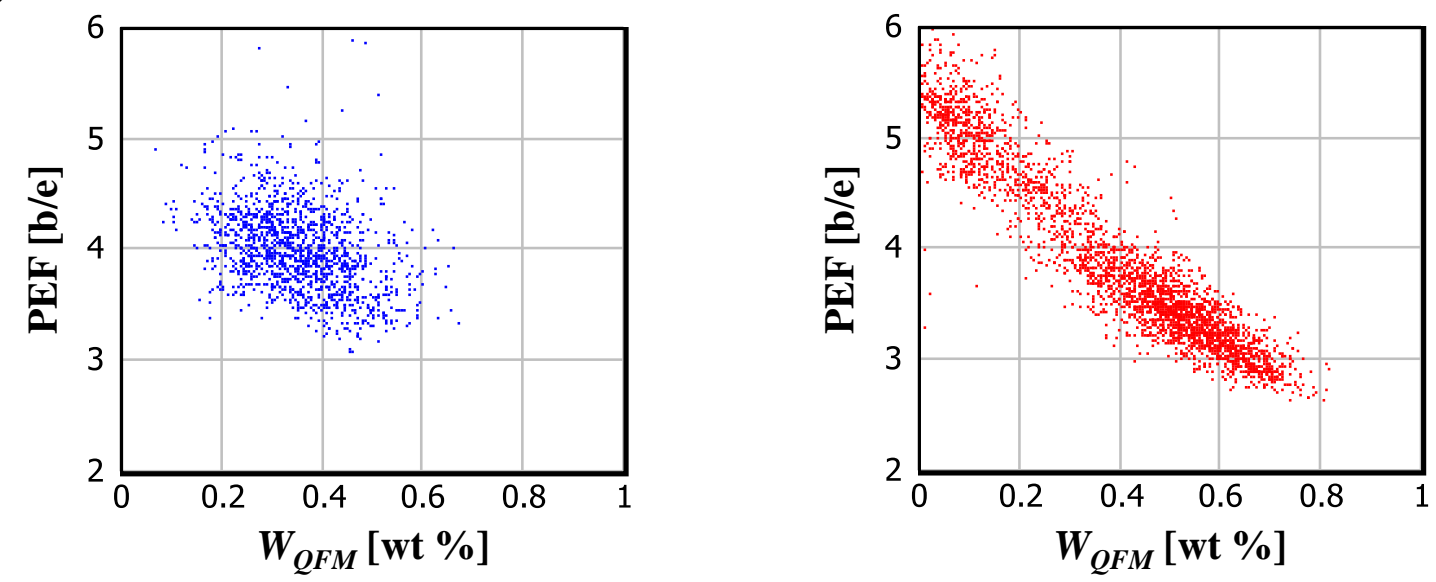

(b)
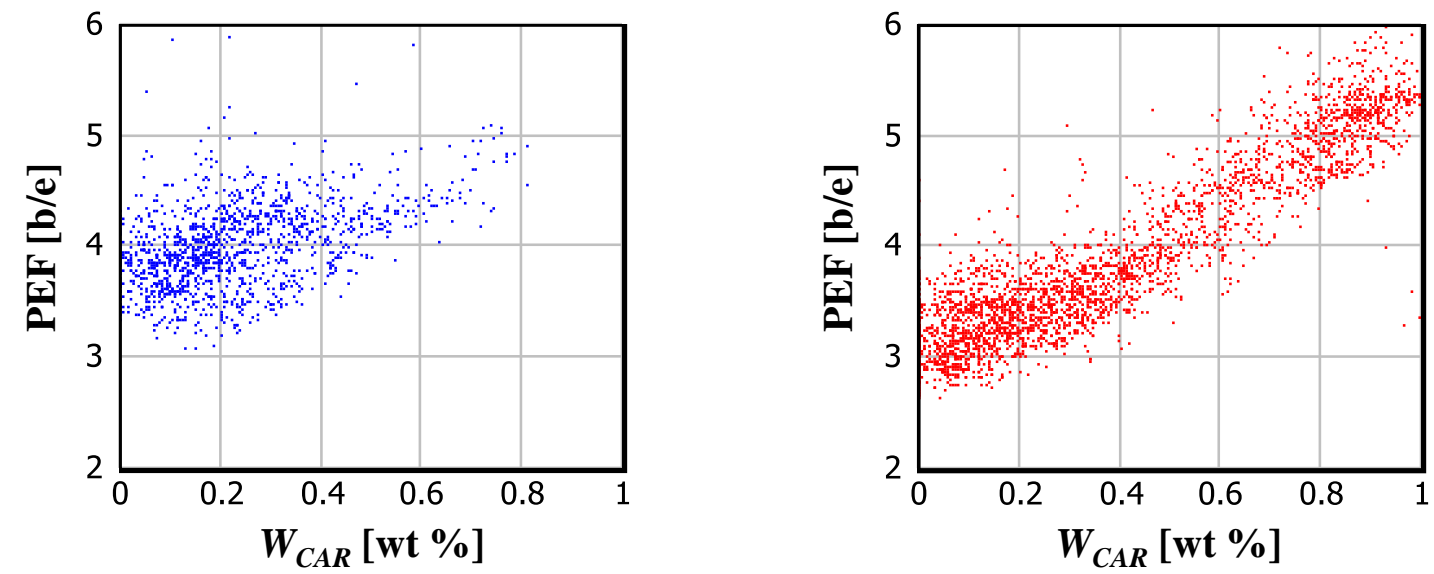

(c)
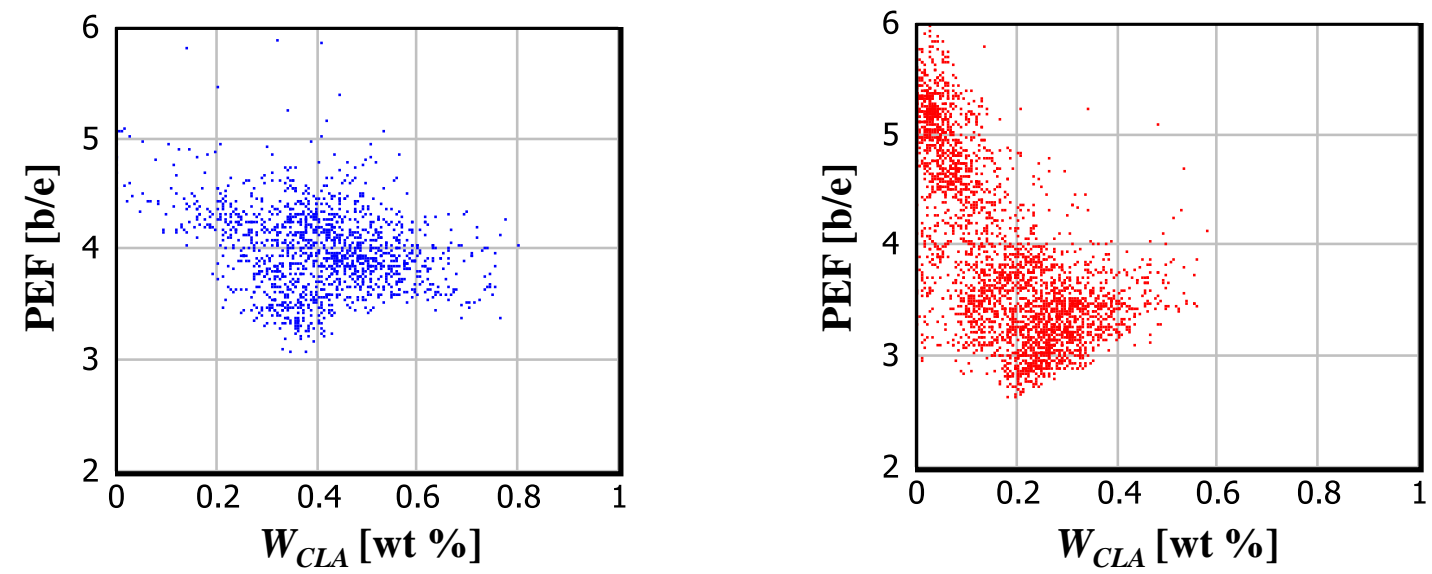
(d)
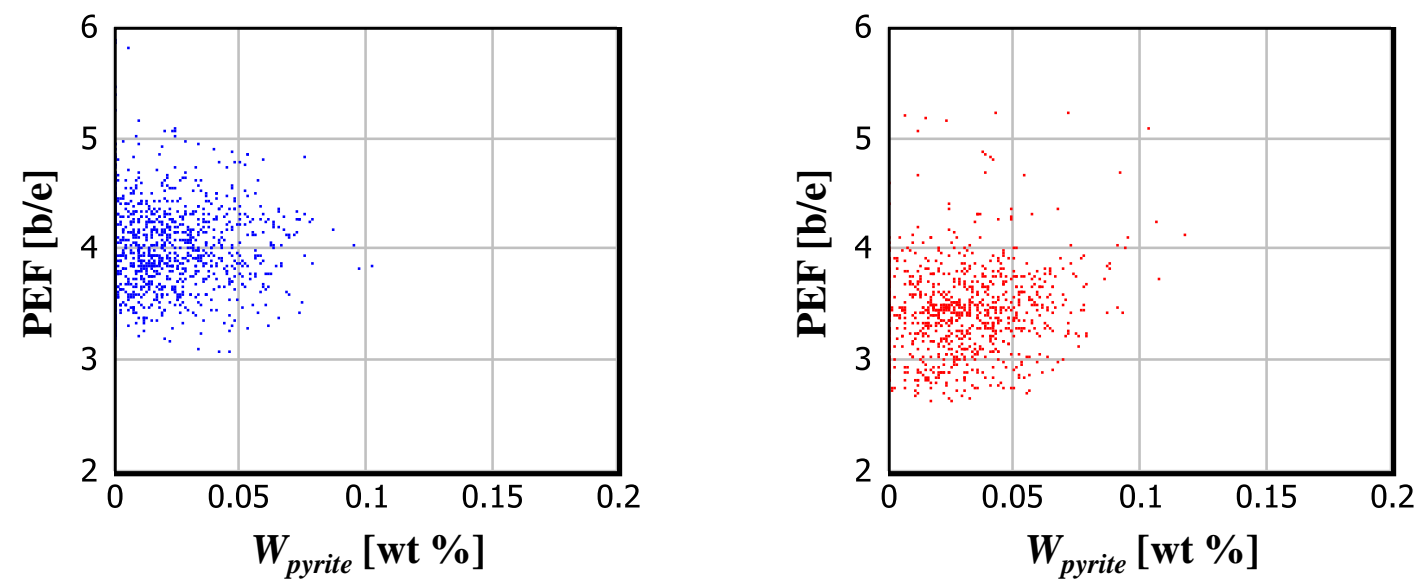

Figure 2.4: Correlation of PEF log with weight concentration of mineral groups estimated from NCS logs in the Haynesville (left), and Barnett shales (right): (a) quartz, feldspar, and mica $\left(W_{Q F M}\right)$, (b) carbonate $\left(W_{C A R}\right)$, (c) clay $\left(W_{C L A}\right)$, and $(\mathrm{d})$ pyrite $\left(W_{\text {pyrite }}\right)$.

The relationship between apparent resistivity logs and petrophysical properties in organic-rich shale is the least understood. Passey et al. (1990) postulated that the resistivity increase observed in mature source rocks is the result of a decrease of water saturation caused by hydrocarbon that is generated from kerogen. Due to lack of water saturation models for organic-rich shale, most petrophysicists resort to Archie's equation (Guidry et al., 1990; Quirein et al., 2010; Ramirez et al., 2011), even though the physical meaning of Archie's parameters $\left(a, m, n\right.$, and $\left.R_{w}\right)$ in shale is not understood.

Luffel and Guidry (1989) attempted to measure $R_{w}$ in Devonian shale by adding water to crushed rock samples and measuring the chloride content. They obtained large variations of salinity ranging from $12 \mathrm{kppm}$ to $102 \mathrm{kppm}$ of $\mathrm{NaCl}$ equivalent. Based on our experience with Haynesville and Barnett shales, Archie's equation can provide a reliable match to core $S_{w t}$ and $\phi_{t}$ by choosing water resistivity $\left(R_{w}\right)$ to fit the data. The value of $R_{w}$ however, often does not make physical sense. For example, in the Haynesville shale, to fit core $S_{w t}$ and $\phi_{t}$ using Archie's equation with $a=1, m=2$, and $n=$ 
2, $R_{w}$ needs to be approximately $0.006 \mathrm{Ohm}-\mathrm{m}$ which equals a salinity of $842 \mathrm{kppm}$ of $\mathrm{NaCl}$ equivalent at formation temperature. This salinity value is unrealistic because it is substantially above the $\mathrm{NaCl}$ solubility of water and is caused by the excess conductivity of clay. Because the dominant facies in both Haynesville and Barnett shales are laminated, instead we choose the classical laminated Poupon equation as the resistivity model used in the thesis (Poupon et al., 1954), which is described by the equation

$$
\frac{1}{R_{t}}=\left[\frac{1-V_{\text {clay }}}{R_{n c}}+\frac{V_{\text {clay }}}{R_{\text {clay }}}\right],
$$

where $R_{t}$ is formation resistivity obtained from the deep apparent resistivity $\log , V_{\text {clay }}$ is volumetric concentration of clay, $R_{w}$ is resistivity of organic-rich layer, and $R_{\text {clay }}$ is resistivity of clay-rich layers; $R_{n c}$ is described by Archie's equivalent equation, namely

$$
R_{n c}=\frac{a R_{w}}{\phi_{n c}{ }^{m} S_{w n c}{ }^{n}},
$$

where $R_{w}$ is the formation water resistivity, $\phi_{n c}$ is non-clay porosity, $S_{w n c}$ is non-clay water saturation, and $a, m$, and $n$ are the corresponding Archie parameters. We assume that the rock consists of laminated layers of conductive clay and resistive organic matter. We examined alternative resistivity models such as Dual Water, Indonesia, and Simandoux and found that all models provided an adequate match with core $S_{w t}$ and $\phi_{t}$ if their associated parameters were properly adjusted to match core data. The choice of model does not appear to significantly affect other interpretation results. 
Electrical micro-resistivity images gave us insight about resistivity log responses. In Barnett shale examples, we noticed that shoulder-bed effects on well logs were conditioned by the presence of thin conductive beds. As shown in Figure 2.5, at a depth of approximately $\mathrm{xx} 02.7 \mathrm{ft}$, a conductive bed thinner than $0.5 \mathrm{ft}$ gives rise to approximately $5 \mathrm{ft}$ of shoulder-bed effects. We suspect that this conductive bed is a pyrite-rich layer because of the associated significant increase in high-resolution PEF and bulk density; however, we do not have petrographic data to support this hypothesis.

The neutron-capture gamma-ray spectroscopy (NCS) tool measures the gammaray energy spectrum generated from the capture of thermal energy neutrons. Relative elemental yields are obtained from the energy spectrum and converted into elemental weight fractions using an oxide closure model. Elemental weight fractions obtained include silica $(S i)$, calcium $(\mathrm{Ca})$, iron $(\mathrm{Fe})$, sulfur $(S)$, gadolinium $(G d)$, and Titanium (Ti). Subsequently, a lithology model is applied to the elemental weight fractions to obtain weight fractions of minerals. Mineral weight fractions generated from the NCS logs are usually lumped into several mineral groups: QFM (quartz, feldspar, and mica), Carbonate (calcite, dolomite, ankerite), and Clay (illite, kaolinite, chlorite, and smectite). The concentrations of these mineral groups can be compared to our grouped mineral model implemented in subsequent field examples. 


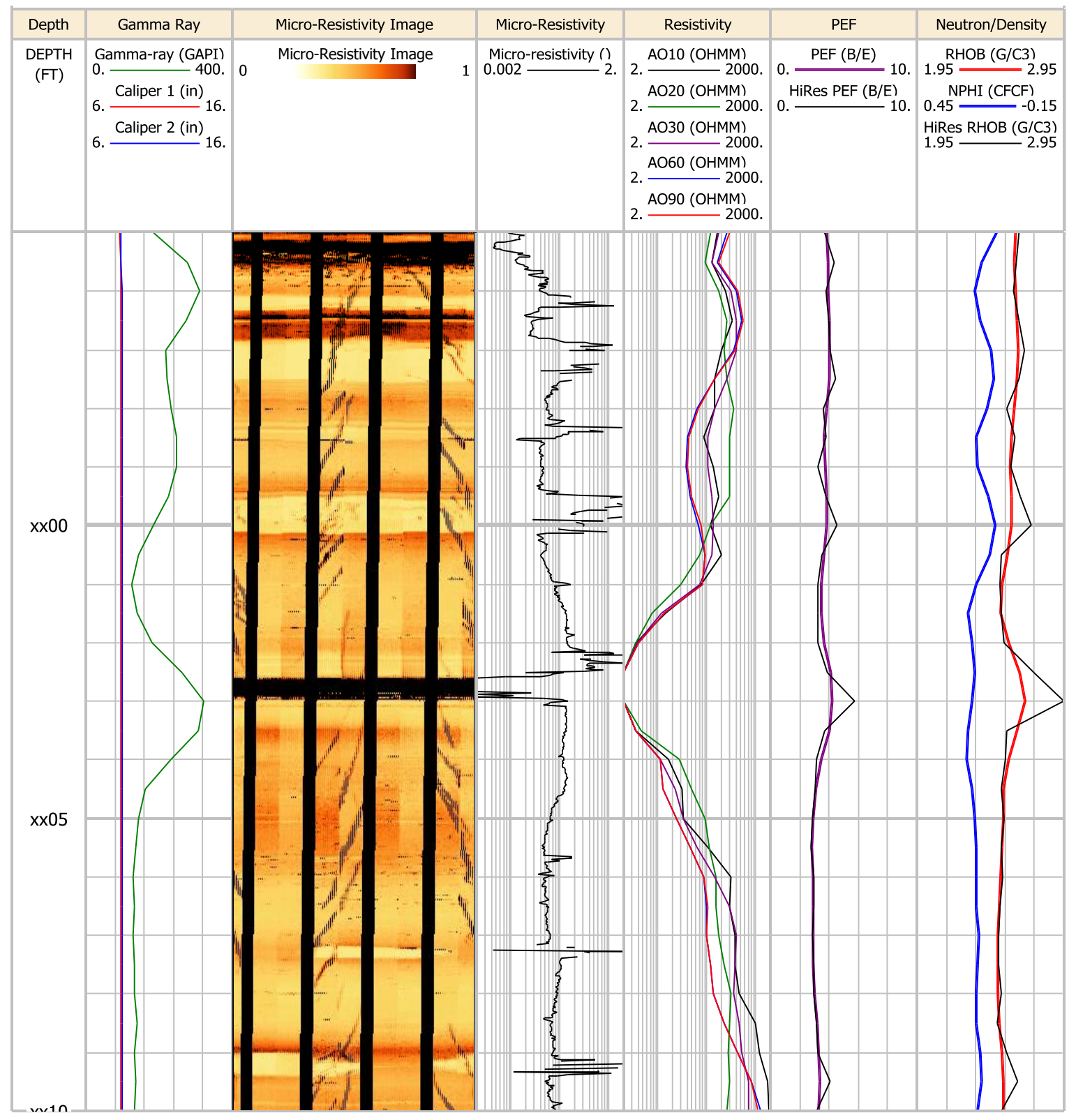

Figure 2.5: Example of shoulder-bed effects on apparent resistivity induction logs originating from thin conductive beds. Track 1: Relative depth. Track 2: Gamma ray and caliper logs. Track 3: Electrical micro-resistivity image logs. Track 4: Electrical micro-resistivity. Track 5: Apparent resistivity induction logs. Track 6: Standard-resolution and high-resolution PEF logs. Track 7: Neutron porosity (limestone matrix), standard-resolution bulk density, and high-resolution bulk density logs. 


\section{Chapter 3: Application of Nonlinear Inversion of Well Logs to Estimate Mineral Concentrations}

The challenge of quantifying mineral compositions and volumetric concentrations from conventional logs is the under-determined nature of the problem. As indicated in Table 3.1, typically the number of unknowns is significantly greater than the number of inputs; the number of inputs depends on the number of well logs used for the estimation and the mass balance equation as an additional constraint. As a result, there is not a unique solution. In addition to this problem, inaccuracies in the petrophysical model, and measurement errors in well logs render the problem not tractable. To obtain accurate and reliable mineral compositions from inversion, we reduce the number of unknowns to construct an even-determined, or slightly under-determined system of equations.

\subsection{Construction Of The Mineral Model}

Our initial approach is to group minerals based on core GRI and XRD analyses. As previously indicated in Table 2.2, the main minerals, consisting of quartz, plagioclase feldspar, calcite, clay, and kerogen, constitute approximately $90 \%$ of the rock's solid composition; therefore, it is appropriate to group the remaining $10 \%$ accessory minerals with main minerals that exhibit similar properties. The first mineral group consists of quartz and feldspars. Table 2.2 shows that the plagioclase feldspar is dominant and that potassium feldspar exhibits smaller concentrations. Because plagioclase feldspar (albite) has similar properties to quartz, we use quartz's properties to represent this group.

The second group is composed of carbonates consisting of calcite, dolomite, and ankerite. In both Haynesville and Barnett shales, the carbonate-rich layer is composed of mainly calcite with smaller concentrations of dolomite and/or ankerite. In the carbonate group, calcite properties are used to represent the group and we assume that well logs are 
marginally sensitive to dolomite and ankerite. The third group is the clay minerals grouped with heavy minerals such as pyrite and flourapatite. To compensate for heavy mineral properties, we made some adjustments to the properties of clay. Bulk and grain densities for each core sample point can be calculated by assuming the density of each mineral and using porosity, water saturation, and mineral concentration from core analyses. Computed bulk densities are compared to those measured with mercury immersion. Similar calculations are also performed using the grouped mineral concentrations; as shown in Figure 3.2, a good agreement to GRI measured bulk density is achieved by increasing the clay bulk density to include the heavy minerals.

Following the reduction of the number of unknowns by means of mineral grouping, the estimation problem now gives rise to an even-determined system of equations. When analyzing inversion results, however, we must bear in mind all assumptions made to simplify the mineral model: (1) well logs are marginally sensitive to variations in clay minerals, (2) feldspars have properties similar to quartz, (3) carbonate composition consists mainly of calcite, (4) the concentration of heavy minerals exhibit a linear correlation with clay concentration, and (5) kerogen properties, such as maturity and density, and fluid properties remain constant throughout the depth inversion interval. 


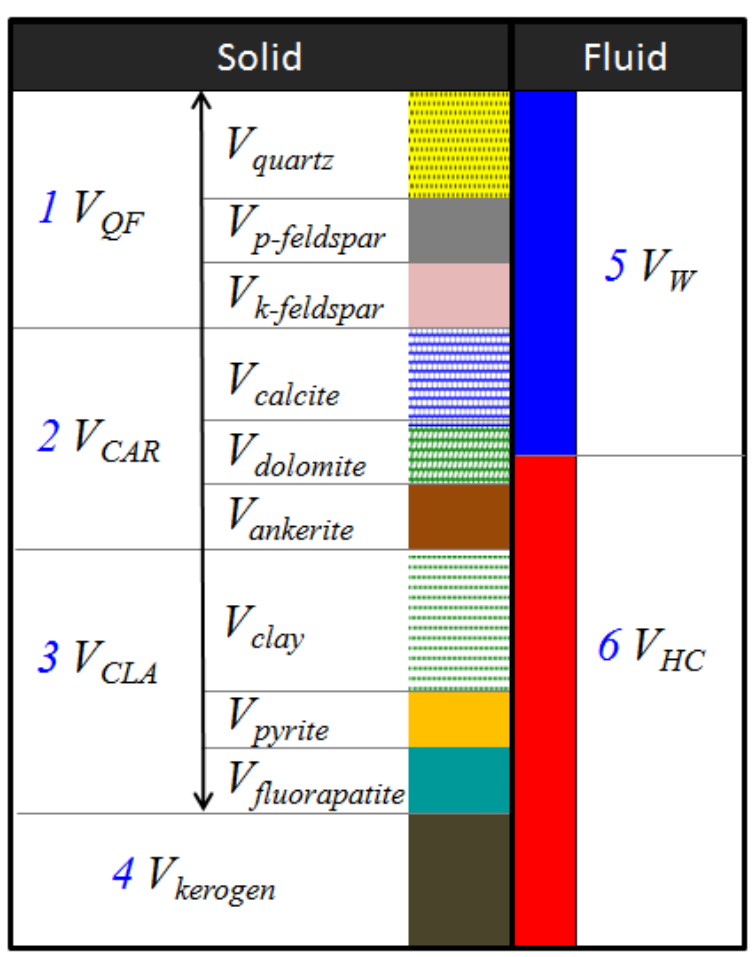

Figure 3.1: Schematic of the grouped mineral model. Three mineral groups are considered: (1) $V_{Q F}$ consisting of quartz $\left(V_{\text {quartz }}\right)$, plagioclase feldspar ( $V_{p \text { - }}$ feldspar $)$, and potassium feldspar $\left(V_{k \text {-feldspar }}\right) ;(2) V_{C A R}$ consisting of calcite $\left(V_{\text {calcite }}\right)$, dolomite $\left(V_{\text {dolomite }}\right)$, and ankerite $\left(V_{\text {ankerite }}\right)$; (3) $V_{C L A}$ consisting of clay $\left(V_{\text {clay }}\right)$, pyrite $\left(V_{\text {pyrite }}\right)$, and fluorapatite $\left(V_{\text {fluorapatite }}\right)$. Remaining constituents are (4) solid kerogen $\left(V_{\text {kerogen }}\right),(5)$ water $\left(V_{W}\right)$, and (6) hydrocarbon $\left(V_{H C}\right)$. 


\begin{tabular}{ll}
\hline Unknown & Input \\
\hline 1. Clay $\left(V_{\text {clay }}\right)$ & 1. Gamma-ray \\
2. Quartz $\left(V_{\text {quartz }}\right)$ & 2. Resistivity \\
3. Calcite $\left(V_{\text {calcite }}\right)$ & 3. Photoelectric Factor $(\mathrm{PEF})$ \\
4. Plagioclase feldspar $\left(V_{p \text {-feldspar }}\right)$ & 4. Bulk density $\left(\rho_{b}\right)$ \\
5. Potassium feldspar $\left(V_{k \text {-feldspar }}\right)$ & 5. Neutron porosity \\
6. Dolomite $\left(V_{\text {dolomite }}\right)$ & 6. Mass balance equation \\
7. Ankerite $\left(V_{\text {ankerite }}\right)$ & \\
8. Pyrite $\left(V_{\text {pyrite }}\right)$ & \\
9. Fluorapatite $\left(V_{\text {fluorapatite }}\right)$ & \\
10. Kerogen $\left(V_{\text {kerogen }}\right)$ & \\
11. Water $\left(V_{W}\right)$ & \\
12. Hydrocarbon $\left(V_{H C}\right)$ & \\
\hline
\end{tabular}

Table 3.1: List of unknowns and inputs of the original system of equations used to estimate mineral concentrations.

\begin{tabular}{lccc}
\hline Mineral Group & Units & Haynesville & Barnett \\
\hline$V_{Q F}\left(V_{\text {quartz }}, V_{p \text {-feldspar }}\right.$, and $\left.V_{\text {k-feldspar }}\right)$ & {[]} & 0.345 & 0.440 \\
$V_{C A R}\left(V_{\text {calcite, }}, V_{\text {dolomite }}\right.$, and $\left.V_{\text {ankerite }}\right)$ & {[]} & 0.229 & 0.174 \\
$V_{C L A}\left(V_{\text {clay }}, V_{\text {pyrite }}\right.$, and $\left.V_{\text {fluorapatite }}\right)$ & {[]} & 0.371 & 0.300 \\
$V_{\text {kerogen }}$ & {[]} & 0.055 & 0.086 \\
\hline
\end{tabular}

Table 3.2: Average solid volumetric concentrations of grouped minerals measured with XRD analysis of core samples from 8 wells in the Haynesville and Barnett organic shales. 
(a)
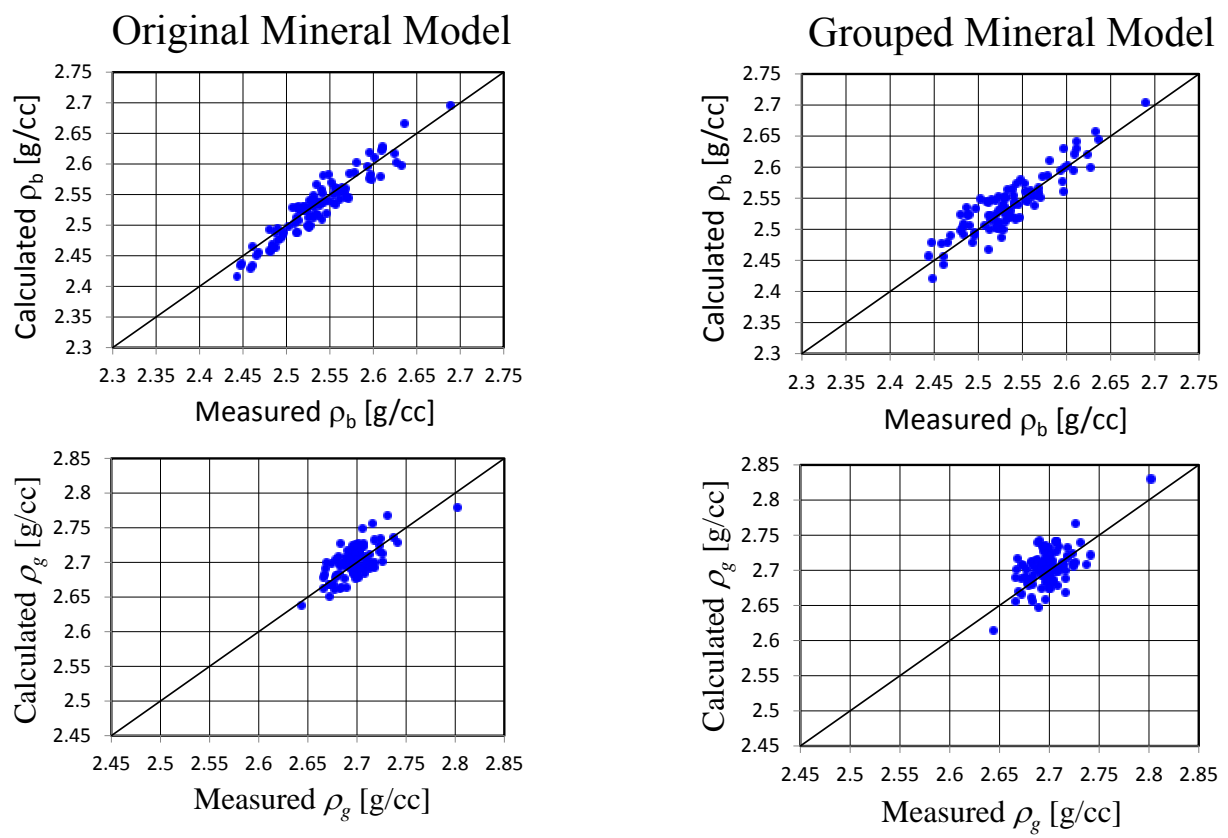

(b)
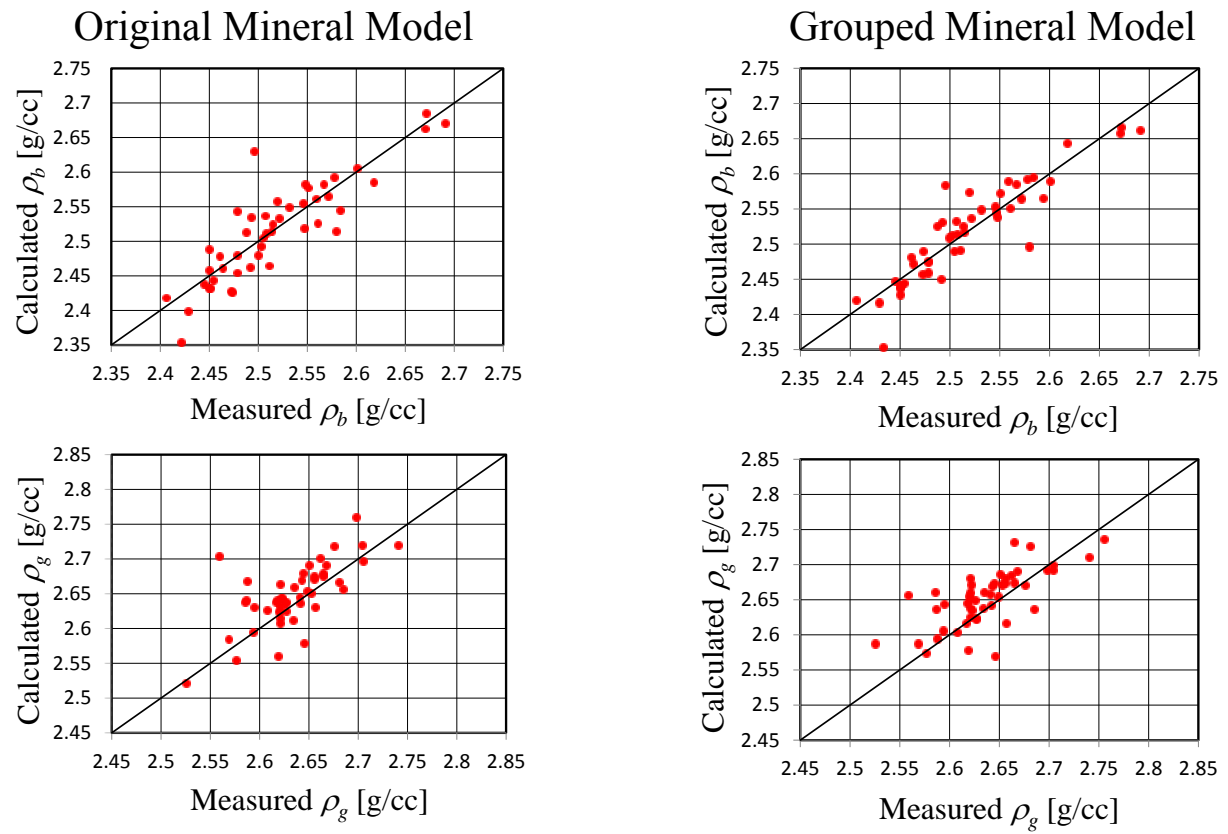

Figure 3.2: Comparison of measured and calculated bulk density $\left(\rho_{b}\right)$ and grain density $\left(\rho_{g}\right)$ based on the original and grouped mineral models for (a) Haynesville, and (b) Barnett shales 


\subsection{Estimation OF TOC AND KEROgEn CONCENTRATION}

The volume of adsorbed gas is directly proportional to TOC and can be estimated experimentally by Canister gas desorption and Langmuir isotherm adsorption methods. Because of its relatively low density, kerogen can fill a large rock volume and its effect on well $\log$ s can be significant, notably in bulk density and gamma-ray logs. With published kerogen density data of approximately 1.2-1.4 g/cc, kerogen volumetric fraction roughly doubles the value of TOC weight fraction. Notice that even though we emphasize the accuracy of $T O C$ estimation, $T O C$ is not the only indicator of good productivity. Geochemical analysis also needs to be conducted to better understand the hydrocarbon-producing potential of kerogen (Dembicki, 2009).

Natural gamma ray has historically been the main log for detecting and quantifying source-rocks. Earlier studies emphasize that authigenic uranium is enriched in anoxic depositional conditions which is the origin of most marine organic-rich shales (Wignall, 1994). However, the relationship between TOC and gamma-ray reading is often nonlinear and other sources of radioactivity may affect gamma-ray logs, thereby making it more difficult to accurately estimate $T O C$. The invention of the spectral gamma-ray tool triggered further studies to better understand the relationship between the uranium $\log$ and TOC (Fertl and Rieke, 1980). Nevertheless, the relationship between uranium log and $T O C$ is also nonlinear and not universal. In addition, environmental effects such as type of drilling fluid, tool configuration, and field calibration accuracy make it difficult to compare gamma-ray and spectral gamma-ray logs acquired in different wells.

In our study of Haynesville and Barnett shales, we observe that gamma-ray logs provides a good estimation of TOC when they are calibrated with core data. We use this method as a secondary source for $T O C$ estimation when our preferred method does not yield reliable estimations. No major improvement is obtained with spectral gamma-ray 
uranium logs even though they enable better estimations in certain depth intervals. Herron (1987) introduced a technique to derive TOC from Carbon/Oxygen (C/O) $\operatorname{logs}$ combined with density porosity. To obtain total carbon content, the technique multiplies the $\mathrm{C} / \mathrm{O} \log$ to estimated oxygen concentration of the formation. Finally, inorganic carbons such as those present in carbonates need to be estimated and subtracted from the total carbon content to determine TOC.

At present, the $\Delta \log R$ method (Passey et al., 1990, 2010) is the most commonly used technique by the industry to estimate TOC. This technique combines apparent resistivity and porosity logs and is calibrated with an LOM (Level of Organic Metamorphism) value which is related to kerogen Vitrinite reflectance and maturity; $L O M$ can be determined by plotting $T O C$ and $S_{2}$ (quantity of hydrocarbon produced by cracking the kerogen from RockEval pyrolysis) values. Kerogen from most shale gas plays is over-mature Type II Kerogen that has passed its oil window and typically has a Vitrinite Reflectance $\left(R_{o}\right)$ value greater than 1\%. Figure 3.3 shows that Haynesville shale has an $R_{o}$ value in dry gas window, while in the Barnett Shale, $R_{o}$ ranges between the oilprone to the wet-gas windows. These high maturities translate to high $L O M(L O M>12$ in Haynesville shale and $11<L O M<12$ in Barnett shale) as determined using the $T O C$ vs. $S_{2}$ cross-plot shown in Figure 3.4. The plots are reconstructed based on figures included in Passey et al.'s papers $(1990,2010)$. Note that Passey et al. (1990) originally constructed the correlation in an oil-mature window, and they subsequently proposed a calibration limit for $L O M>10.5$ based on studies of shale gas formations. Our reconstruction of the calibration limit shown in their paper yields an LOM of approximately 10.4 .

The $\Delta \log R$ technique provides reliable $T O C$ approximations in our field examples of Haynesville and Barnett shales. Resistivity and porosity baseline values often have to be adjusted to obtain the best match with core-measured TOC. We suspect that baseline 
variations are caused by the large difference in mineralogy between the baseline shale and the organic-rich shale. We also observed that the $\Delta \log R$ estimation was affected by conductive beds such as pyrite in certain depth sections of the Barnett shale. Figure 3.5 illustrates this behavior. Resistivity images indicate that the depth zone between $x 735$ $\mathrm{x} 760 \mathrm{ft}$ is pyrite rich. We suspect that the apparent resistivity measured by the induction tool is lower than the actual bed resistivity due to conductive pyrite. Therefore, $\Delta \log R$ underestimates $T O C$ while the gamma-ray log leads to a better estimation in this depth interval. In the well B5 example, the Barnett shale formation consists of alternating shale and carbonate layers. The $\Delta \log R$ method can only be applied to shale (Passey et al., 1990), whereby it gives an erroneous TOC estimation in carbonate beds. To obtain a continuous and accurate $T O C$ estimation that can be used as input to the inversion algorithm, we splice TOC estimated from the gamma-ray log in clean formations to that obtained with the $\Delta \log R$ method in shales. 
Generic window guidelines for Vitrinite Reflectance

\begin{tabular}{|c|c|c|c|c|c|c|c|c|}
\hline & \multicolumn{2}{|c|}{ Immature } & & Oil Window & Wet Gas & & \multicolumn{2}{|c|}{ Dry Gas } \\
\hline 0 & 0.2 & 0.4 & 0.6 & 0.8 & 1.2 & 1.4 & 1.6 & 1.8 \\
\hline
\end{tabular}

(a)

\begin{tabular}{|c|c|c|c|c|c|c|c|c|}
\hline & & 0 & & & & & $\begin{array}{cc}0 & \infty \\
00000 \infty\end{array}$ & \\
\hline 0 & 0.2 & 0.4 & 0.6 & 0.8 & 1.2 & 1.4 & 1.6 & 1.8 \\
\hline
\end{tabular}

(b)

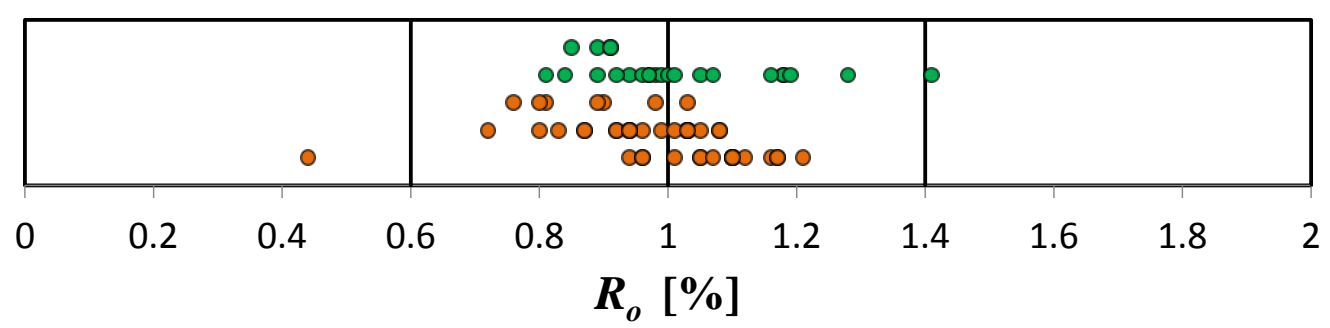

Figure 3.3: Measured (in green) and calculated (in orange) Vitrinite reflectance values $\left(R_{o}\right)$ based on core samples from a total of 5 wells in (a) Haynesville, and (b) Barnett shales. 
(a)

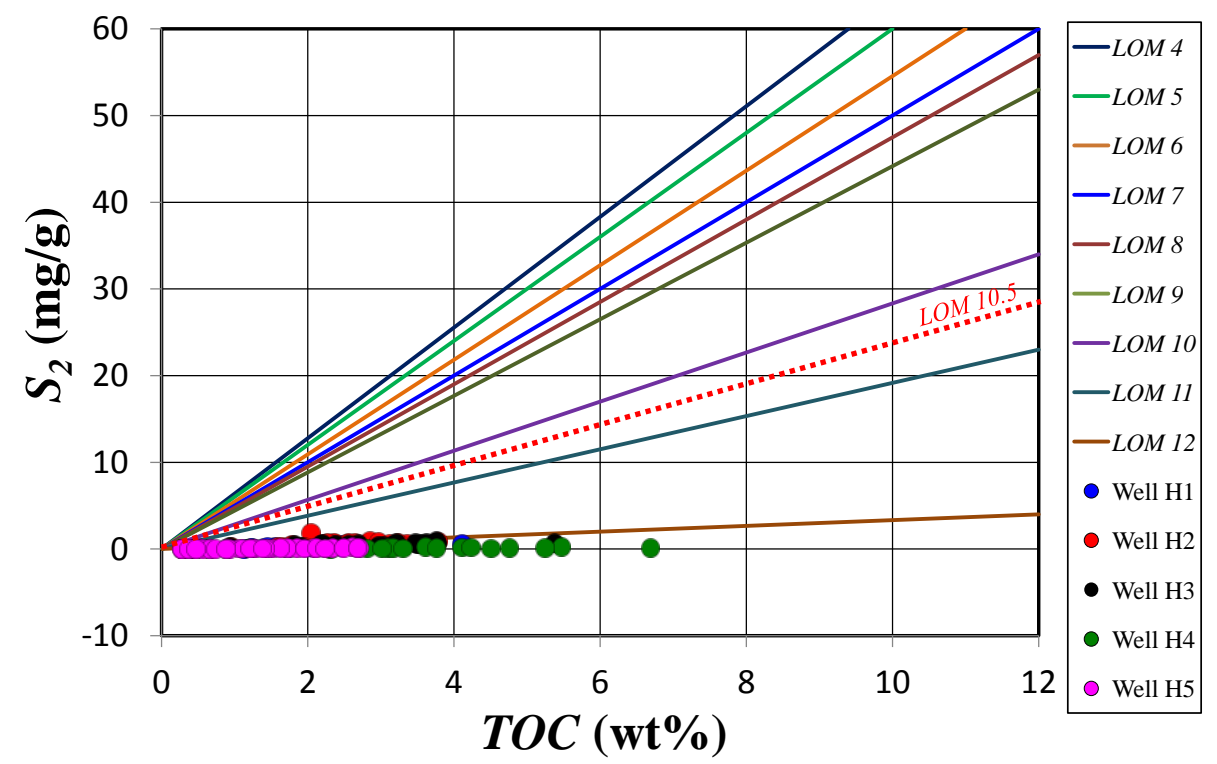

(b)

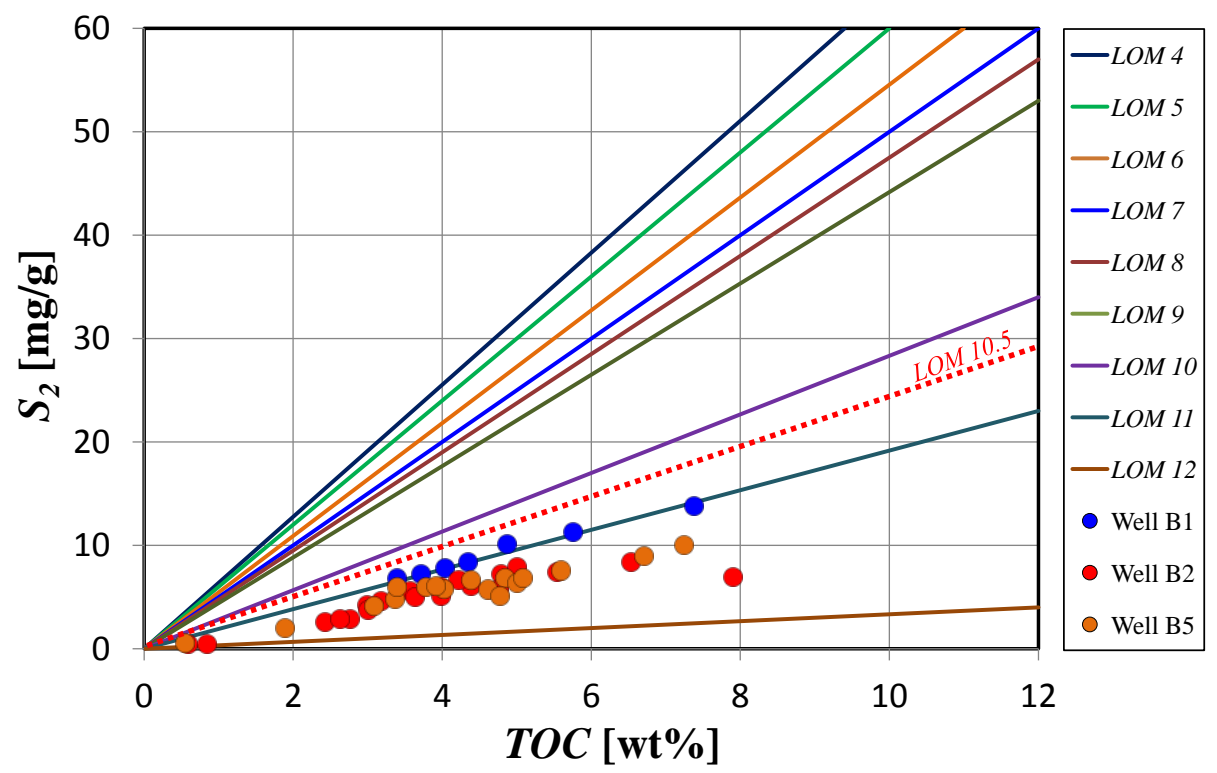

Figure 3.4: Determination of $L O M$ from $S_{2}$ vs. $T O C$ cross-plot obtained from RockEval pyrolysis measurements of core samples in (a) Haynesville, and (b) Barnett shales. The cross-plot is adapted from Passey et al. (1990). 


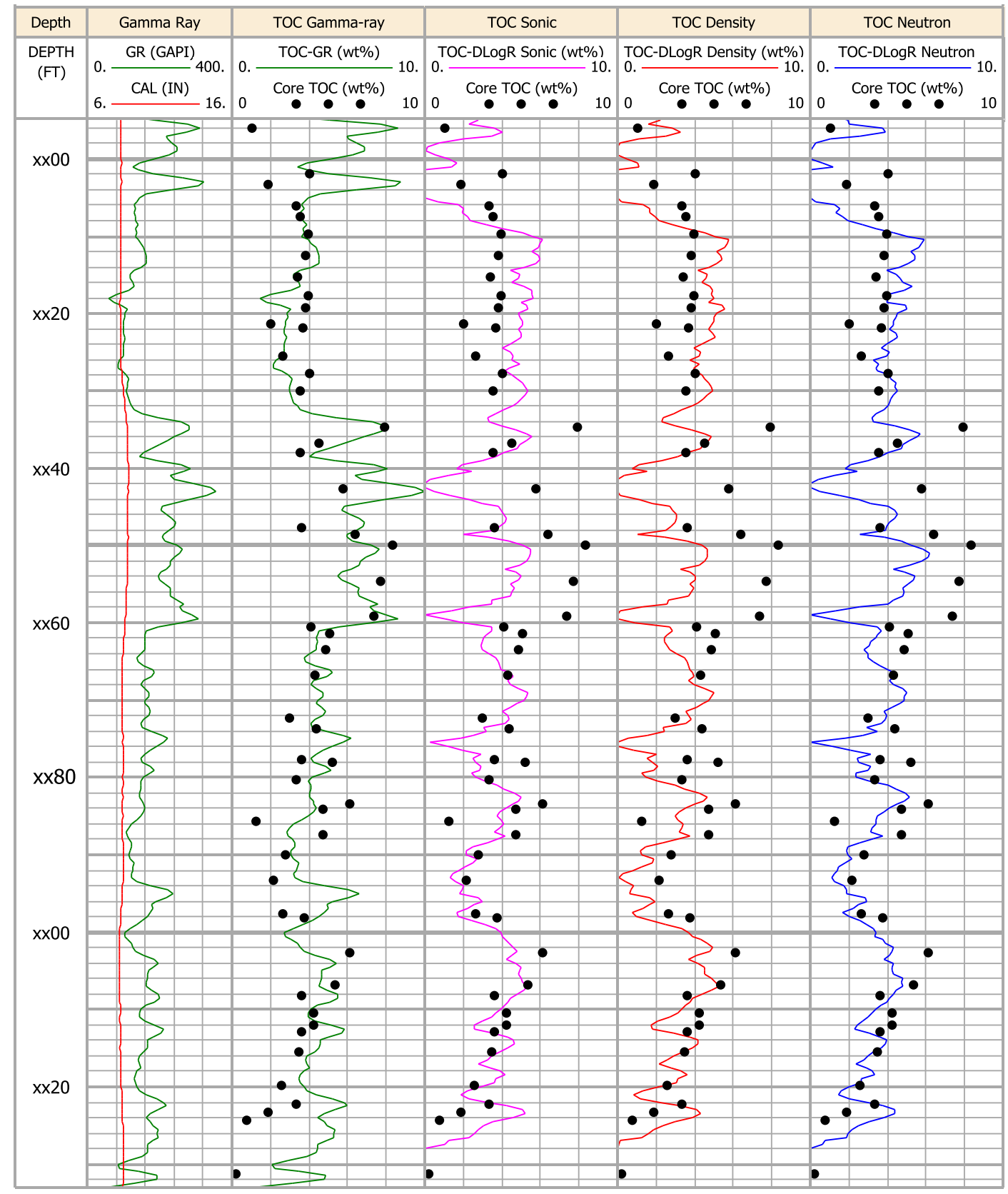

Figure 3.5: Comparison of various TOC estimation methods and core data for a Barnett shale field example. Track 1: Relative depth. Track 2: Gamma-ray and caliper logs. Track 3: TOC estimated from the gamma-ray log. Track 4: $T O C$ calculated with the sonic/resistivity $\triangle \log R$ method. Track 5: TOC calculated with the bulk density/resistivity $\Delta \log R$ method. Track 6: TOC calculated with the neutron porosity/resistivity $\Delta \log R$ method. 


\subsection{Calibration of Mineral Model and Petrophysical Properties}

Using selected mineral properties and chemical formulas, bulk density, PEF, and neutron porosity values at each core-plug data point are calculated and compared to available logs. Clay properties are used as calibration variables to best fit the available logs. We use a 2-clay component model combining illite and chlorite and vary the compositions to obtain the best match between reconstructed nuclear properties from core and well logs. Mineral calibration is an important step in this method because the same properties will be used in the inversion throughout the depth interval of interest.

Our main benchmark data used to evaluate the performance of the method is based on core measurements. Porosity and water saturation are compared to GRI crushed rock analysis, whereas $V_{\text {kerogen }}$ is compared to TOC (from Leco or RockEval Pyrolysis) that is converted to kerogen volumetric concentration using the previously explained methods; XRD analysis is the main data source when comparing mineral compositions. However, the scarcity of data makes it difficult to properly evaluate inversion results throughout the depth interval of interest. Consequently, mineral weight fractions obtained from processed neutron capture spectroscopy logs are best suited for comparison to estimated results.

To consistently compare data measured by a number of service providers, the following groups are used to group the minerals from NCS logs: QFM (quartz, feldspar, and mica), CAR (calcite, dolomite, and ankerite), and CLA (illite, chlorite, smectite, and kaolinite). Other minerals such as pyrite, anhydrite, and siderite, whenever present, are shown separately in the analysis. 


\subsection{NONLINEAR JoInt INVERSION OF CONVENTIONAL WELL LOGS}

We make use of the nonlinear joint inversion method introduced by Heidari et al. (2012) to estimate mineral and fluid concentrations from well logs. This inversion algorithm can operate in two modes: depth-by-depth and layer-by-layer. The depth-bydepth mode treats well logs at each sampling point as the formation property and does not implement corrections for shoulder-bed effects. The inversion is performed directly from well logs to obtain mineral and fluid concentrations. In doing so, the layer-by-layer mode allows corrections for shoulder-bed effects. This method is based on the concept of Common Stratigraphic Framework (CSF) (Voss et al., 2009), and requires bed boundaries as additional input. Accordingly, the layer-by-layer inversion is performed in two steps: first, inversion is performed on individual well logs to estimate properties for each bed (gamma ray, electrical conductivity, bulk density, photoelectric factor, and migration length). Next, joint inversion is performed from previously-inverted bed properties to estimate mineral and fluid concentrations. The inversion is initially carried out by simulating well logs based on an initial guess. Differences between simulated and measured properties are calculated and minimized through an iterative process. Final inversion results are simulated again and validated against input well logs.

Field examples indicate that stable inversion results are obtained using only resistivity, photoelectric factor, bulk density, and neutron porosity as input well logs. The gamma-ray log often leads to non-reliable inversion results due to noise, environmental effects, and the nonlinear relationship that it bears with volumes of clay and organic matter. Schlumberger's SNUPAR software (McKeon and Scott, 1989) is used to calculate photoelectric factor and thermal neutron porosity using chemical formulas of minerals and fluids included in the rock and their volumetric concentrations. Solutions 
could still be non-unique even though the problem is now even-determined. Thus, a good initial guess is necessary to secure convergence of the nonlinear inversion algorithm.

We develop empirical formulas to construct an initial guess that is relatively close to the correct answer. For example, we calculate density porosity using an average value of matrix density $\left(\rho_{m a}\right)$ and fluid density $\left(\rho_{f}\right)$ from GRI analysis. Similarly, to estimate $V_{\text {clay }}$, we use the difference between neutron and density porosity calibrated with XRD analysis and/or NCS logs. Figure 3.6 confirms that $V_{\text {clay }}$ calculated with differences between density and neutron porosity correlates well with $W_{\text {clay }}$ obtained from NCS logs.

(a)

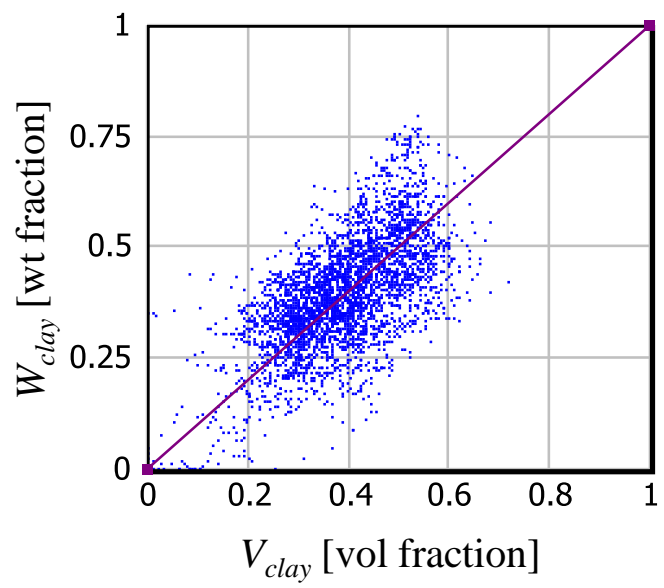

(b)

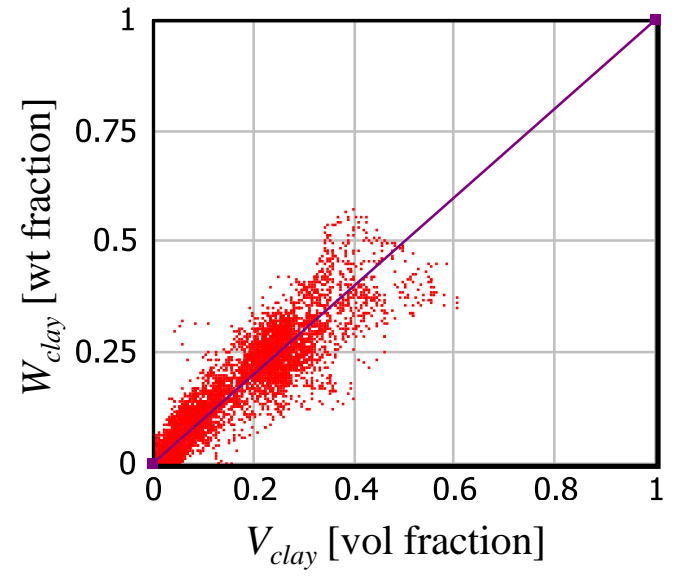

Figure 3.6: Comparison between estimated initial clay volumetric concentration $\left(V_{\text {clay }}\right)$ and clay weight concentration $\left(W_{\text {clay }}\right)$ from NCS logs for field examples in (a) Haynesville, and (b) Barnett shales. 


\section{Chapter 4: Synthetic Case Study}

Two synthetic examples are presented in this thesis to illustrate the application of nonlinear inversion to well logs acquired in formations with known mineral compositions and petrophysical properties. Formation models assume a vertical well where individual bed is isotropic, homogenous, and horizontal. Mineral compositions and petrophysical properties of formation models are constructed based on field examples from the Barnett and Haynesville shales.

\subsection{Construction of The Synthetic Model And Simulated Well LogS}

The process of constructing synthetic logs is described in detail by Voss et al. (2009) and referred to as static modeling. To briefly summarize the main procedures involved in static modeling, we initially construct layers within the formation by selecting bed boundaries. Subsequently, mineral volumetric concentrations, porosity, water, and other petrophysical properties are populated within each layer. SNUPAR (McKeon and Scott, 1989) is used to calculate photoelectric factor (PEF) and neutron migration length $\left(L_{m}\right)$ based on chemical formulas specified for each mineral and fluid component. Gamma-ray values are calculated based on potassium, thorium, and uranium concentrations assigned to each mineral. Similarly, bulk density is calculated as a linear superposition of the density of each mineral and fluid component. A resistivity model is then selected to calculate the electrical resistivity of each layer based on porosity, water saturation, and water resistivity. Numerical simulations are performed to obtain synthetic logs using UTAPWeLS software with the Wireline Longhorn Nuclear tool and the Schlumberger Array Induction Tool (AIT) choices. 


\subsection{Synthetic CASE 1}

The purpose of the first synthetic case is to examine shoulder-bed effects on inverted properties. It also serves to compare depth-by-depth and layer-by-layer inversion results. The earth model consists of interbedded layers of organic-rich shale and tight carbonate with bed thicknesses equal to $10 \mathrm{ft}, 5 \mathrm{ft}, 3 \mathrm{ft}, 2 \mathrm{ft}, 1 \mathrm{ft}$, and $0.5 \mathrm{ft}$. In this example, the shale layer contains mainly quartz, clay, and kerogen with slight calcite concentration, whereas the carbonate layer is composed of mostly calcite and minor amounts of quartz and clay. We model the formation based on similar variations of mineralogy commonly observed in both Haynesville and Barnett shales. In addition, a sharp variation of mineralogy gives rise to a deflection of all well logs, thereby causing shoulder-bed effects. In order to avoid non-unique solutions, we construct an evendetermined problem with six unknowns and six inputs. The inputs are five well logs (gamma ray, resistivity, PEF, density, and neutron porosity) together with the mass balance equation. Six main constituents commonly found in organic-rich shale are used to populate the earth model: quartz, calcite, clay, kerogen, water, and gas. Track 8 in Figure 4.2 displays the mineral distribution and thickness of each layer, whereas tracks 5, 6, and 7 display porosity, water saturation, and kerogen volumetric concentration, respectively. Table 4.1 summarizes the mineral concentrations, porosity, and water saturation within each layer, whereas Table 4.2 summarizes assumed Archie's parameters and matrix, fluid, and formation properties.

Figure 4.2 compares inversion results obtained from depth-by-depth and layer-bylayer inversion modes. For the $10 \mathrm{ft}$ and $5 \mathrm{ft}$ layers, both modes produce similar results even though the depth-by-depth mode introduces slight error spikes near bed boundaries. These errors become more significant in thin beds. On the other hand, the layer-by-layer inversion performs better across thinner beds even though errors arise across the $1 \mathrm{ft}$ and 
$0.5 \mathrm{ft}$ layers. We notice that the limitation of minimum bed thickness faced by inversion is due to the tool sampling interval. The most common sampling interval used in DLIS and LAS files is $0.5 \mathrm{ft}$. Accordingly, the Nyquist theorem, commonly used in digital signal processing, states that the sampling frequency used to reconstruct a signal has to be at least twice the highest frequency present in the analog signal. If this theorem is applied to our case, the thinnest bed that can be resolved effectively with a $0.5 \mathrm{ft}$ sampling interval is $1 \mathrm{ft}$.

\begin{tabular}{lccc}
\hline $\begin{array}{l}\text { Mineral / Petrophysical } \\
\text { Properties }\end{array}$ & $\begin{array}{c}\text { Shale } \\
\text { Layer }\end{array}$ & $\begin{array}{c}\text { Carbonate } \\
\text { Layer }\end{array}$ & Units \\
\hline Quartz $\left(V_{\text {quartz }}\right)$ & 0.460 & 0.0825 & {[]} \\
Calcite $\left(V_{\text {calcite }}\right)$ & 0.066 & 0.7425 & {[]} \\
Clay $\left(V_{\text {clay }}\right)$ & 0.255 & 0.1275 & {[]} \\
Kerogen $\left(V_{\text {kerogen }}\right)$ & 0.131 & 0 & {[]} \\
Total porosity $\left(\phi_{t}\right)$ & 0.088 & 0.0475 & {[]} \\
Total water saturation $\left(S_{w t}\right)$ & 0.3 & 0.3 & {[]} \\
\hline
\end{tabular}

Table 4.1: Assumed mineral and fluid constituents for Synthetic Case 1. The multilayer formation is comprised of these two layers alternating with different thickness, ranging from 0.5 to $10 \mathrm{ft}$. 


\begin{tabular}{lcc}
\hline Variable & Value & Units \\
\hline Archie's Winsauer factor, $a$ & 1 & {[]} \\
Archie's porosity exponent, $m$ & 2 & {[]} \\
Archie's saturation exponent, $n$ & 2 & {[]} \\
Connate water resistivity at formation temperature, $R_{w}$ & 0.1 & Ohm-m \\
Water density, $\rho_{W}$ & 1.07 & $\mathrm{~g} / \mathrm{cc}$ \\
Hydrocarbon density, $\rho_{H C}$ & 0.20 & $\mathrm{~g} / \mathrm{cc}$ \\
Dry clay density, $\rho_{\text {clay }}$ & 2.80 & $\mathrm{~g} / \mathrm{cc}$ \\
Clay porosity, $\phi_{\text {clay }}$ & 0.05 & {[]} \\
\hline
\end{tabular}

Table 4.2: Synthetic Case 1: Summary of assumed Archie's parameters, and matrix, fluid, and formation properties

\subsection{Synthetic CASE 2}

The second synthetic case is intended to study a gas-bearing, organic-rich shale formation with large variations in kerogen volumetric concentration and mineral constituents. In addition to the same mineral constituents assumed in the first synthetic case, a small amount of pyrite is added here. The problem is now slightly underdetermined, with six inputs (five logs plus the mass balance equation) and seven unknowns ( $V_{\text {quartz }}, V_{\text {calcite }}, V_{\text {clay }}, V_{\text {kerogen }}, V_{\text {pyrite }}, \phi_{t}$, and $\left.S_{w t}\right)$. The top-most layer is a clayrich, organic-poor shale formation with moderate amounts of quartz and calcite, whereas the bottom-most layer is a low porosity carbonate formation with a small amount of clay and kerogen. In this example, the organic-rich shale is located between the top and bottom beds and is modeled based on petrophysical properties and mineralogy of the Barnett shale. Similar to the first synthetic case, we apply inversion in depth-by-depth and layer-by-layer modes and compare the corresponding results. 
Figure 4.3 shows inversion results compared to the original earth model properties. Both inversion modes show excellent estimations because the thinnest bed is 1 ft. The depth-by-depth method is slightly noisy and exhibits shoulder-bed effects. Table 4.4 summarizes the arithmetic mean errors of porosity, water saturation, and mineral volumetric concentration associated with the two modes of inversion.

Figure 4.1 displays a cross-plot of simulated bulk density against kerogen volumetric concentration for the second synthetic case. We note that the earth model is not intentionally designed for this purpose. Instead, the example illustrates why a linear correlation between bulk density and kerogen concentration has been commonly observed in organic-rich shales. Variations in kerogen concentration have a larger effect on bulk density than variations of grain density due to changes in mineralogy. We emphasize that variations of mineral compositions and kerogen concentration have been taken into account in the inversion process.

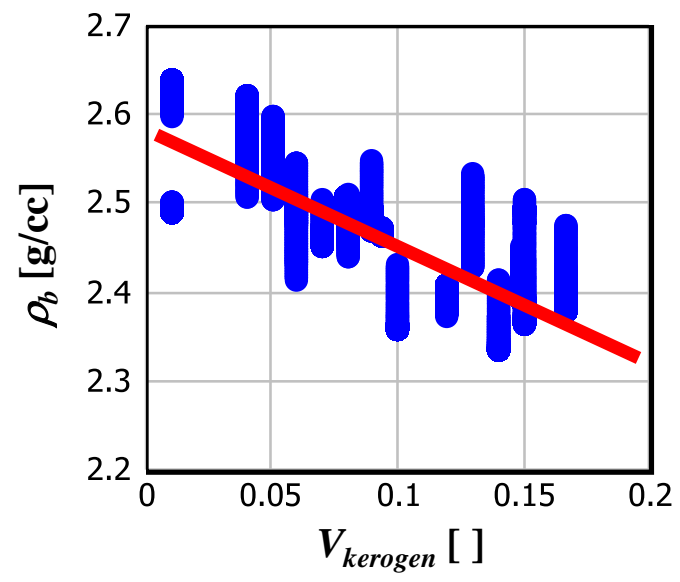

Figure 4.1: Cross-plot of log bulk density $\left(\rho_{b}\right)$ and kerogen volumetric concentration ( $\left.V_{\text {kerogen }}\right)$ for Synthetic Case 2. 


\begin{tabular}{lcc}
\hline Variable & Value & Units \\
\hline Archie's Winsauer factor, $a$ & 1 & {[]} \\
Archie's porosity exponent, $m$ & 2 & {[]} \\
Archie's saturation exponent, $n$ & 2 & {[]} \\
Connate water resistivity at formation temperature, $R_{w}$ & 0.1 & Ohm-m \\
Water density, $\rho_{W}$ & 1.07 & $\mathrm{~g} / \mathrm{cc}$ \\
Hydrocarbon density, $\rho_{H C}$ & 0.20 & $\mathrm{~g} / \mathrm{cc}$ \\
Dry clay density, $\rho_{c l a y}$ & 2.80 & $\mathrm{~g} / \mathrm{cc}$ \\
Clay porosity, $\phi_{c l a y}$ & 0.05 & [ ] \\
\hline
\end{tabular}

Table 4.3: Summary of assumed Archie's parameters, and matrix, fluid, and formation properties for Synthetic Case 2.

\begin{tabular}{lcc}
\hline $\begin{array}{l}\text { Mineral / Petrophysical } \\
\text { Properties }\end{array}$ & $\begin{array}{c}\text { Depth-by-depth Inversion } \\
\text { Mean Error [\%] }\end{array}$ & $\begin{array}{c}\text { Layer-by-layer Inversion } \\
\text { Mean Error [\%] }\end{array}$ \\
\hline Quartz $\left(V_{\text {quartz }}\right)$ & 5.0 & 2.4 \\
Calcite $\left(V_{\text {calcite }}\right)$ & 9.2 & 5.2 \\
Clay $\left(V_{\text {clay }}\right)$ & 6.4 & 2.5 \\
Kerogen $\left(V_{\text {quartz }}\right)$ & 7.3 & 2.7 \\
Pyrite $\left(V_{\text {pyrite }}\right)$ & 0.2 & 0.4 \\
Total porosity $\left(\phi_{t}\right)$ & 8.1 & 2.2 \\
Total water saturation $\left(S_{w t}\right)$ & 7.0 & 1.9 \\
\hline
\end{tabular}

Table 4.4: Comparison of the arithmetic mean percent error of petrophysical properties and mineral volumetric concentrations estimated from depth-by-depth and layer-by-layer inversions for Synthetic Case 2. 


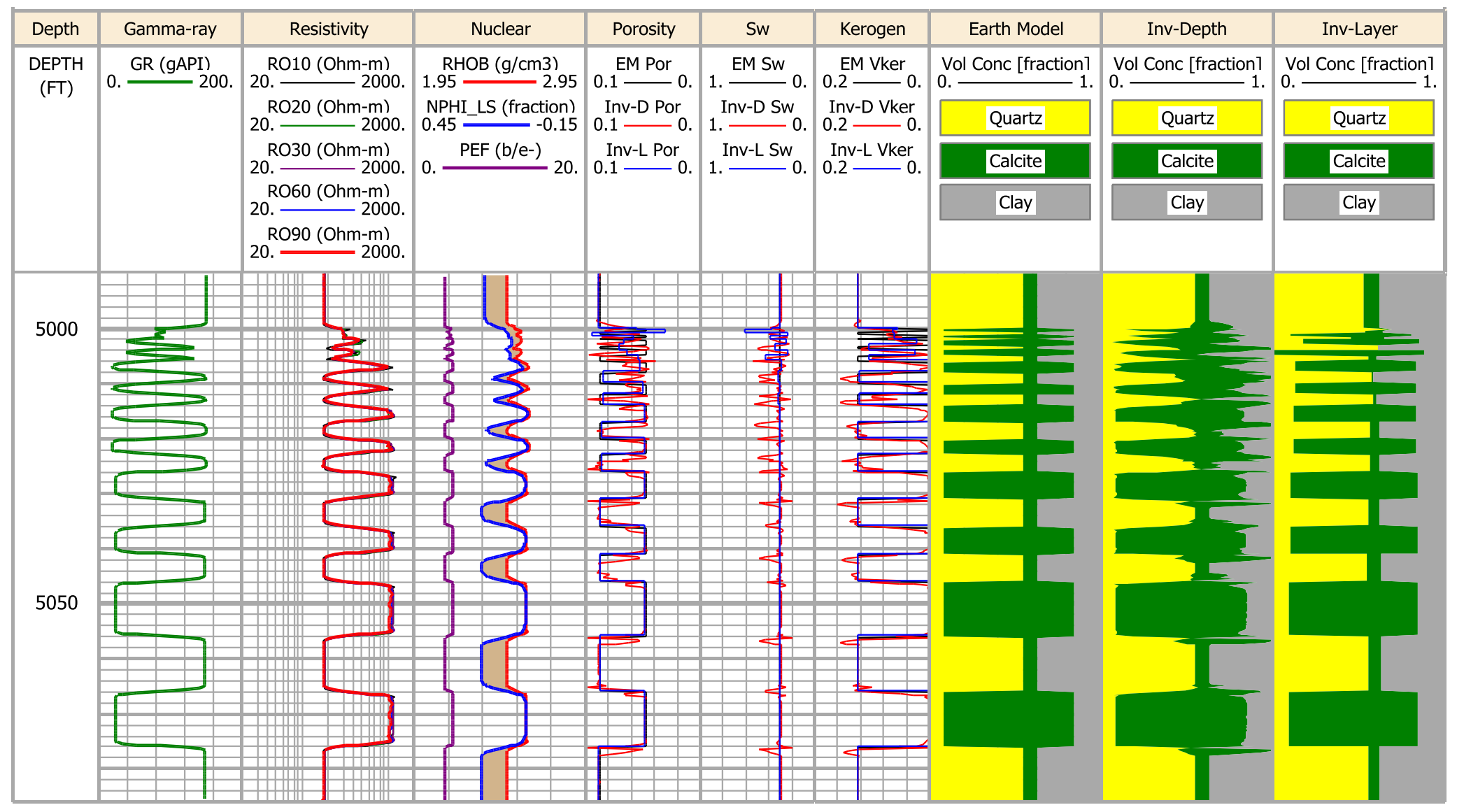

Figure 4.2: Synthetic Case 1. Track 1: Relative depth. Track 2: Gamma-ray log. Track 3: Array-induction apparent resistivity logs. Track 4: PEF, bulk density, and neutron (limestone matrix) porosity logs. Track 5: Earth model and inverted porosity. Track 6: Earth model and inverted water saturation. Track 7: Earth model and inverted kerogen volumetric concentration. Track 8: Earth model mineral compositions. Track 9: Mineral compositions obtained from depth-by-depth inversion. Track 10: Mineral compositions obtained from layer-by-layer inversion. 


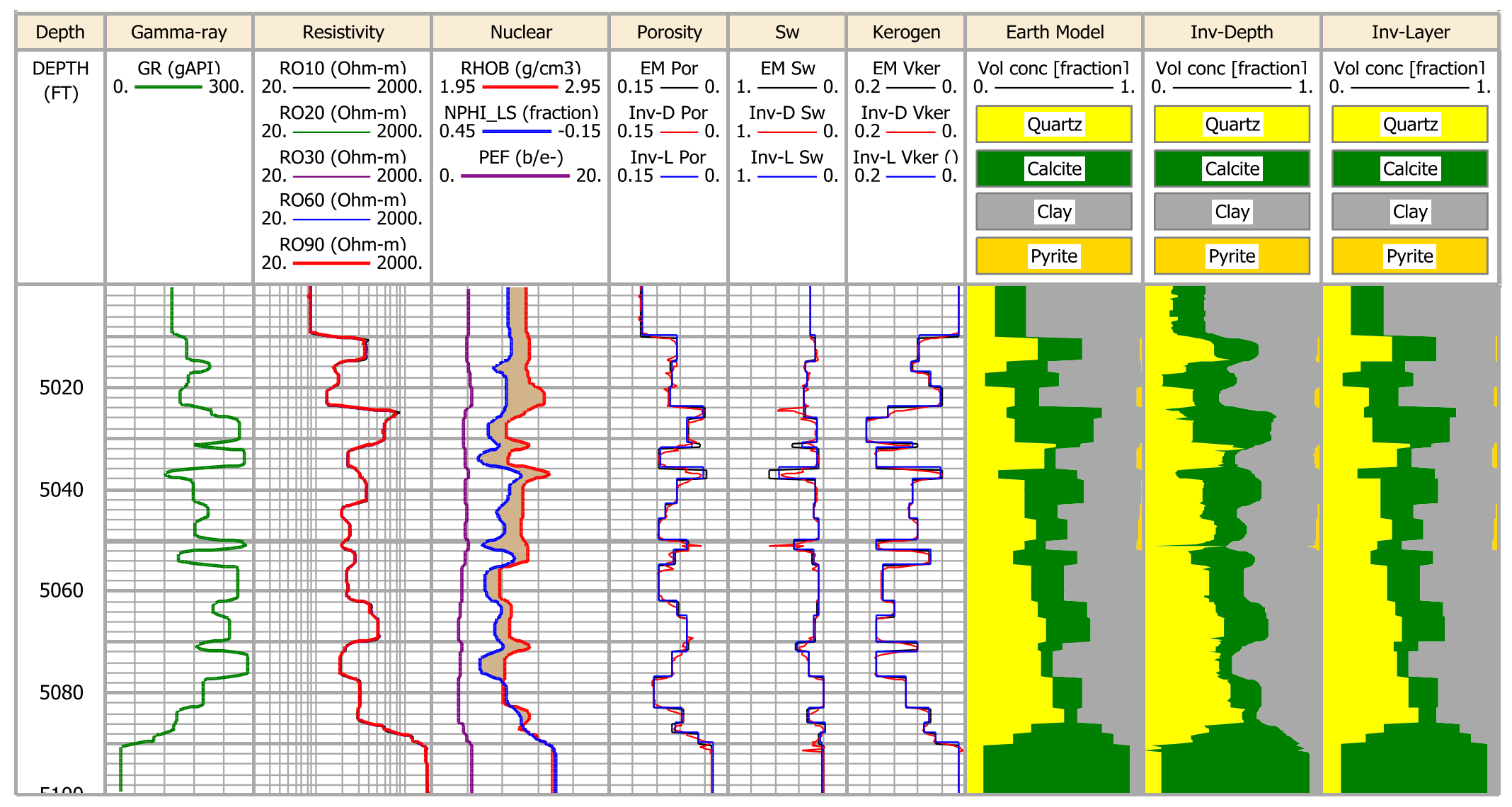

Figure 4.3: Synthetic Case 2. Track 1: Relative depth. Track 2: Gamma-ray log. Track 3: Array-induction apparent resistivity logs. Track 4: PEF, bulk density, and neutron (limestone matrix) porosity logs. Track 5: Earth model and inverted porosity. Track 6: Earth model and inverted water saturation. Track 7: Earth model and inverted kerogen volumetric concentration. Track 8: Earth model mineral compositions. Track 9: Mineral compositions obtained from depth-by-depth inversion. Track 10: Mineral compositions obtained from layer-by-layer inversion. 


\section{Chapter 5: Haynesville Shale Case Study}

In this chapter, we describe the application of the developed interpretation workflow with field data acquired in the Haynesville shale formation. Haynesville is one of the largest shale gas fields discovered in the United States. The reservoir is located in east Texas and northwest Louisiana, at a depth of approximately 10,000 ft.

\subsection{RESERVOIR BACKGROUND}

The Haynesville shale is an upper Jurassic organic-rich mudrock extending from east Texas to western Louisiana and covering an area of approximately 9,000 square miles (U.S. Energy Information Administration, 2011). It has been known as a source rock for conventional carbonate and siliciclastic hydrocarbon reservoirs located in east Texas and Louisiana (Hammes et al., 2011). Above the Haynesville shale is the Bossier shale, a thick clay and silica-rich mudstone. Both Haynesville and Bossier shales exhibit similar high gamma-ray readings ranging from 100 to 200 GAPI. The most common well-log signature used to identify the transition from Haynesville shale to Bossier shale is the increase of neutron/density separation attributed to an increase in clay content. Underlying the Haynesville shale is a short section of the slightly muddy, tight Haynesville limestone, marked by a decrease in gamma-ray, neutron, and density porosity. Beneath the Haynesville limestone, the Smackover limestone is a much cleaner limestone that can be recognized with a further decrease in gamma-ray readings.

Hammes and Frébourg (2012) identified 3 main facies in the Haynesville shale: (1) unlaminated siliceous mudstone, (2) laminated calcareous or siliceous mudstone, and (3) bioturbated calcareous or siliceous mudstone. Kerogen in the Haynesville organic- 
rich shale is of Type II/III (Hammes, 2012). The study performed in this thesis is based on five wells located in the Gregg, Panola, and DeSoto counties.

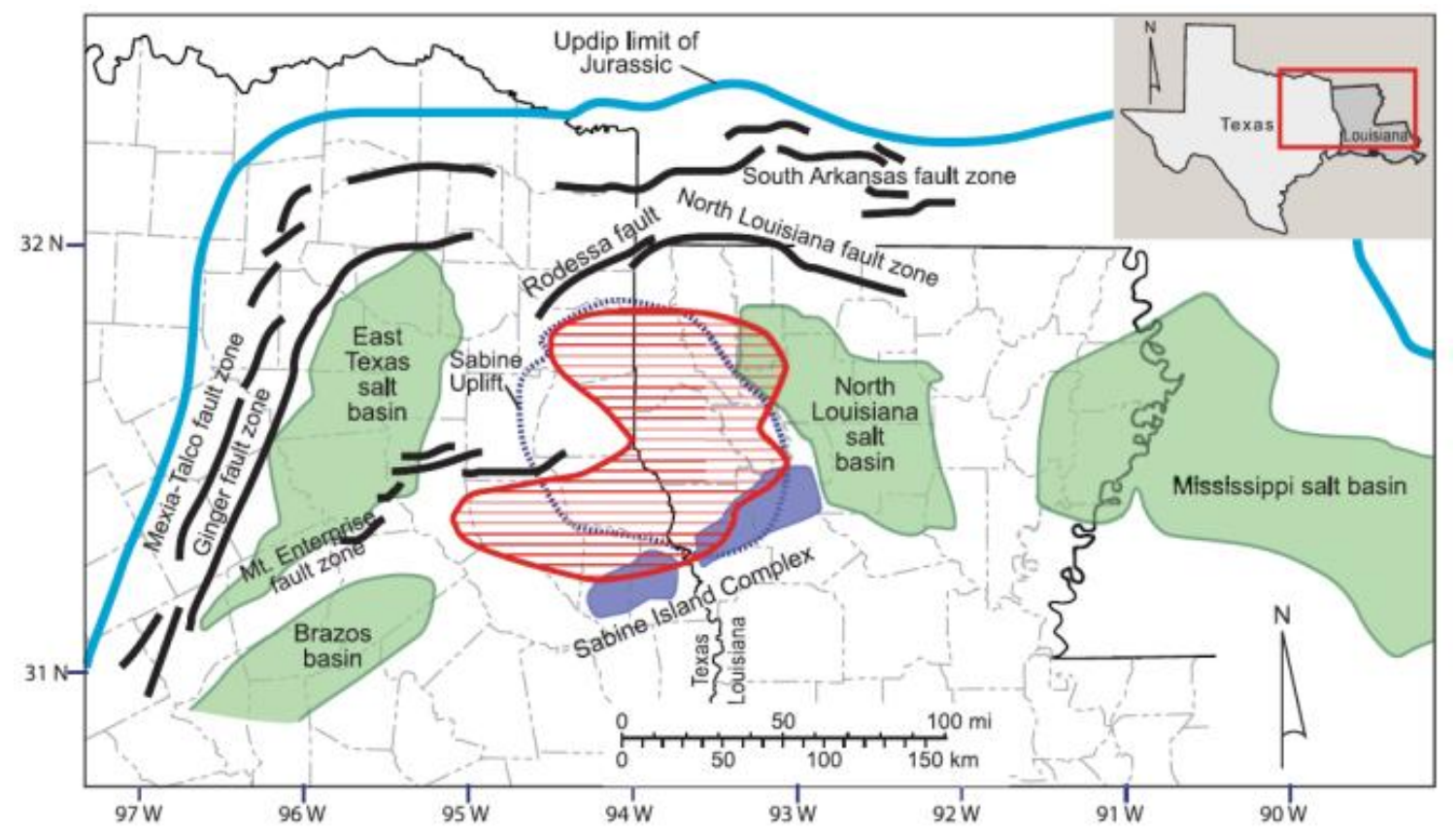

Figure 5.1: Map of Haynesville shale showing surrounding basins and main structural elements during the time of deposition. Haynesville shale productive areas are highlighted with red stripes (Hammes et al., 2011, (C) AAPG 2011, reprinted by permission of the AAPG, whose permission is required for further use). 


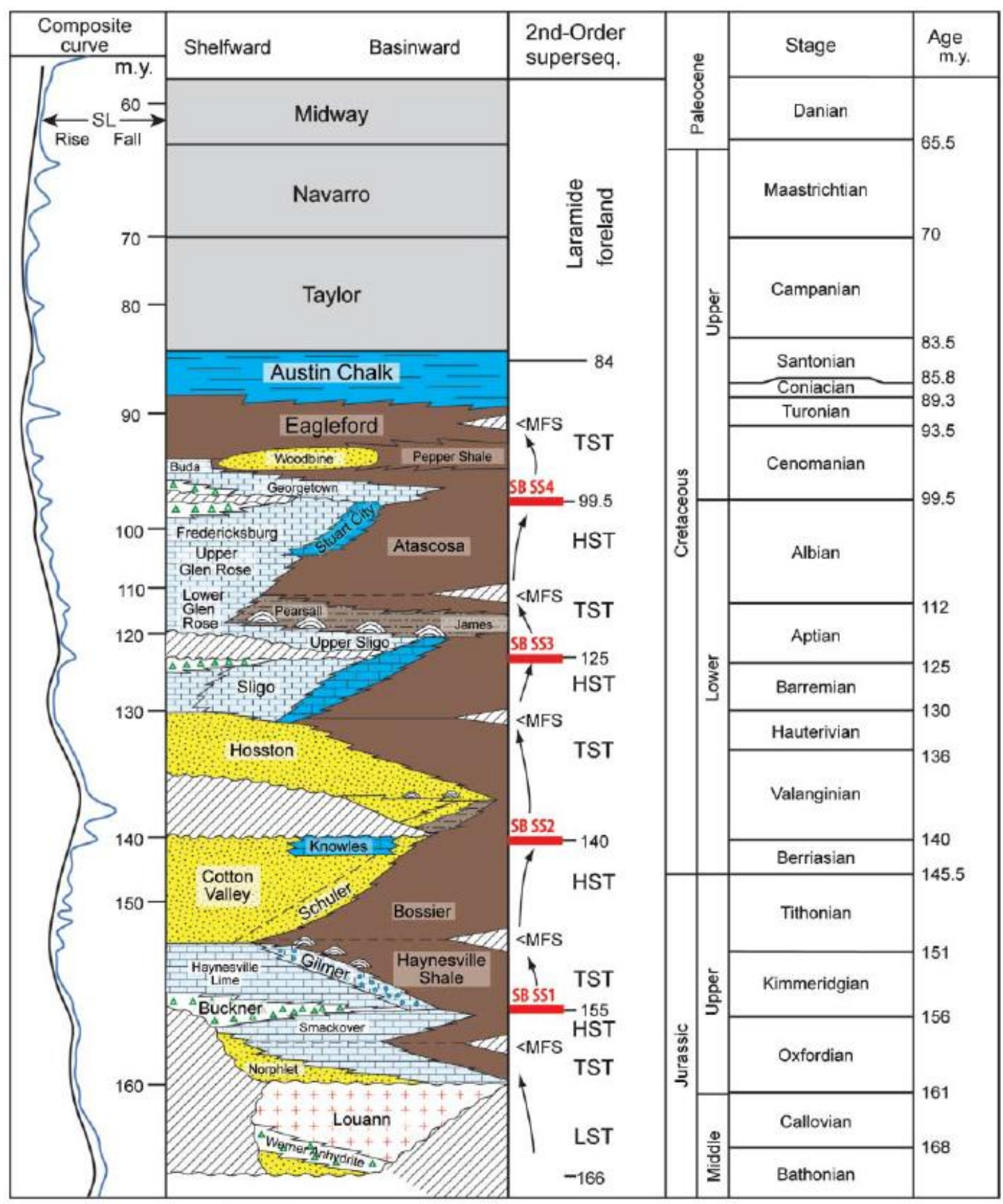

Figure 5.2: Haynesville shale stratigraphic column. The right-most track shows the geological age in million years. $\mathrm{LST}=$ lowstand systems tract, TST $=$ transgressive systems tract, HST = highstand systems tract, MFS = maximum flooding surface. (Hammes et al., 2011, C AAPG 2011, reprinted by permission of the AAPG, whose permission is required for further use). 


\subsection{Mineral Model ANd Associated Parameters}

The Haynesville shale shows large variations of mineral composition from silica and clay-rich, to carbonate-rich layers. Hammes et al. (2011) suggested that siliciclastic sedimentation was dominant in the north and east while the main carbonate production came from south and west. Core XRD data and NCS logs also indicate alternation from carbonate-rich to silica-rich layers and progressive increase of carbonate concentration toward the Haynesville limestone. This feature also appears in a ternary diagram where points are distributed from approximately the middle of the clay and quartz vertices toward the carbonate vertex. Table 5.1 shows the chemical formulas and density values used for the study in the Haynesville shale. Chemical formulas and density values of most minerals are adopted from the Schlumberger Chart Book (Schlumberger, 2009). No specific chemical formula is available for kerogen; we choose a generic chemical formula for that purpose.

\subsection{INVERSION RESULTS AND DISCUSSION}

Haynesville shale data are segmented between Bossier shale and Haynesville limestone to obtain an accurate mineral model. We found petrophysical properties of Bossier shale to differ considerably from those of the Haynesville shale; hence a separate inversion is required to analyze the Bossier shale. Figures 5.4 through 5.8 show estimated porosity, water saturation, kerogen content, and mineral volumetric concentrations obtained from inversion, for well $\mathrm{H} 1$ through $\mathrm{H} 5$, respectively. Results from all five wells confirm that estimated porosity, water saturation, and kerogen volumetric concentrations are in good agreement with core data. They also successfully predict important trends such as decreasing porosity and kerogen concentration in the depth transition toward the Haynesville limestone. 


\begin{tabular}{llc}
\hline Solid Component & Chemical Formula & Density (g/cc) \\
\hline Quartz & $\mathrm{SiO}_{2}$ & 2.65 \\
Plagioclase Feldspar & $\mathrm{NaAlSi}_{3} \mathrm{O}_{8}$ & 2.61 \\
Potassium Feldspar & $\mathrm{KAlSi}_{3} \mathrm{O}_{8}$ & 2.57 \\
Calcite & $\mathrm{CaCO}_{3}$ & 2.71 \\
Dolomite & $\mathrm{CaMg}_{\left(\mathrm{CO}_{3}\right)_{2}}$ & 2.87 \\
Ankerite & $\mathrm{CaFe}_{0.6} \mathrm{Mg}_{0.3} \mathrm{Mn}_{0.1}\left(\mathrm{CO}_{3}\right)_{2}$ & 3.05 \\
Pyrite & $\mathrm{FeS}_{2}$ & 5.01 \\
Fluorapatite & $\mathrm{Ca}_{5}\left(\mathrm{PO}_{4}\right)_{3} \mathrm{~F}$ & 3.17 \\
Kerogen & $\mathrm{C}_{102} \mathrm{H}_{94} \mathrm{O}_{17}$ & 1.4 \\
Illite & $\mathrm{K}_{0.8} \mathrm{Al}_{1.6} \mathrm{Fe}_{0.2} \mathrm{Mg}_{0.2} \mathrm{Si}_{3.4} \mathrm{Al}_{0.6} \mathrm{O}_{10}(\mathrm{OH})_{2}$ & \\
Fe-Chlorite & $\mathrm{Fe}_{5} \mathrm{AlSi}_{3} \mathrm{AlO}_{10}(\mathrm{OH})_{8}$ & \\
\hline
\end{tabular}

\section{Clay Composition:}

$80 \%$ Illite and $20 \%$ Fe Chlorite

$\phi_{\text {clay }}=0.05$

$\rho_{\text {clay }}=3 \mathrm{~g} / \mathrm{cc}$

\section{Hydrocarbon Composition:}

$100 \% \mathrm{CH}_{4}$

$\rho_{H C}=0.151 \mathrm{~g} / \mathrm{cc}$

\section{Resistivity Parameters:}

$a=1, m=2, n=2$

$R_{w}=0.1 \mathrm{Ohm}-\mathrm{m}$

$R_{\text {clay }}=1 \mathrm{Ohm}-\mathrm{m}$

Table 5.1: Description of the mineral model for the Haynesville shale. 
With respect to the five wells considered in this study, we observed inconsistencies in PEF and bulk density logs that were caused by presence of barite in the drilling mud. The inversion requires good data quality and repeatability across wells in order to provide accurate estimations of petrophysical properties without having to customize the mineral model for each well. We performed a 2-point histogram normalization of the PEF curve across wells to repair bad-quality measurements. Figure 5.4 shows an example where low-quality PEF readings cause an incorrect mineralogy interpretation. A quality control curve, shown in the second track, provided by the welllog company, flags the zone where the PEF log is out of tolerance. In the same depth interval, we observe large discrepancies between our interpretation and NCS mineralogy, indicating that the PEF log is not repairable in this particular depth interval.

Sizable differences in mineral compositions estimated with inversion and NCS logs lead one to question the validity of NCS logs. Wells drilled in the Haynesville shale formation are relatively deep at approximately $10,000 \mathrm{ft}$ with high bottom-hole temperatures between 250 and $300^{\circ} \mathrm{F}$. These logging conditions are unfavorable for NCS logging whose detector resolution degrades at high temperatures, resulting in data with poor statistical precision. Repeat section data from wells $\mathrm{H} 2$ and $\mathrm{H} 3$ indicated marginal repeatability for all dry weight mineral outputs from NCS logs. Pyrite measurements, in particular, are rendered useless due to their excessively noisy data. In these two cases, inversion appears to yield more reliable mineral compositions than NCS logs even though the scarcity of core mineralogy prevents us from performing accurate quantification of errors.

One distinct geological feature that is present in most well logs acquired in the Haynesville shale is the two low gamma-ray peaks located approximately in the middle of the Haynesville shale formation. This log signature, often referred to as "rabbit ears" 
by the industry, corresponds to two calcite-rich layers that are frequently used as targets for horizontal well drilling (Buller and Dix, 2009; Hammes, 2012). Figures 5.6 and 5.7 show two examples where inversion correctly predicts the increase in carbonate concentrations across these two low gamma-ray peaks. This feature also appears in NCS logs even though the corresponding signature is slightly obscured by noise.

Case studies in wells $\mathrm{H} 4$ and H5, shown in Figure 5.7 and 5.8, respectively, are deviated well examples. Similar to well H1, the PEF log from acquired in these two wells is severely affected by presence of barite in the drilling fluid. Because the PEF log is sensitive mainly to mineral compositions, its effect on estimated porosity, water saturation, and kerogen concentration appears to be marginal. Estimated mineral compositions, on the other hand, are severely affected by the poor quality of the PEF log, which is not repairable.

Mineral compositions obtained from inversion are also reported in ternary diagrams and compared to those constructed with NCS logs (Figure 5.3); mineralogy variations across different wells have unique distributions in the ternary diagrams. These ternary diagrams prove to be useful to validate the mineral compositions obtained from inversion. 
(a)
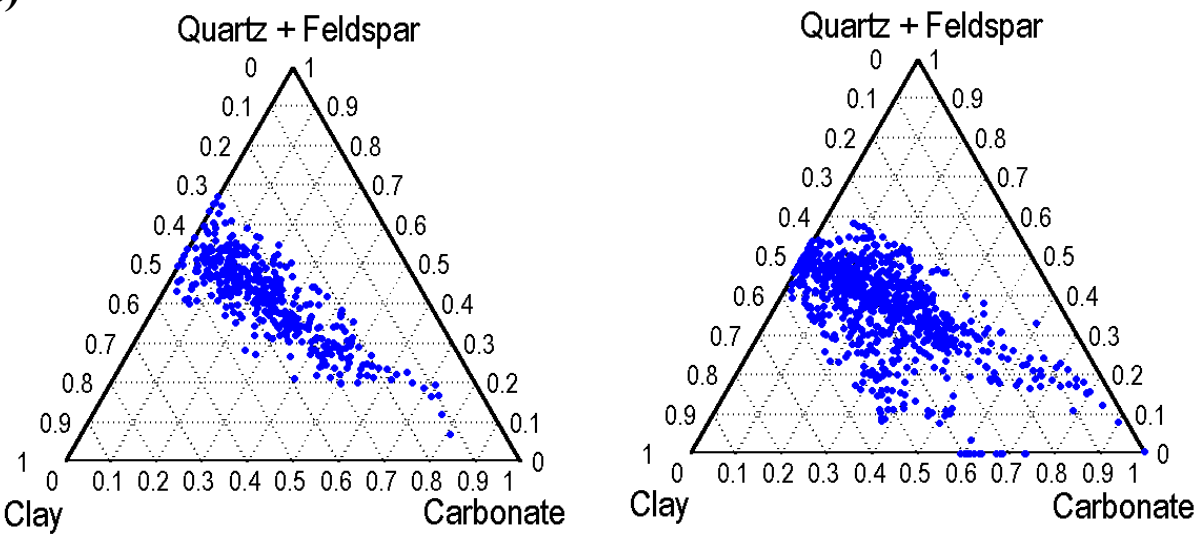

(b)
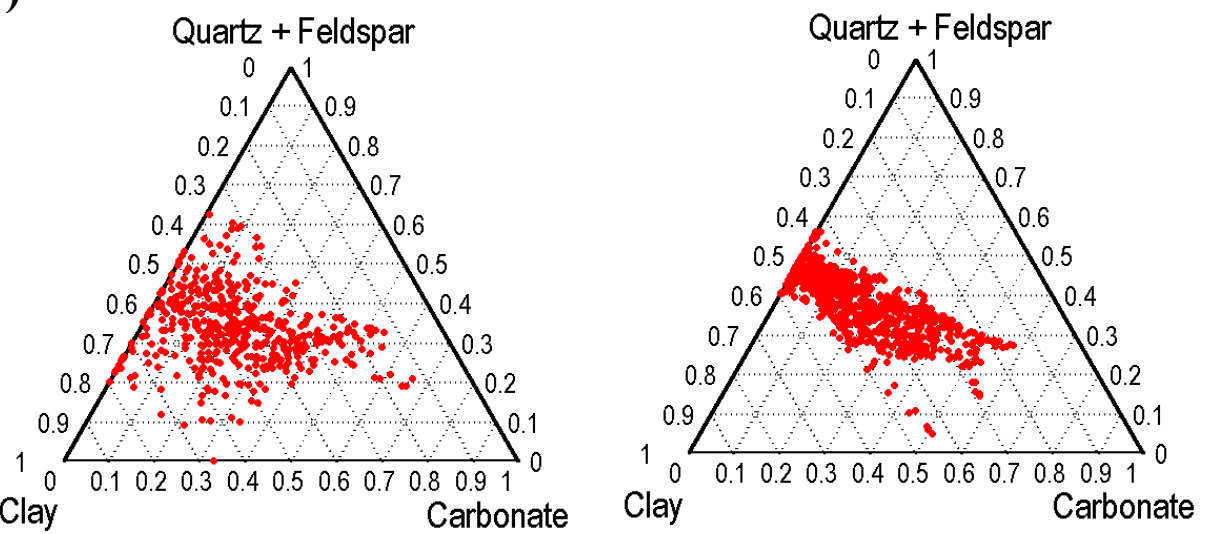

(c)
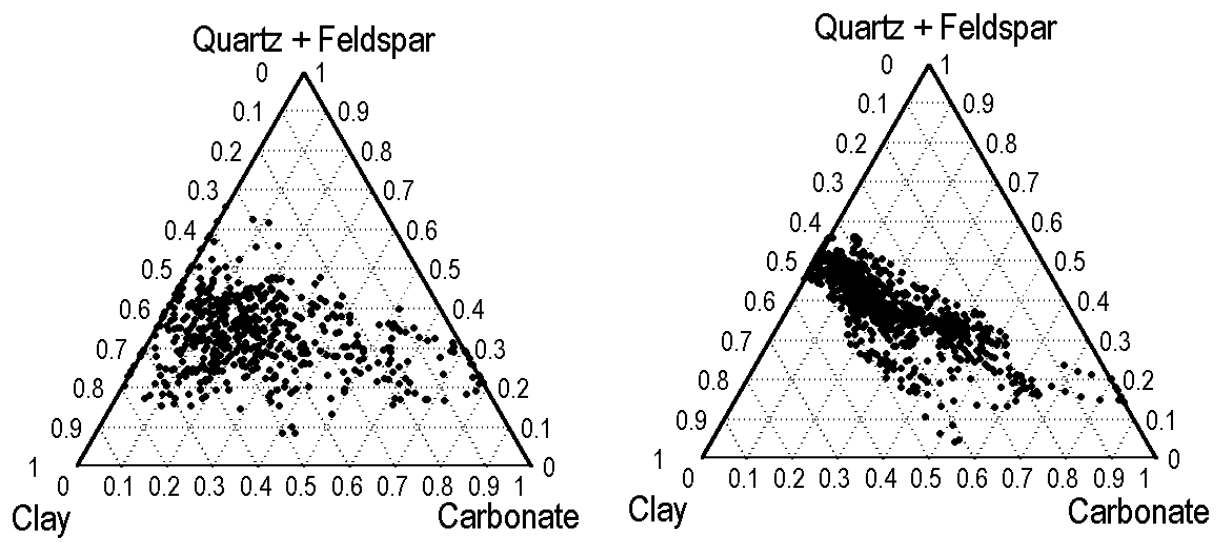
(d)
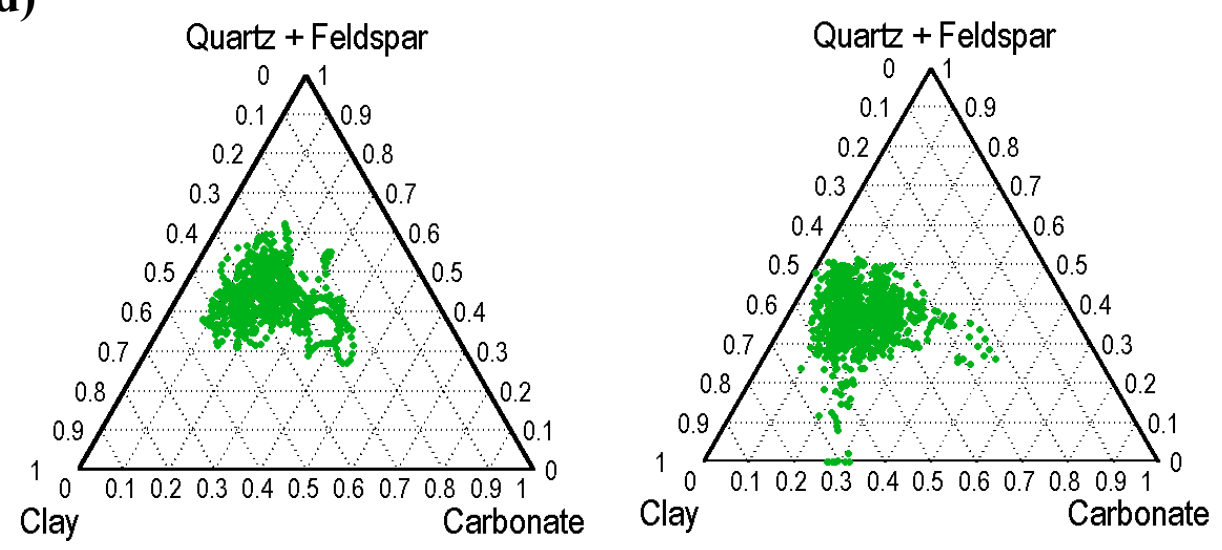

(e)

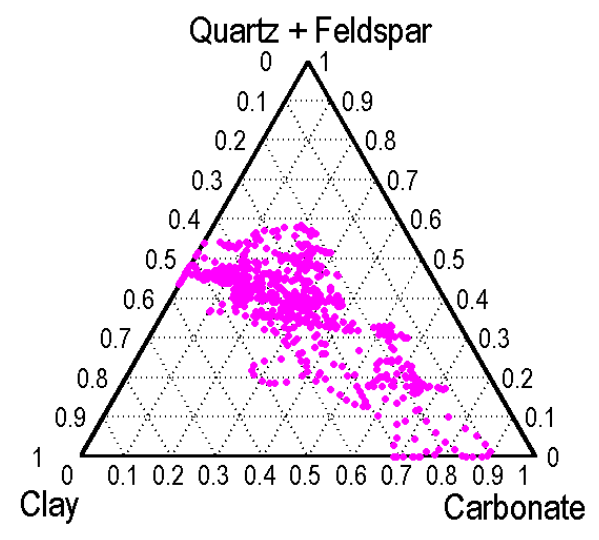

Figure 5.3: Ternary diagram showing the Haynesville shale mineral distribution estimated from NCS log mineral weight concentrations (left), and mineral group weight concentrations obtained from inversion of well logs (right): (a) Well H1, (b) Well H2, (c) Well H3, (d) Well H4, and (e) Well H5. 


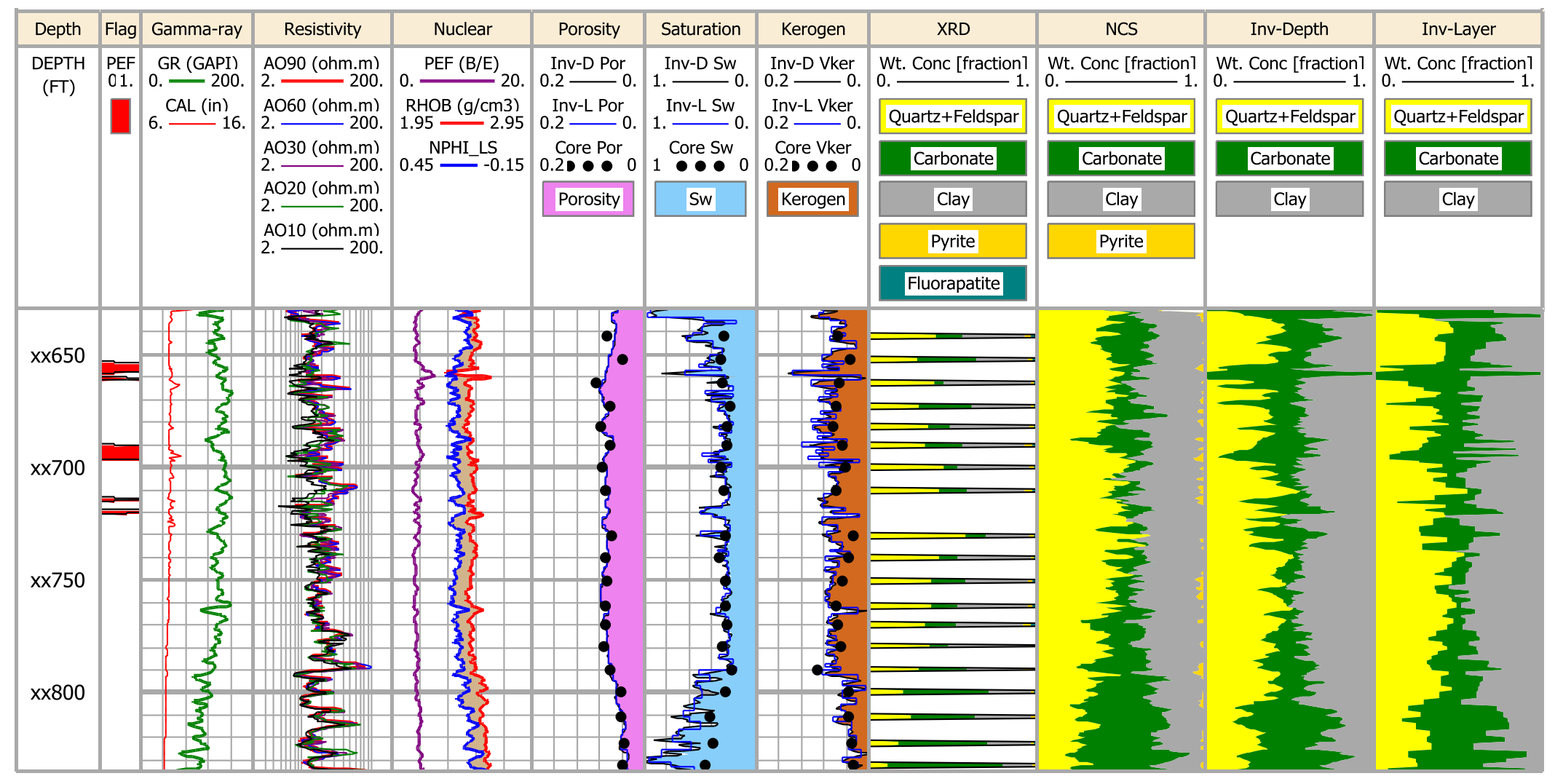

Figure 5.4: Case study in well H1. Track 1: Relative depth. Track 2: PEF quality control flag. Track 3: Gamma-ray and caliper logs. Track 4: Array-induction apparent resistivity logs. Track 5: PEF, bulk density, and neutron (limestone matrix) porosity logs. Track 6: Core and inverted porosity. Track 7: Core and inverted water saturation. Track 8: Core and inverted kerogen volumetric concentration. Track 9: XRD mineral compositions. Track 10: NCS log mineral compositions. Track 11: Mineral compositions obtained from depth-by-depth inversion. Track 12: Mineral compositions obtained from layer-by-layer inversion. 


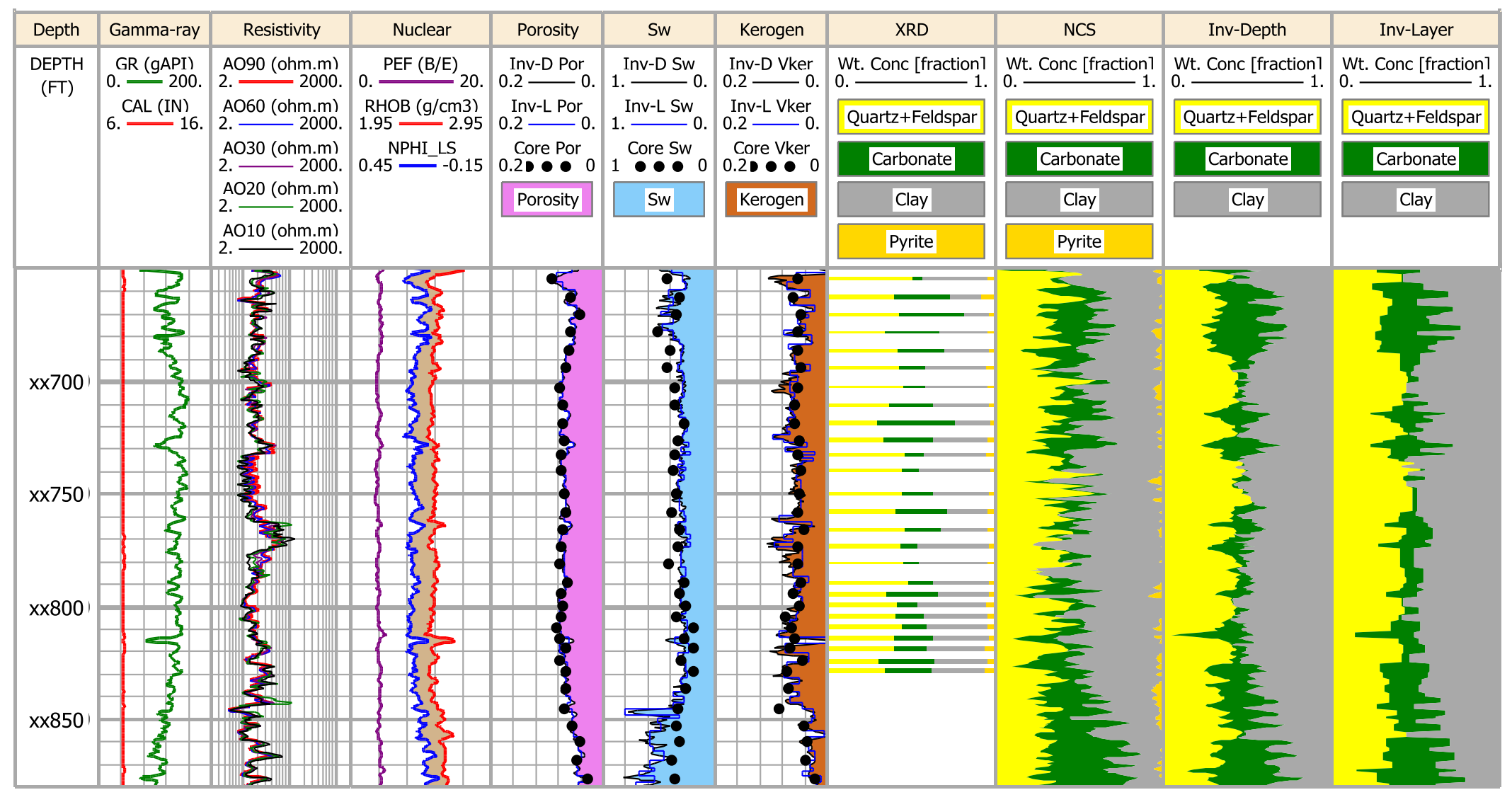

Figure 5.5: Case study in well H2. Track 1: Relative depth. Track 2: Gamma-ray and caliper logs. Track 3: Array-induction apparent resistivity logs. Track 4: PEF, bulk density, and neutron (limestone matrix) porosity logs. Track 5 Core and inverted porosity. Track 6: Core and inverted water saturation. Track 7: Core and inverted kerogen volumetric concentration. Track 8: XRD mineral compositions. Track 9: NCS log mineral compositions. Track 10: Mineral compositions obtained from depth-by-depth inversion. Track 11: Mineral compositions obtained from layer-by-layer inversions. 


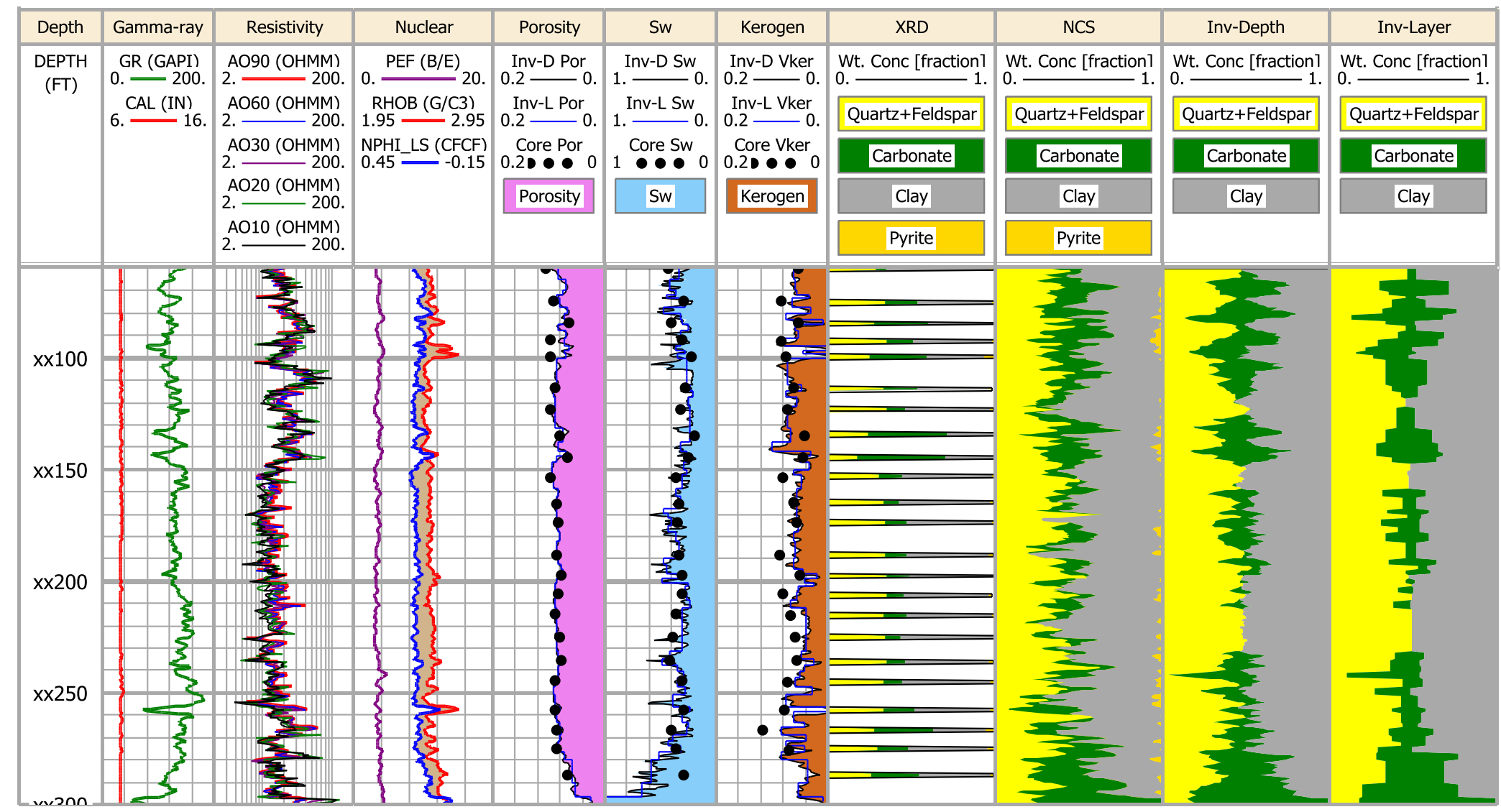

Figure 5.6: Case study in well H3. Track 1: Relative depth. Track 2: Gamma-ray and caliper logs. Track 3: Array-induction apparent resistivity logs. Track 4: PEF, bulk density, and neutron (limestone matrix) porosity logs. Track 5 Core and inverted porosity. Track 6: Core and inverted water saturation. Track 7: Core and inverted kerogen

volumetric concentration. Track 8: XRD mineral compositions. Track 9: NCS log mineral compositions. Track 10: Mineral compositions obtained from depth-by-depth inversion. Track 11: Mineral compositions obtained from layer-by-layer inversion. 


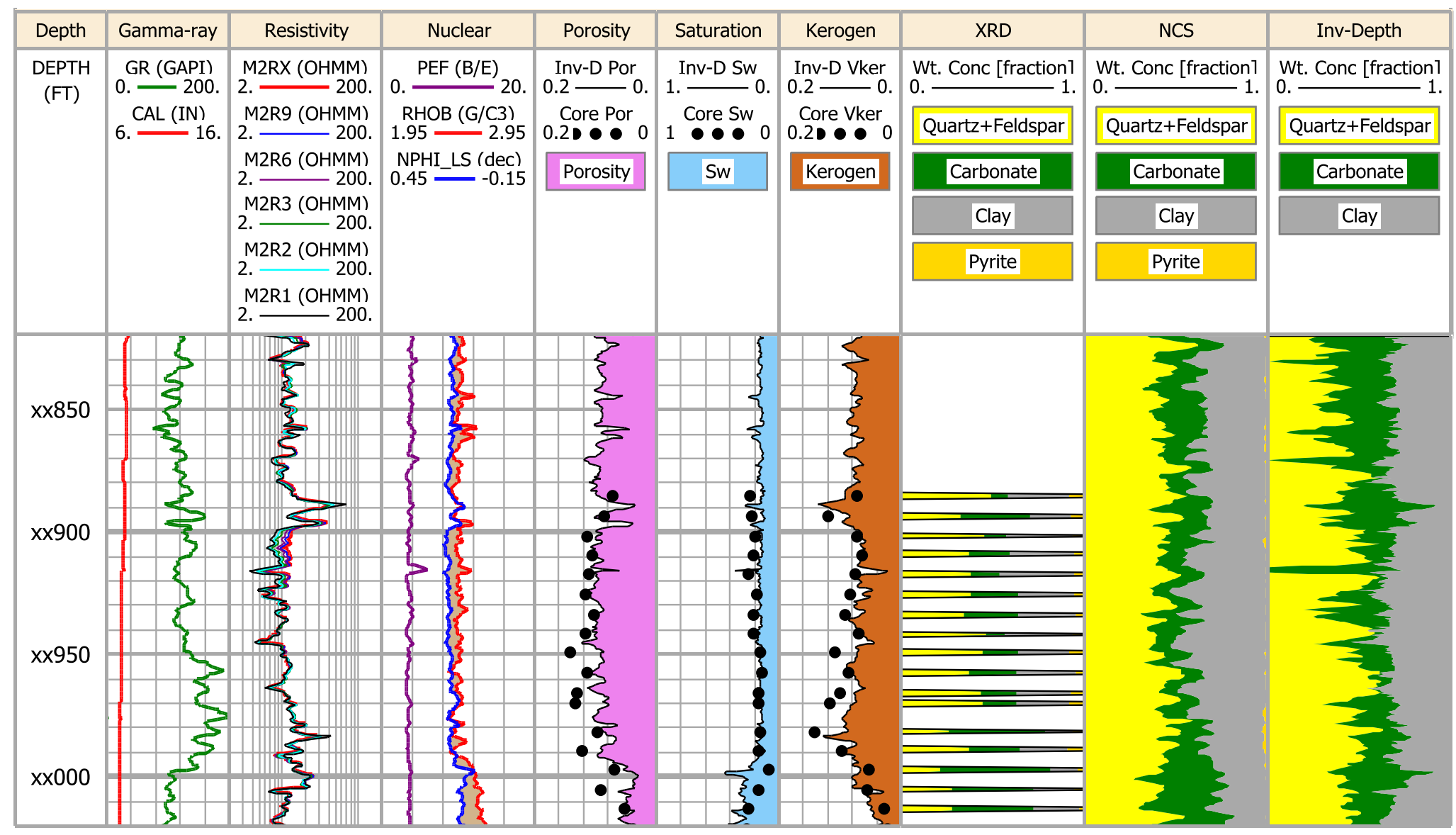

Figure 5.7: Case study in well H4. Track 1: Relative depth. Track 2: Gamma-ray and caliper logs. Track 3: Array-induction apparent resistivity logs. Track 4: PEF, bulk density, and neutron (limestone matrix) porosity logs. Track 5 Core and inverted porosity. Track 6: Core and inverted water saturation. Track 7: Core and inverted kerogen volumetric concentration. Track 8: XRD mineral compositions. Track 9: NCS log mineral compositions. Track 10: Mineral compositions obtained from depth-by-depth inversion. 


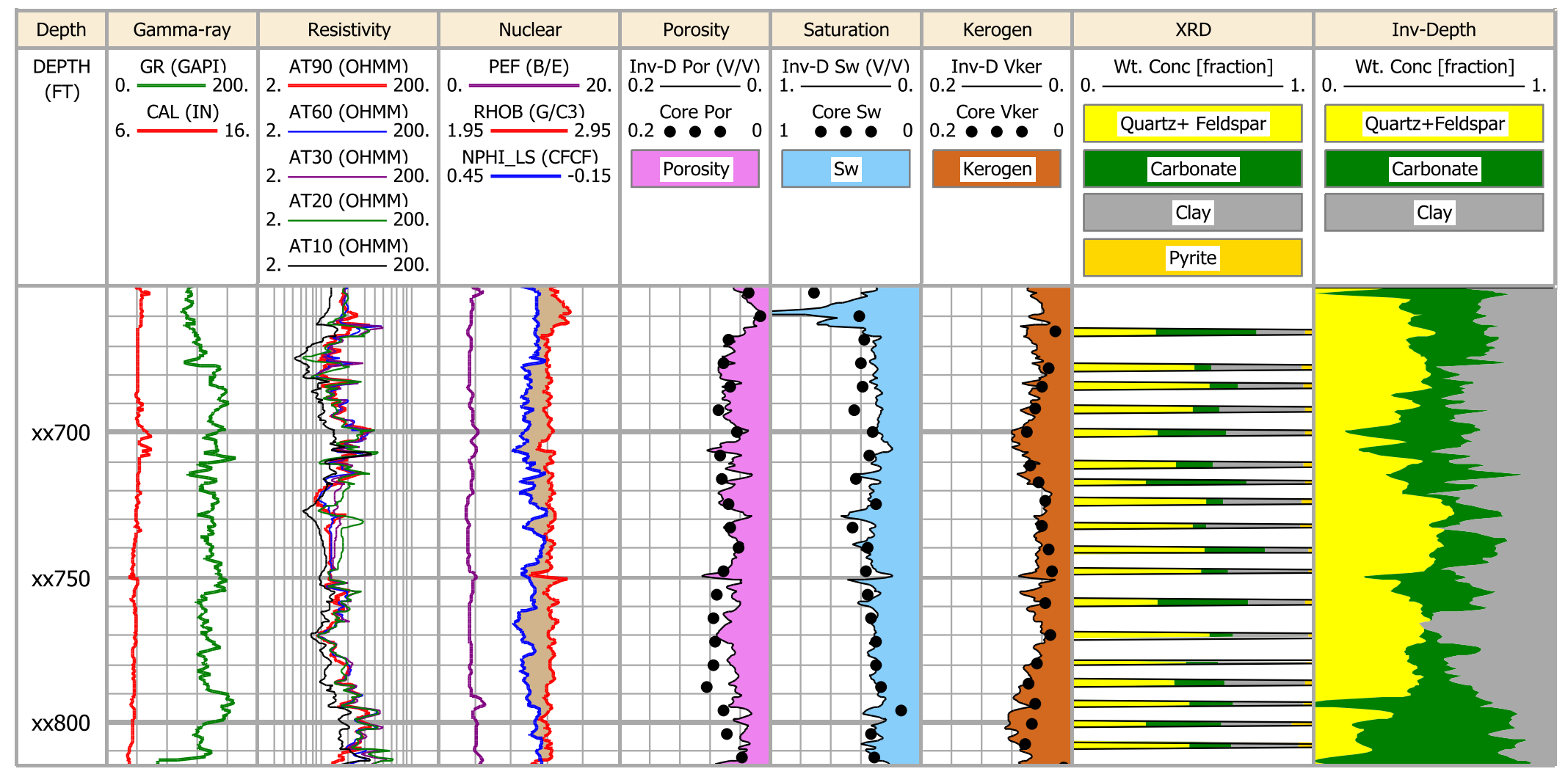

Figure 5.8: Case study in well H5. Track 1: Relative depth. Track 2: Gamma-ray and caliper logs. Track 3: Array-induction apparent resistivity logs. Track 4: PEF, bulk density, and neutron (limestone matrix) porosity logs. Track 5 Core and inverted porosity. Track 6: Core and inverted water saturation. Track 7: Core and inverted kerogen volumetric concentration. Track 8: XRD mineral compositions. Track 9: Mineral compositions obtained from depth-by-depth inversion. 


\section{Chapter 6: Barnett Shale Case Study}

This chapter describes case studies for the interpretation of data acquired in five wells within the Barnett shale formation. Barnett is one of the first shale gas fields

developed using horizontal drilling and hydraulic fracturing techniques. In addition to natural gas as its main production, certain areas produce natural gas liquid (NGL) in this formation. Barnett shale reservoir depth ranges widely from approximately $3,000 \mathrm{ft}$ to $9,000 \mathrm{ft}$.

\subsection{RESERVOIR BACKGROUND}

The Barnett shale is located in north-central Texas from the Texas-Oklahoma border extending south and covering an area of approximately 6,500 square miles (Figure 6.1) (Bruner and Smosna, 2011; U.S. Energy Information Administration, 2011). It is a Mississippian source rock that was a primary supplier of hydrocarbons to Paleozoic reservoirs in the Forth Worth basin area (Pollastro et al., 2007). On top of the Barnett shale is the Marble Falls formation consisting of limestone in its upper interval and interbedded limestone and shale in its lower interval (Montgomery et al., 2005). Underlying the Barnett shale is the Chappel limestone or Ellenburger dolomite/limestone group in the $\mathrm{S} / \mathrm{SW}$ section and the Viola/Simpson limestone group in the N/NE section (Figure 6.2) (Montgomery et al., 2005). The Viola/Simpson group is a fracture barrier while the Ellenburger formation is porous and water bearing, hence should be avoided in hydraulic fracturing operations. Around the N/NE section, the Barnett shale is separated into upper and lower Barnett by the Forestburg limestone, a tight impermeable formation that acts as a fracture barrier. Extending south and southwest, the Forestburg limestone disappears and the Barnett shale becomes one single unit. 


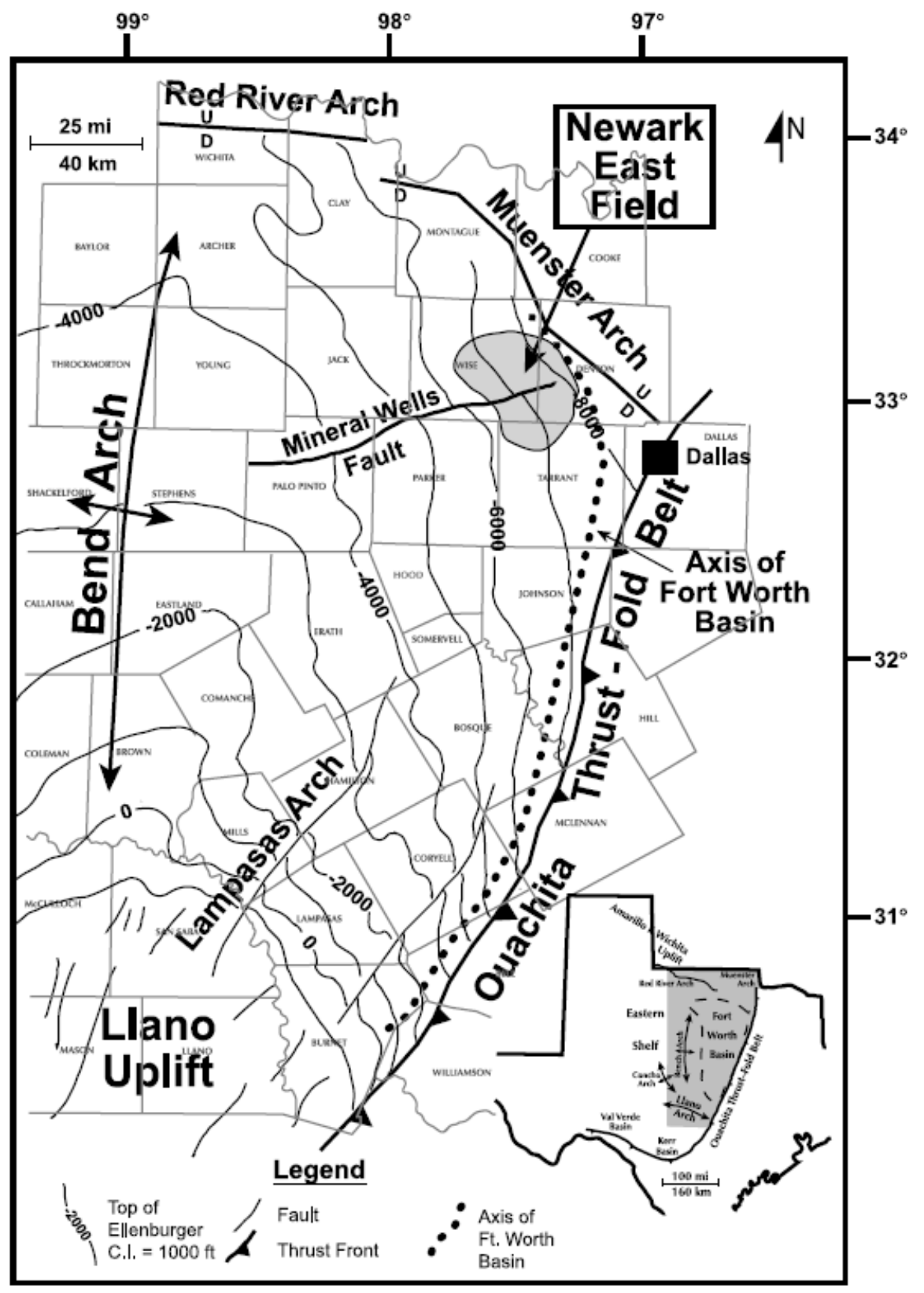

Figure 6.1: Map of the Barnett shale showing contour lines drawn from top of the Ellenburger formation. Newark East field, one of the main producing areas, is shaded in gray (Montgomery et al., 2005, (C) AAPG 2005, reprinted by permission of the AAPG, whose permission is required for further use). 


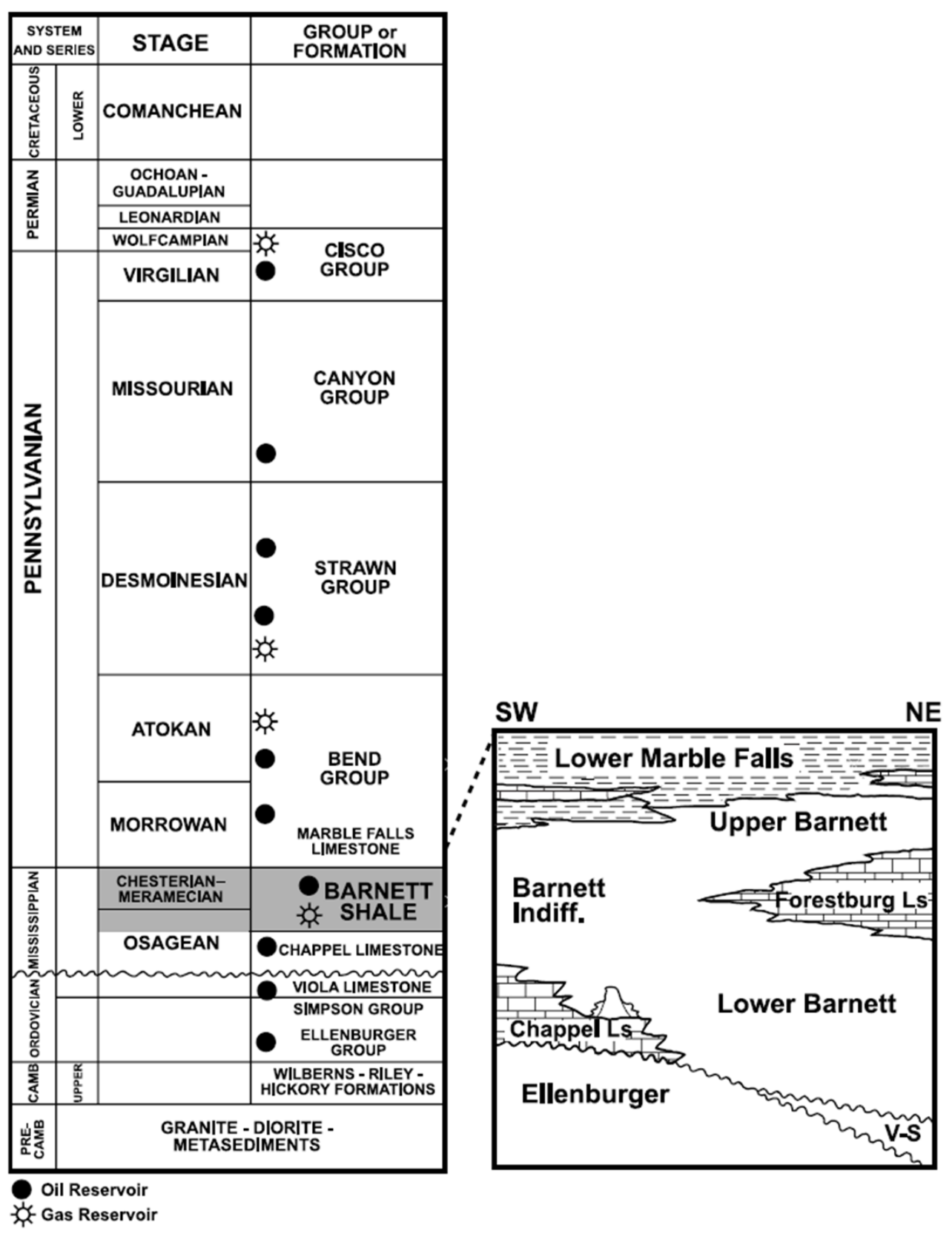

Figure 6.2: Stratigraphic column of the Fort Worth basin. The expanded section shows interpreted stratigraphic variations across the basin in the SW-NE orientation (Montgomery et al., 2005, (C) AAPG 2005, reprinted by permission of the AAPG, whose permission is required for further use). 
Our Barnett shale case studies consider 5 wells located in Denton and Hamilton counties. In well B5, the upper Barnett and lower Barnett shales are separated, while wells B1, B2, B3, and B4 exhibit a continuous Barnett shale unit. Loucks and Ruppel (2007) specified three lithofacies when describing this zone: (1) laminated siliceous mudstone, (2) laminated argillaceous lime mudstone, and (3) skeletal, argillaceous lime packstone.

\subsection{Mineral Model ANd Associated Parameters}

The Barnett shale is silica-rich mudrock with moderate amounts of carbonate and clay minerals. Clay mineral is composed of mainly illite, some mixed layer illite/smectite, and minor amounts of chlorite and kaolinite. The mineral distribution is well depicted with the ternary diagrams shown in Figure 6.3. Most points concentrate at the upper left of the triangle, at approximately 50\% quartz and feldspar concentrations, thereby suggesting that most depth intervals are silica-rich with small amounts of carbonates. This behavior agrees with Loucks and Ruppel's (2007) finding, who determined that siliceous mudstone is the predominant lithofacies. In the ternary diagram constructed for wells B1 through B4, there also exist several points near the Carbonate end-point which predominantly correspond to calcareous concretions. We noticed that some depth sections in the Barnett shale exhibit a large distribution of pyrite which is also evident in the electrical image logs. 


\begin{tabular}{lll}
\hline Solid Component & Chemical Formula & Density (g/cc) \\
\hline Quartz & $\mathrm{SiO}_{2}$ & 2.65 \\
Plagioclase Feldspar & $\mathrm{NaAlSi}_{3} \mathrm{O}_{8}$ & 2.61 \\
Potassium Feldspar & $\mathrm{KAlSi}_{3} \mathrm{O}_{8}$ & 2.57 \\
Calcite & $\mathrm{CaCO}_{3}$ & 2.71 \\
Dolomite & $\mathrm{CaMg}_{\left(\mathrm{CO}_{3}\right)_{2}}$ & 2.87 \\
Ankerite & $\mathrm{CaFe}_{0.6} \mathrm{Mg}_{0.3} \mathrm{Mn}_{0.1}\left(\mathrm{CO}_{3}\right)_{2}$ & 3.05 \\
Pyrite & $\mathrm{FeS}_{2}$ & 5.01 \\
Fluorapatite & $\mathrm{Ca}_{5}\left(\mathrm{PO}_{4}\right)_{3} \mathrm{~F}$ & 3.17 \\
Kerogen & $\mathrm{C}_{40} \mathrm{H}_{51} \mathrm{O}_{3} \mathrm{~S}_{2} \mathrm{~N}$ & 1.4 \\
Illite & $\mathrm{K}_{0.8} \mathrm{Al}_{1.6} \mathrm{Fe}_{0.2} \mathrm{Mg}_{0.2} \mathrm{Si}_{3.4} \mathrm{Al}_{0.6} \mathrm{O}_{10}(\mathrm{OH})_{2}$ & \\
Fe-Chlorite & $\mathrm{Fe}_{5} \mathrm{AlSi}_{3} \mathrm{AlO}_{10}(\mathrm{OH})_{8}$ & \\
\hline
\end{tabular}

\section{Clay Composition:}

70\% Illite and $30 \%$ Fe Chlorite

$\phi_{\text {clay }}=0.05$

$\rho_{\text {clay }}=3.3 \mathrm{~g} / \mathrm{cc}$

\section{Hydrocarbon Composition:}

$60 \% \mathrm{CH}_{4}, 23 \% \mathrm{C}_{2} \mathrm{H}_{6}, 17 \% \mathrm{C}_{3} \mathrm{H}_{8}$

$\rho_{H C}=0.179 \mathrm{~g} / \mathrm{cc}$

\section{Resistivity Parameters:}

$a=1, m=2, n=2$

$R_{w}=0.09$ Ohm-m

$R_{\text {clay }}=80 \mathrm{Ohm}-\mathrm{m}$

Table 6.1: Description of the mineral model for the Barnett shale. 
Well B5 exhibits greater variations in mineralogy than wells B1-B4. In the upper Barnett, shale layers are interbedded with carbonate layers and can be identified by a large deflection present in most well logs. An increase in carbonate concentration is also observed at depths near the Forestburg limestone. Table 6.1 summarizes the mineral compositions and chemical formulas used for the Barnett shale study; they are very similar to those used in the Haynesville shale study with the exception of clay. Clay composition was adjusted during calibration by reconstructing nuclear properties based on mineral compositions from XRD analysis and petrophysical properties from crushed rock core analysis.

\subsection{INVERSION RESULTS AND DISCUSSION}

Figures 6.4 to 6.9 show inversion results compared to GRI and XRD analysis and NCS logs. Good agreement between core measurements and NCS logs suggests that the mineral properties, in particular clay compositions, do not vary significantly between wells. High quality well logs allow the use of a uniform set of parameters in the five wells under consideration without having to normalize well logs across different wells.

Pyrite occurs in nearly all depth intervals throughout the Barnett shale formation; it appears in two forms on electrical resistivity images: (1) thin laminae and (2) patchy, dispersed distribution. The presence of pyrite is identified by well logs with high conductivity on the electrical resistivity image and increased PEF and bulk density. When thick enough, these pyritic laminae gives rise to very low apparent resistivity; they also correlate with high gamma-ray peaks, thereby suggesting high concentration of organic matter. Papazis (2005) performed a petrographic study of Barnett shale core samples and observed thin pyritic concretions with strong petroliferous odor. 
Shoulder-bed effects produced by thin pyritic laminae on apparent resistivity logs can cause errors in the estimation of porosity, water saturation, and kerogen concentration. Figure 6.4 shows the well B1 case study, where many of these laminae are present. Notice how spikes in apparent resistivity logs produce an anomalous increase in estimated porosity and water saturation that are inconsistent with core data. Moreover, estimated kerogen concentration decreases in order to compensate for the increase in estimated porosity. In the well B2 case study shown in Figure 6.5, these pyritic laminae are much thinner than in the case of well B1. Consequently, shoulder-bed effects on estimated porosity, water saturation, and kerogen concentration are marginal. To the author's knowledge, currently there are no water saturation models published in the open technical literature that correct for the effect of pyrite.

For inversion purposes, the high-resolution apparent resisitivity log is preferred to match the high resolution exhibited by other well logs such as PEF, bulk density, and neutron porosity. For example, the AO10 (10 inch radial length of investigation and $1 \mathrm{ft}$ vertical resolution) curve is the preferred apparent resistivity log for the Schlumberger Array-Induction Tool (AIT). However, large separation in apparent resistivity curves with different radial lengths of investigation is commonly observed in the Barnett shale. Examples of this behavior can be observed in Figures 6.4, 6.5, and 6.6. The degree of separation varies between wells and is larger when the resistivity is high. In the absence of mud-filtrate invasion, one plausible explanation for these apparent resistivity separations is the presence of vertical fractures; electrical resistivity images indicated that natural and drilling-induced fractures take place in the wellbore. Furthermore, we observe that the highest resolution apparent-resistivity curve usually reads the highest resistivity and often reaches 2,000 Ohm-m. We hypothesize that the highest resolution curve (i.e. 
AO10 curve for AIT) is on the upper limit of the tool's operating range and therefore unreliable.

The accuracy of core measurements based on crushed rocks has been questioned before (Passey et al., 2010; Sondergeld et al., 2010); variations in procedures implemented by different commercial laboratories have also been observed to yield inconsistent petrophysical properties. Because inversion results presented in this study are calibrated with core measurements, they are susceptible to errors associated with core measurements. In wells B1 and B2, for example, we observe significant differences in porosity and water saturation measured from core samples even though the wells were drilled in the same area. Core analyses for these wells were performed by two different commercial laboratories and we suspect that those core-measurement variations are caused by differences in core handling and measurement procedures. Even though a proper comparison study needs to be performed on the same core samples, we observe major differences in procedures and associated interpretations of core measurements that lead us to such a conclusion.

Figures 6.8 and 6.9 describe case studies in well B5, upper Barnett and lower Barnett shale sections. One interesting feature of this well is that shale layers are interbedded with carbonate mudrocks, thereby giving rise a large variation of mineral compositions from a mixed silica and clay layer to a pure carbonate layer. Only a small number of core measurements are available both in the upper and lower Barnett formations to compare estimated porosity, water saturation, and kerogen concentration. However, the long section of the Barnett shale formation provides vast amounts of data to compare estimated mineral compositions to NCS logs. An excellent match against NCS logs despite large variations in mineralogy in such long depth intervals confirms the accuracy and reliability of the inversion method. Comparisons of mineral distributions 
plotted in the ternary diagrams shown in Figure 6.3 provide additional confirmation of the reliability of the inversion method in the Barnett shale field examples. 

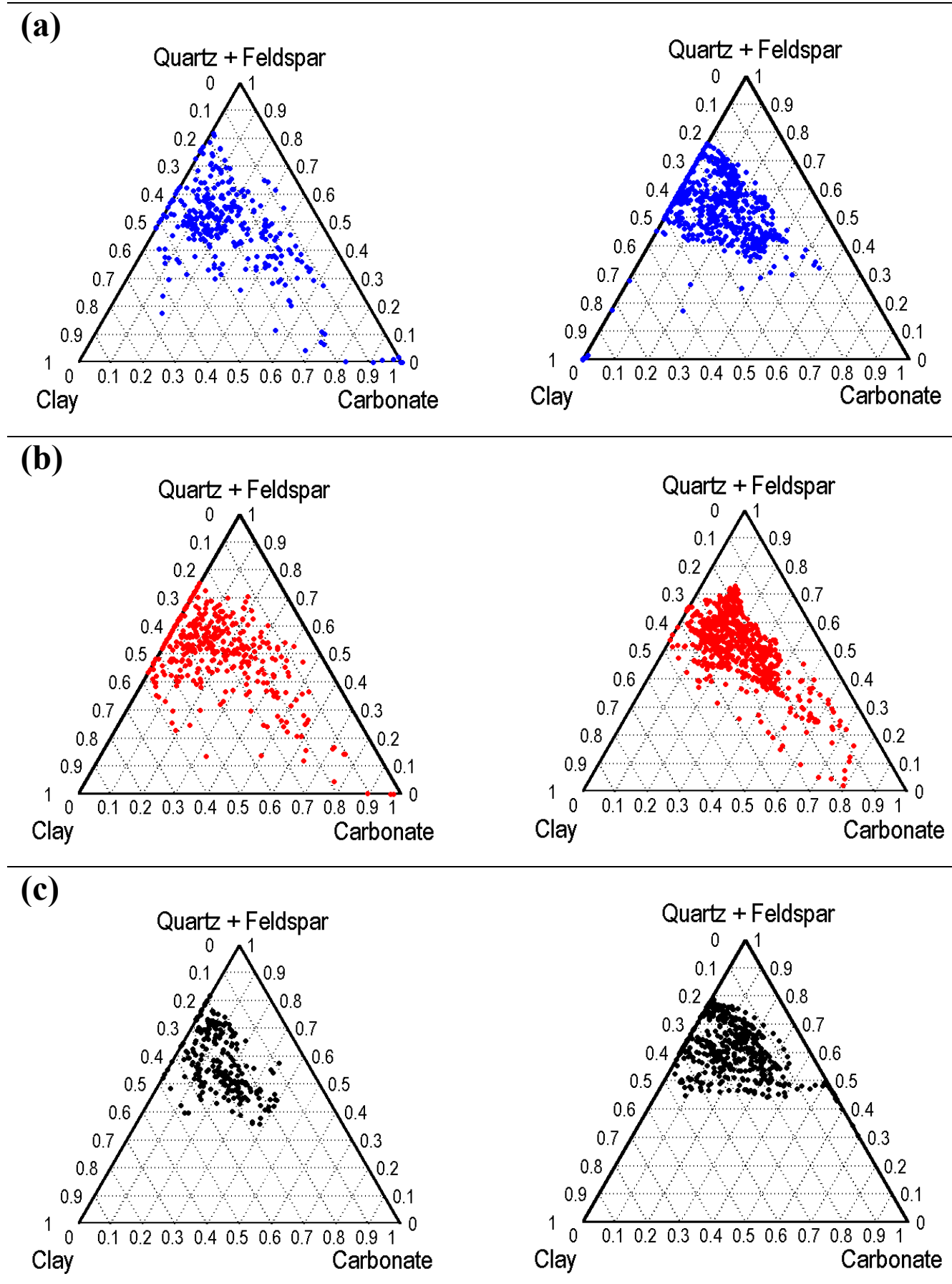
(d)
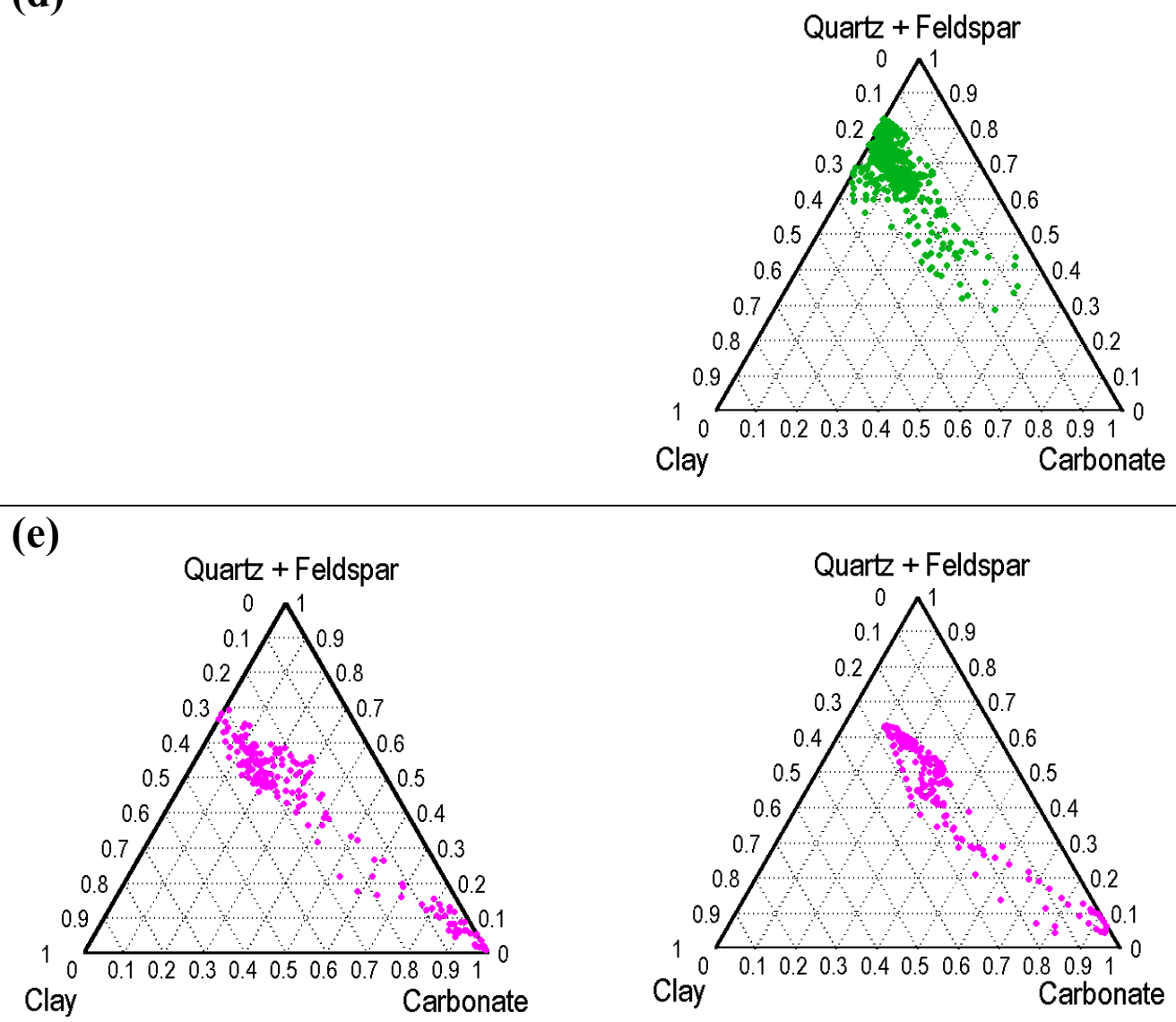

(f)
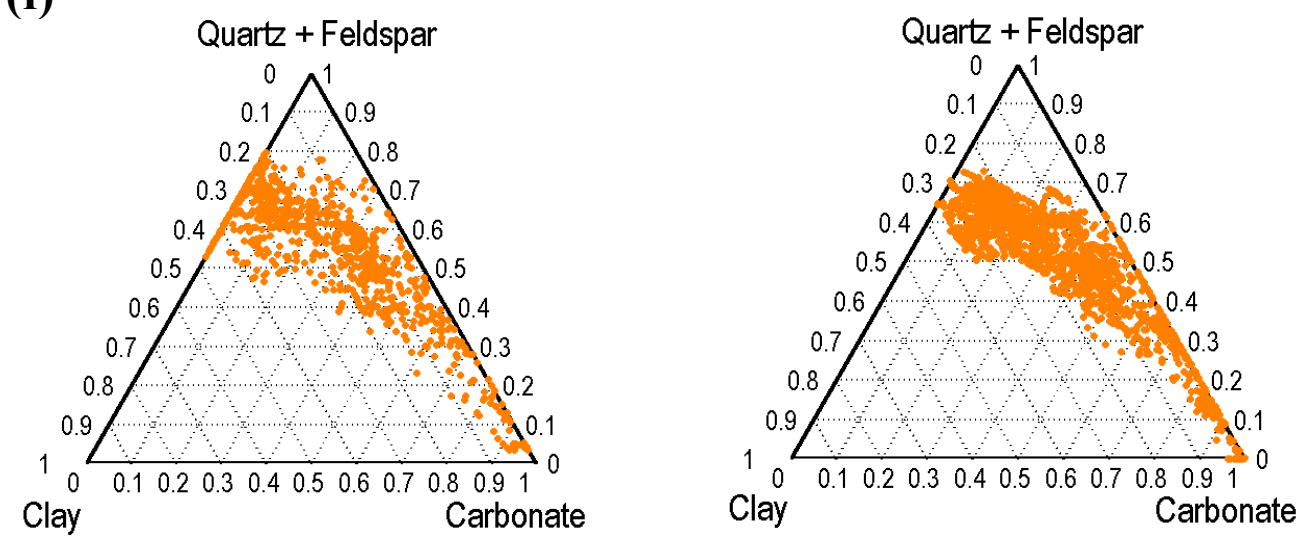

Figure 6.3: Ternary diagram showing the Barnett shale mineral distribution estimated from NCS log mineral weight concentrations (left), and mineral group weight concentrations obtained from inversion (right): (a) Well B1, (b) Well B2, (c) Well B3, (d) Well B4, (e) Well B5 upper Barnett section, and (e) Well B5 lower Barnett section. 


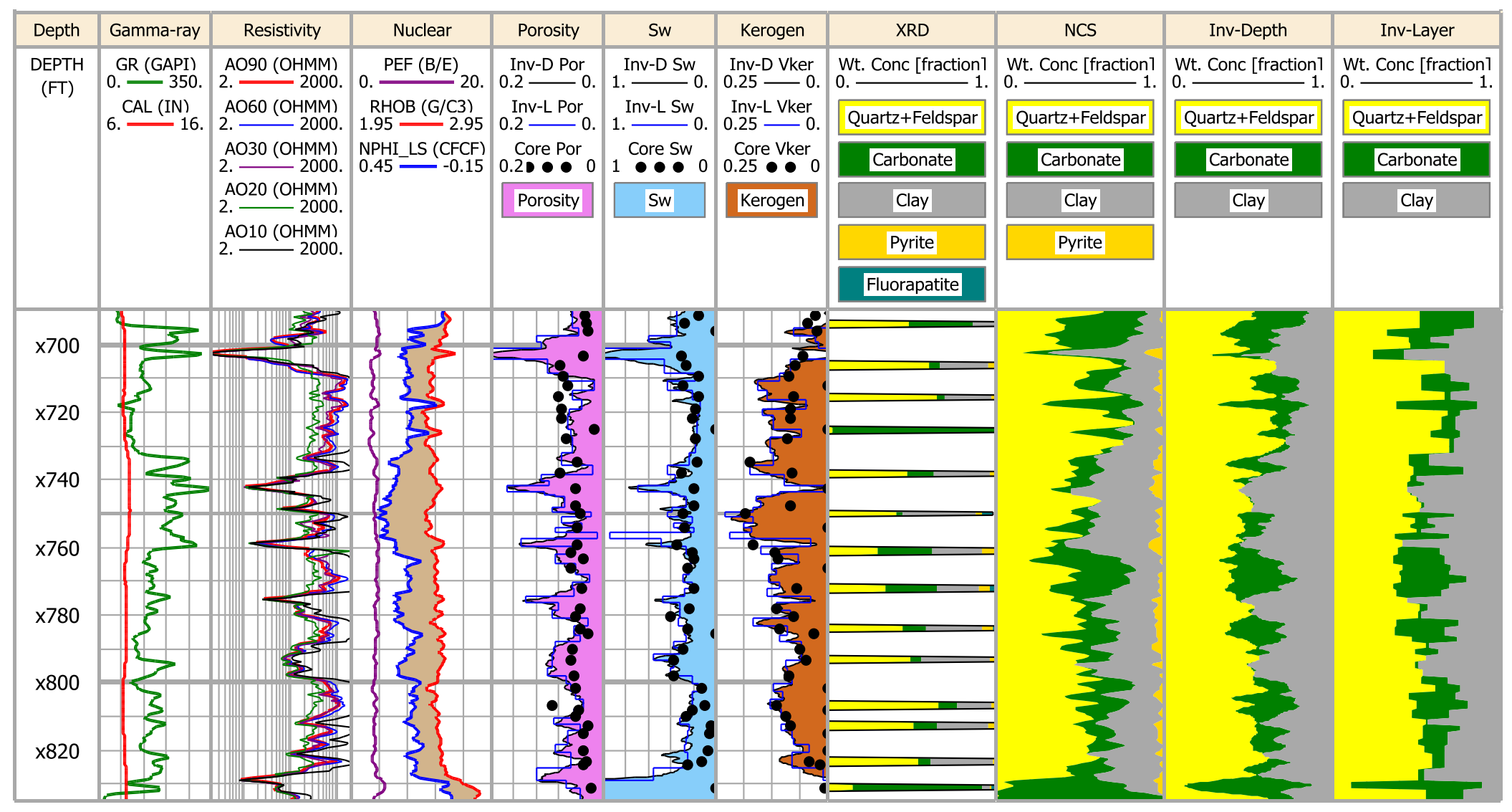

Figure 6.4: Case study in well B1. Track 1: Relative depth. Track 2: Gamma-ray and caliper logs. Track 3: Array-induction apparent resistivity logs. Track 4: PEF, bulk density, and neutron (limestone matrix) porosity logs. Track 5: Core and inverted porosity. Track 6: Core and inverted water saturation. Track 7: Core and inverted kerogen

volumetric concentration. Track 8: XRD mineral compositions. Track 9: NCS log mineral compositions. Track 10: Mineral compositions obtained from depth-by-depth inversion. Track 11: Mineral compositions obtained from layer-by-layer inversion. 


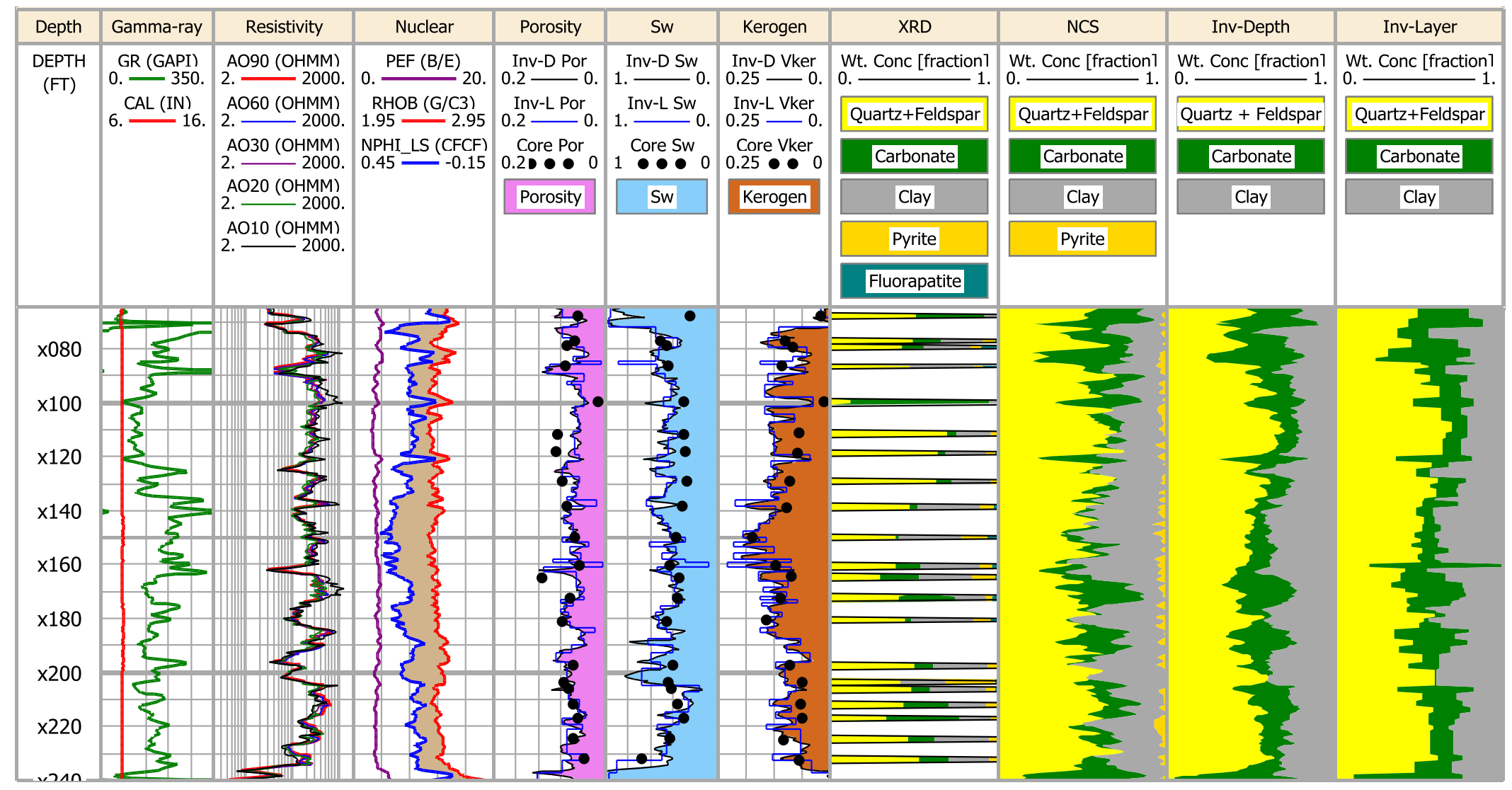

Figure 6.5: Case study in well B2. Track 1: Relative depth. Track 2: Gamma-ray and caliper logs. Track 3: Array-induction apparent resistivity logs. Track 4: PEF, bulk density, and neutron (limestone matrix) porosity logs. Track 5: Core and inverted porosity. Track 6: Core and inverted water saturation. Track 7: Core and inverted kerogen volumetric concentration. Track 8: XRD mineral compositions. Track 9: NCS log mineral compositions. Track 10: Mineral compositions obtained from depth-by-depth inversion. Track 11: Mineral compositions obtained from layer-by-layer inversion. 


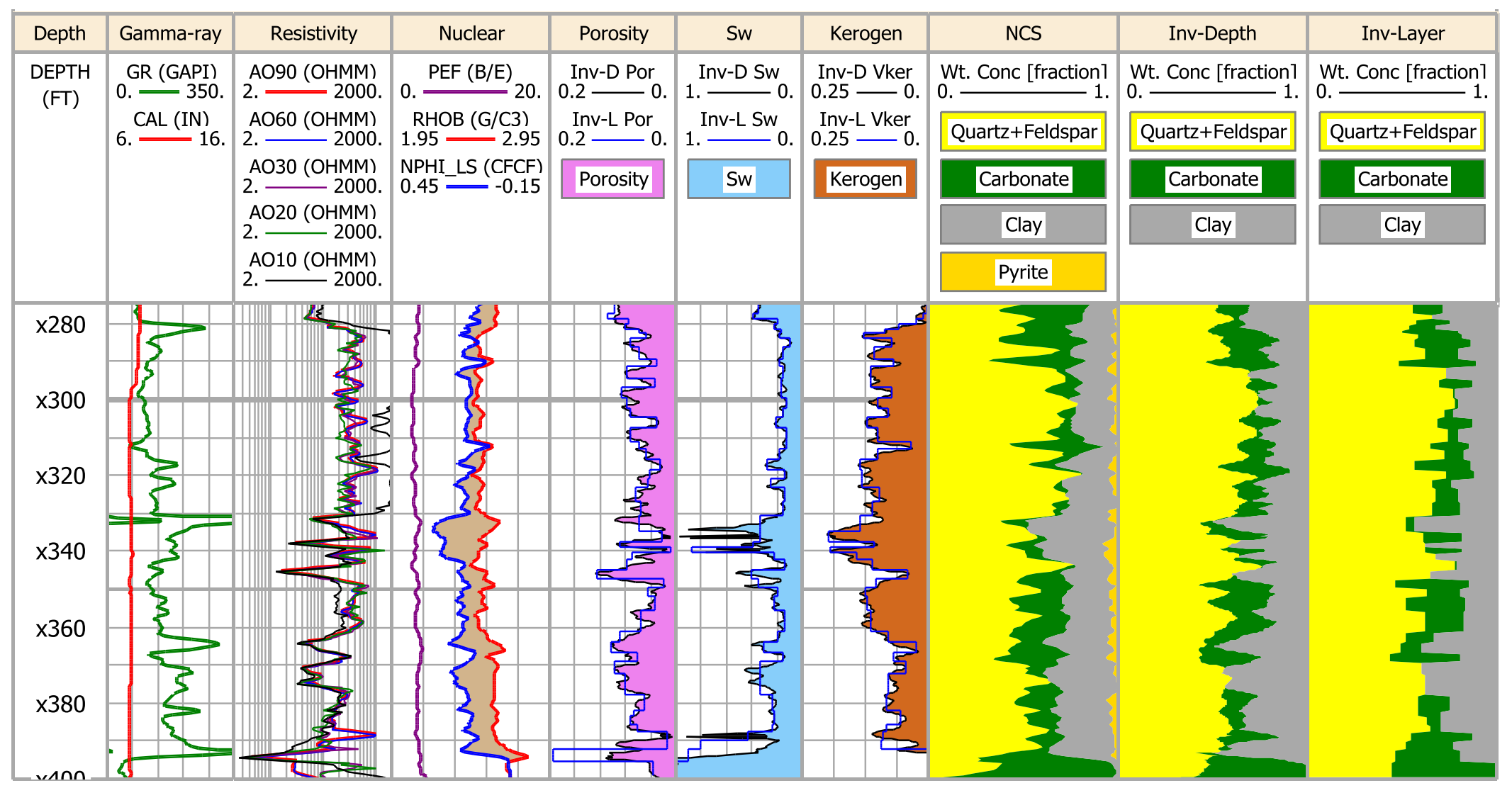

Figure 6.6: Case study in well B3. Track 1: Relative depth. Track 2: Gamma-ray and caliper logs. Track 3: Array-induction apparent resistivity logs. Track 4: PEF, bulk density, and neutron (limestone matrix) porosity logs. Track 5: Inverted porosity. Track 6: Inverted water saturation. Track 7: Inverted kerogen volumetric concentration. Track 8: NCS log mineral compositions. Track 9: Mineral compositions obtained from depth-by-depth inversion. Track 10: Mineral compositions obtained from layer-by-layer inversion. 


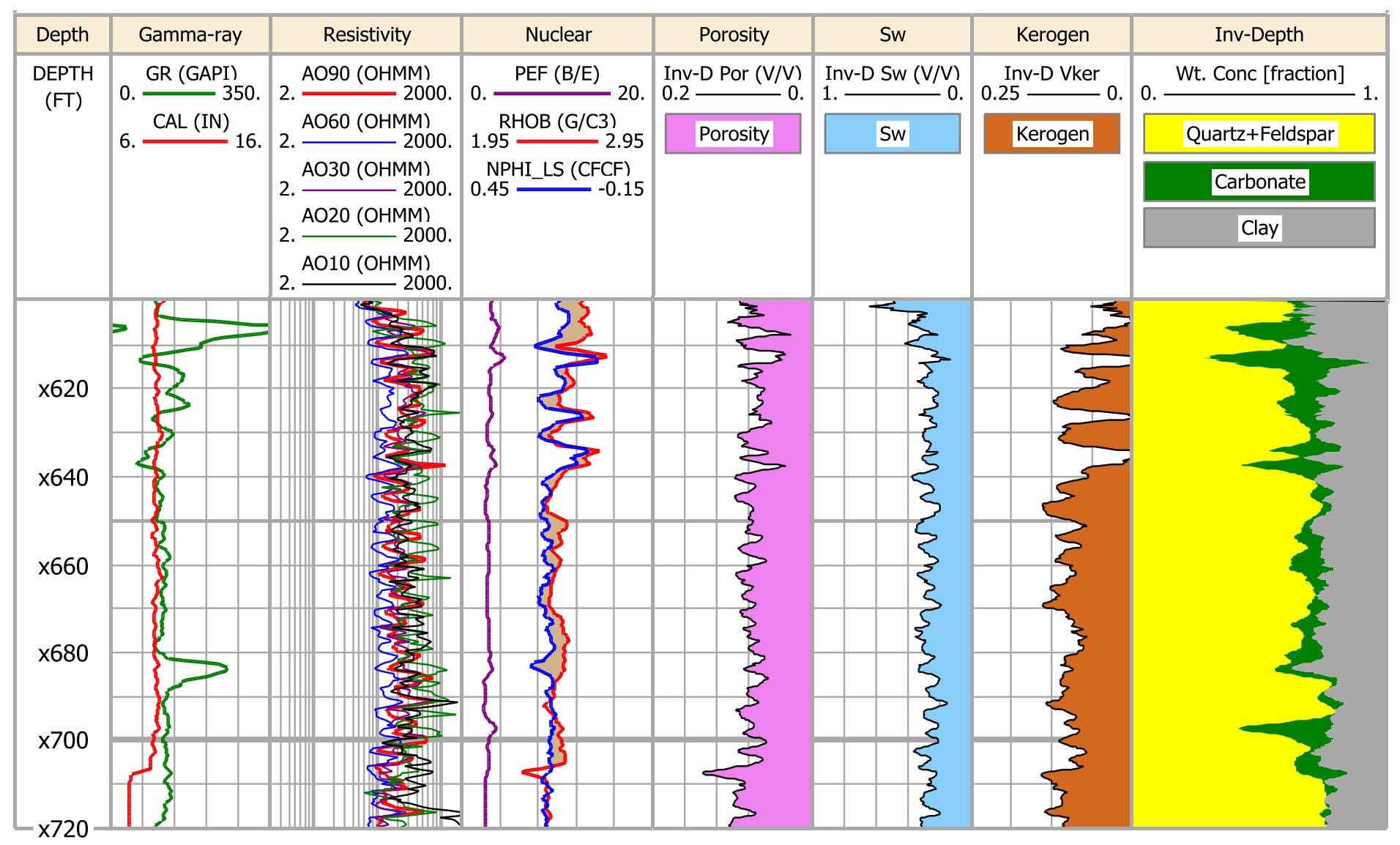

Figure 6.7: Case study in well B4. Track 1: Relative depth. Track 2: Gamma-ray and caliper logs. Track 3: Array-induction apparent resistivity logs. Track 4: PEF, bulk density, and neutron (limestone matrix) porosity logs. Track 5:

Inverted porosity. Track 6: Inverted water saturation. Track 7: Inverted kerogen volumetric concentration. Track 8: Mineral compositions obtained from depth-by-depth inversion. 


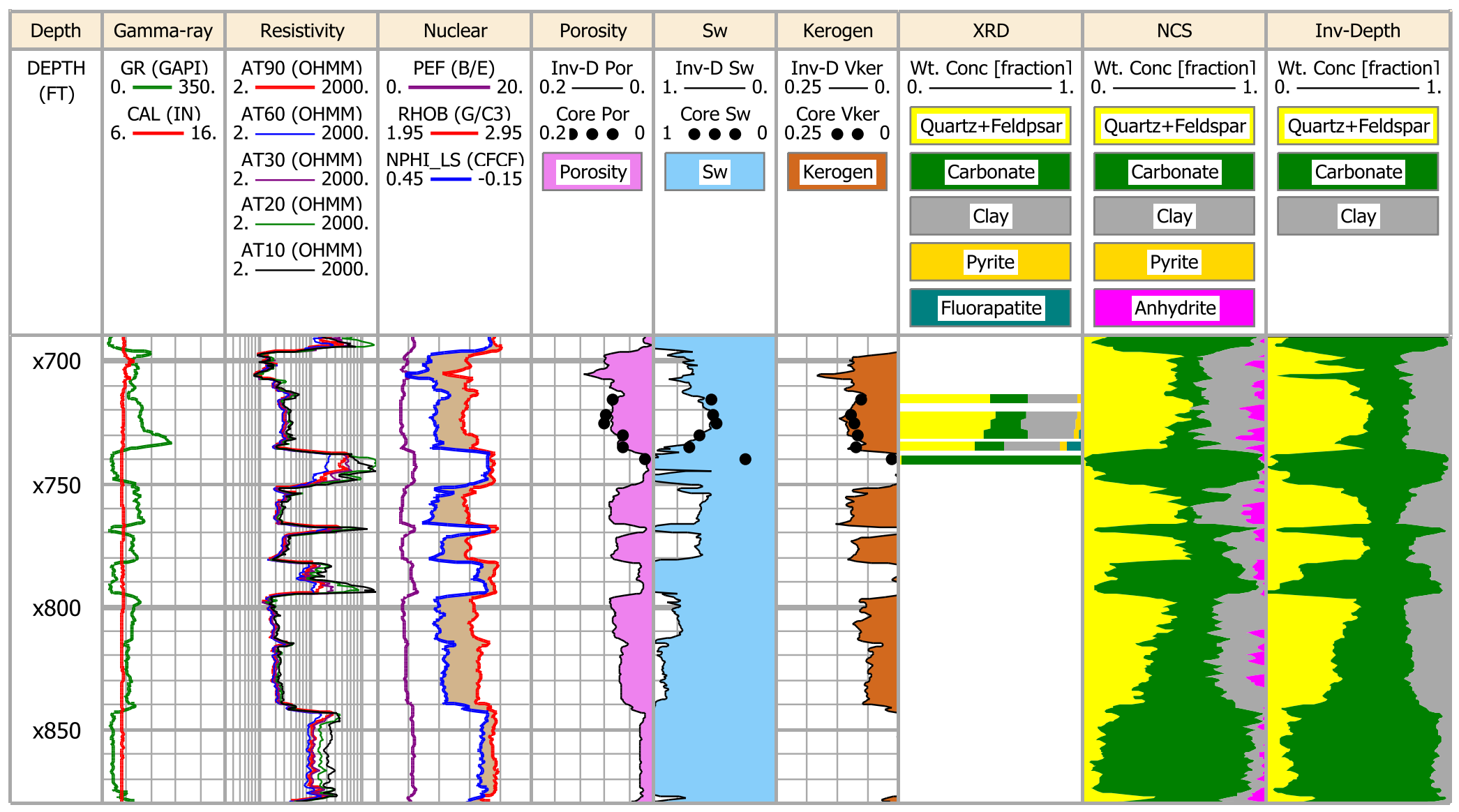

Figure 6.8: Case study in well B5, upper Barnett section. Track 1: Relative depth. Track 2: Gamma-ray and caliper logs. Track 3: Array-induction apparent resistivity logs. Track 4: PEF, bulk density, and neutron (limestone matrix) porosity logs. Track 5: Core and inverted porosity. Track 6: Core and inverted water saturation. Track 7: Core and inverted kerogen volumetric concentration. Track 8: XRD mineral compositions. Track 9: NCS log mineral compositions. Track 10: Mineral compositions obtained from depth-by-depth inversion. 


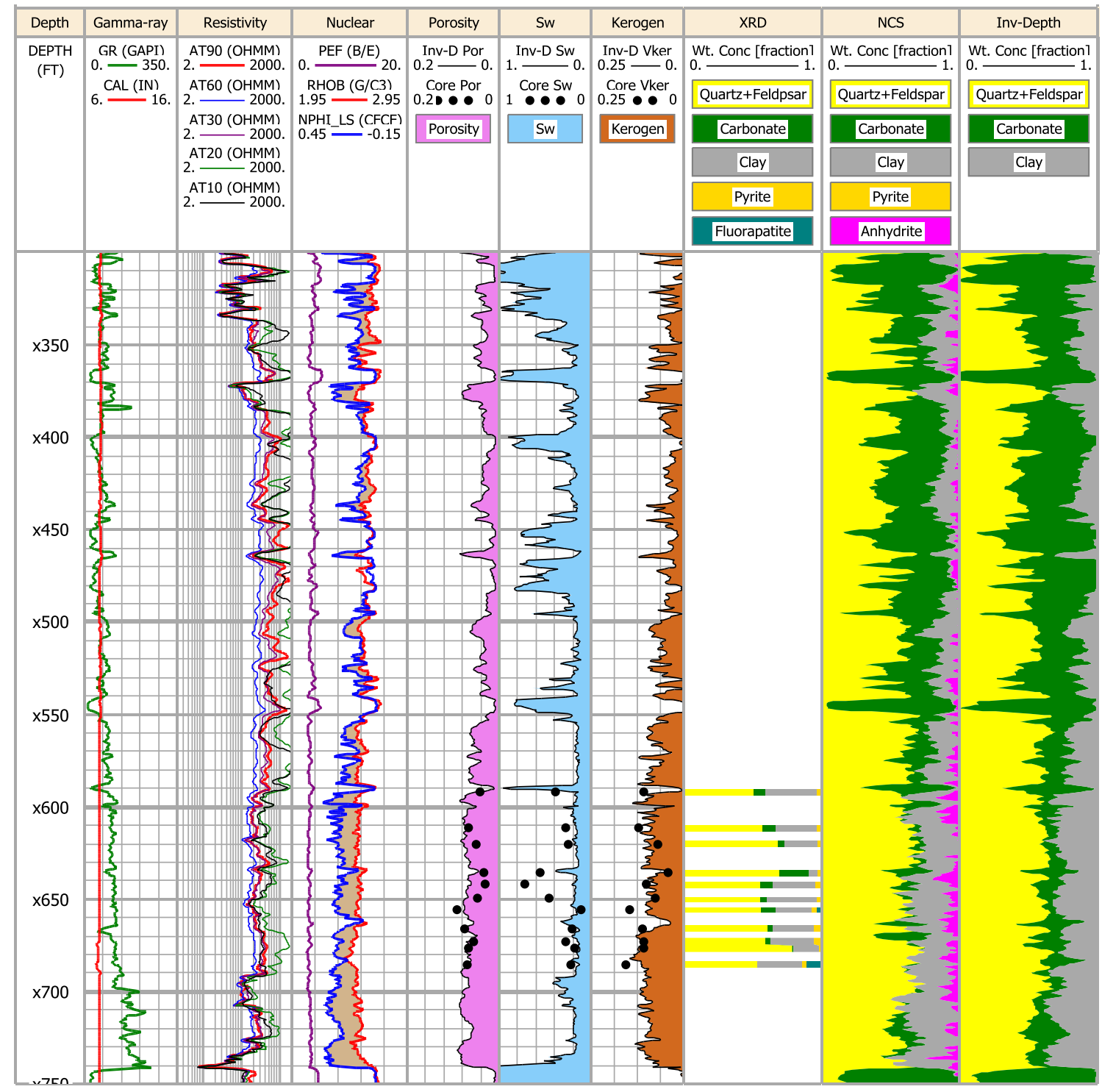

Figure 6.9: Case study in well B5, lower Barnett section. Track 1: Relative depth. Track 2: Gamma-ray and caliper logs. Track 3: Array-induction apparent resistivity logs. Track 4: PEF, bulk density, and neutron (limestone matrix) porosity logs. Track 5: Core and inverted porosity. Track 6: Core and inverted water saturation. Track 7: Core and inverted kerogen volumetric concentration. Track 8: XRD mineral compositions. Track 9: NCS log mineral compositions. Track 10: Mineral compositions obtained from depthby-depth inversion. 


\section{Chapter 7: Summary and Conclusions}

This chapter summarizes the recommended best practices to estimate mineral and fluid concentrations from conventional well logs. It also reports the main conclusions stemming from the thesis and discusses possible applications and future research directions.

\subsection{ReCommended Best Practices}

Figure 7.1 summarizes our recommended best practices for interpretation. This interpretation workflow enables a selection of a mineral model and related petrophysical parameters based on core measurements that can be used to reliably estimate mineral and fluid concentrations from conventional well logs. Prior to the analysis of mineralogy from XRD analysis, a few standard procedures are required to obtain a petrophysically consistent mineral model. First, core-log depth matching should be performed accurately using gamma-ray logs measured from core samples. Identification of formation tops is required to separate core data of formations of interest from those of other geological formations. In addition, a sufficient number of samples is necessary to represent mineralogy variations with depth within the organic-rich shale formation.

Based on XRD data, minerals are organized into two groups: main minerals and accessory minerals. In our Barnett and Haynesville case studies, main minerals and kerogen constituted an average of approximately $90 \%$ of the solid rock composition. Remaining minerals were referred to as accessory minerals. Density and chemical formulas of the most common minerals such as quartz, calcite, and dolomite are well defined and available in mineral data sheets such as those of the Schlumberger Interpretation Chart (Schlumberger, 2009). On the other hand, density values and 
chemical formulas for clay minerals and kerogen vary considerably. These properties are adjusted during mineral calibration.

We introduced a mineral grouping approach intended to reduce the number of unknowns in the estimation without loss of accuracy in the representation of main minerals. The main minerals determine the number of groups required to adequately represent mineral variations. Accessory minerals, with smaller concentrations, are lumped with the main mineral that exhibits similar properties or depositional environment. For example: silica-based minerals can be lumped with quartz. Equivalent mineral group density is obtained by computing bulk density and grain density and comparing them to measured values obtained from GRI analysis.

The chemical formula for each mineral is selected and calibrated with well logs by reconstructing nuclear properties (PEF, bulk density, and neutron porosity) from core measurements using SNUPAR. Clay properties have significant effects on nuclear properties and are treated as adjustable parameters in the mineral model. Good initial values for $V_{\text {clay }}, \phi_{t}$, and $V_{\text {kerogen }}$ are essential for the inversion to converge to the correct answer. Well-log based empirical equations can provide good initial values in most cases. Many resistivity models provide good estimations of $S_{w t}$ by adjusting parameters such as water resistivity $R_{w}$ and clay resistivity $R_{\text {clay }}$; these parameters are used in the inversion.

After the mineral model is built and its associated petrophysical properties are determined, a nonlinear inversion algorithm is employed to determine the mineral and fluid concentrations. Several iterations for fine-tuning the mineral model are usually required before reaching the final results. After a good match is obtained, a rock classification technique based on inverted properties (as discussed by Popielski, 2011), can be performed to determine favorable production intervals. 


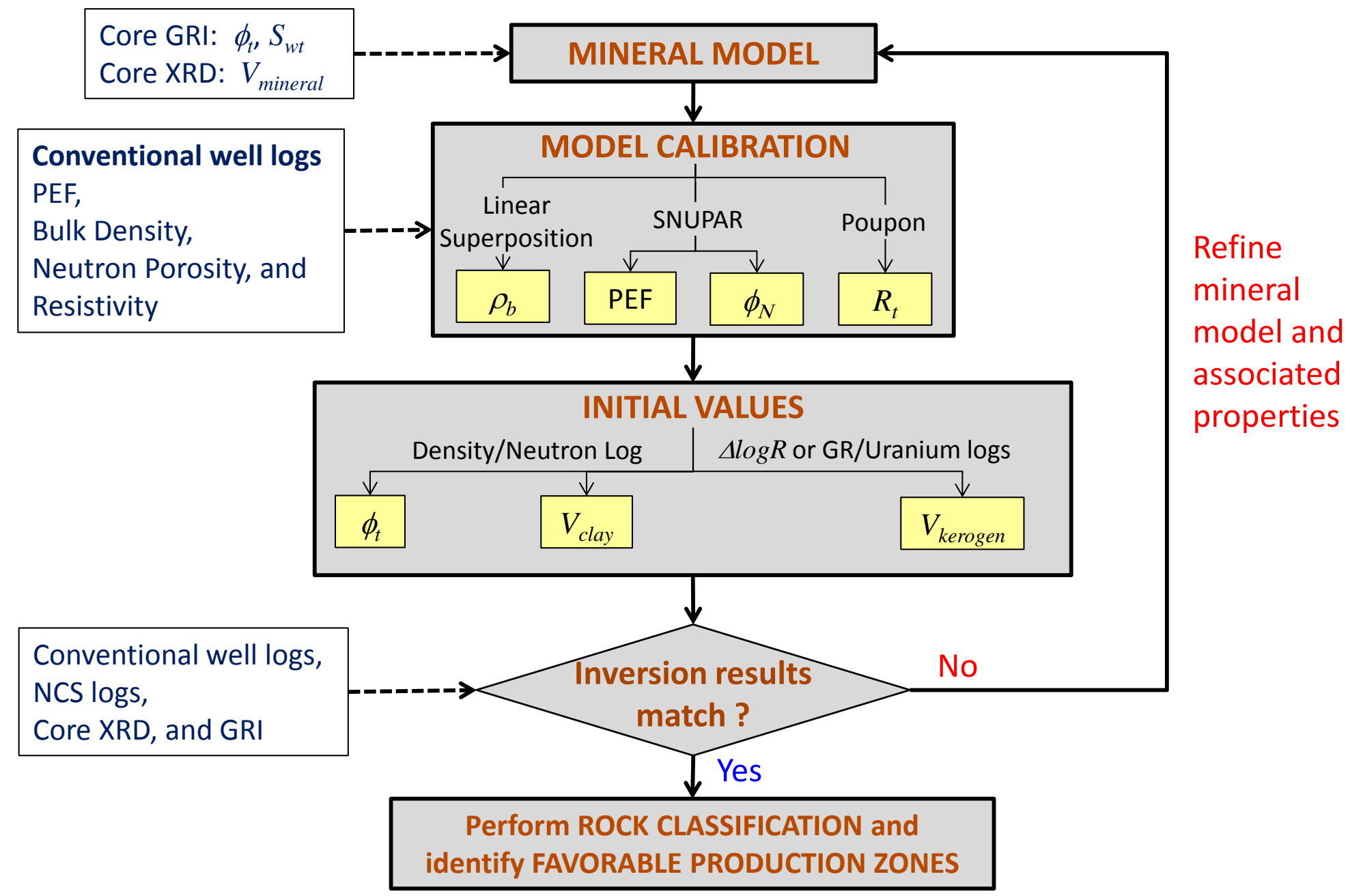

Figure 7.1: Flow chart describing our recommended best practices for interpretation of conventional well logs acquired in organic shale 


\subsection{CONCLUSIONS}

The following itemized list summarizes the most important conclusions stemming from this thesis:

(1) Nonlinear inversion combining several conventional well logs reliably estimates porosity, water saturation, kerogen concentration, and mineral composition in hydrocarbon-bearing shale. The proposed interpretation workflow takes into consideration petrophysical and mineral models selected to honor core data and available well logs. Several field examples confirmed the accuracy and reliability of the interpretation workflow.

(2) A mineral model constructed by grouping minerals enables a reduction in the number of unknowns, yet accurately describes the impact on well logs of main minerals included in organic shale formations. Several major assumptions are made in the construction of the mineral model: (1) properties of feldspars are similar to those of quartz, (2) ankerite and dolomite only occur in small volumetric concentrations, and (3) pyrite and fluorapatite are evenly distributed in the formation and their volumetric concentrations correlate linearly with the volumetric concentration of clay minerals. These assumptions have proven to be valid in the Haynesville and Barnett shales; they need to be re-assessed for their application in other organic shale formations.

(3) Synthetic case studies show that the layer-by-layer inversion reduces shoulderbed effects on well logs and improves vertical resolution over the depth-by-depth inversion. The sampling interval is determined to be a limiting factor for the minimum bed thickness that inversion can resolve. Adapting the Nyquist theorem on a typical $0.5 \mathrm{ft}$ sampling interval for logging tools, the thinnest bed that can be resolved is approximately $1 \mathrm{ft}$. 
(4) In most field examples considered in this thesis, inversion was performed in slightly under-determined conditions. Good initial values, particularly for porosity, kerogen concentration, and clay mineral volumetric concentration are important to secure convergence of inversion to the correct answer. Initial values can be calculated using empirical relationships constructed with core data and NCS logs. Commercial multi-mineral solvers usually require an even or overdetermined system of equations to produce reliable results. They commonly do not use initial values, but instead implement confidence/weighting factors as adjustable parameters.

(5) The number of minerals that can be resolved with inversion is limited by the number of available well logs. In the field examples considered in this thesis, the volumetric concentration of three groups of mineral, equivalent to the QFM, Carbonate, and Clay mineral groups obtained from NCS logs, were reliably estimated from conventional well logs. Additional inputs to the inversion are required if more minerals are added to the interpretation; they can be in the form of well logs, empirical correlations between mineral concentrations, or constraint equations.

(6) Inversions performed on field examples assumed uniform kerogen and clay properties throughout the interpreted depth intervals. It is possible that these properties vary within the formation. In such cases, rock classification is required prior to inversion to define class-dependent mineral models and their associated parameters.

(7) Excellent well-log quality is essential to obtain accurate and reliable results. In a Haynesville shale field example, the effect of barite on PEF logs proved detrimental to inverted mineral composition. A normalization of PEF logs from 
several nearby wells improved inversion results even though it did not fully restore the accuracy expected when inverting noise-free data.

(8) The relationship between electrical resistivity, porosity, water saturation, and clay volumetric concentration in organic shale is poorly understood. Several water saturation models such as Archie, Dual Water, Indonesia, Modified Simandoux, and Poupon were studied in this thesis and provided accurate predictions of water saturation $\left(S_{w t}\right)$ when associated parameters such as $R_{w}$ and $R_{\text {clay }}$ were adjusted to honor available measurements. It is possible, however, that some of the selected parameters to honor the measurements become unrealistic (e.g. excessively low values of $R_{w}$ ) because the physical model is inadequate.

(9) The highest-resolution apparent resistivity log is preferred to match the resolution of other well logs included in the inversion. However, in highly resistive formation such as those encountered in the Barnett shale, the measured resistivity appears to be at the upper limit of the tool's operating range and, therefore, can be unreliable.

(10) In Barnett field examples, pyrite appears in two forms: (1) thin laminae, and (2) patchy, dispersed distribution. When thick enough, thin conductive pyritic laminae give rise to large shoulder-bed effects on apparent resistivity logs that affect the estimation of porosity, water saturation, and kerogen concentration. The severity of these shoulder-bed effects is a function of laminae thickness and varies from well to well.

(11) Differences between apparent resistivity logs with multiple radial lengths of investigation were observed in all Barnett shale field examples. The degree of separation varies between wells and is larger across beds which exhibit the highest resistivity. The cause of these separations remains unclear; however, 84 
many natural and drilling-induced fractures observed on electrical resistivity images in nearly all depths intervals indicated that vertical fractures could be the cause of those differences.

\subsection{APPLiCATIONS ANd SUGgESTIONS FOR FUTURE RESEARCH}

The main application of this thesis is to develop a consistent and reliable method for petrophysical interpretation and mineralogy estimation in shale-gas formations where only conventional well logs are available. Possible applications of accurate mineralogy estimation enabled by this method include advanced petrophysical studies such as rock classification, fracturability prediction, and improved permeability estimation. 


\section{Appendix A: TOC Estimation}

The purpose of this appendix is to compare various methods to estimate TOC examined in the thesis. An initial value for TOC was determined to be fundamental for obtaining accurate and reliable inversion results.

We compare TOC estimation results with gamma-ray logs, uranium logs, and $\Delta \log R$ methods. Figure A.1 shows cross-plots of gamma-ray and uranium logs against TOC. Figures A.2 through A.11 display the estimation of $T O C$ in all of our field examples and compare them to measured TOC in core samples. The inversion takes into account variations of mineralogy when reconstructing the bulk density log; therefore, we do not include an empirical estimation from the bulk density log to estimate TOC.

TOC estimation from gamma-ray and uranium logs is obtained by linear regression because we did not observe improvement in the prediction when using other types of regression. This linear correlation is correct only when kerogen is laminated (see Figure A.1). Empirical estimation using the gamma-ray log assumes that the contribution from clay is negligible and is calculated using the relationship

$$
T O C_{G R}=\frac{G R-G R_{0}}{G R_{100}-G R_{0}},
$$

where $T O C_{G R}$ is the total organic-carbon content estimated with the gamma-ray log, $G R_{100}$ is the hypothetical gamma-ray reading in $100 \% T O C$, and $G R_{0}$ is the gamma-ray reading in $0 \% T O C$ (wet-shale); $G R_{0}$ and $G R_{100}$ are calibrated using core measurements. Similarly, an empirical correlation based on the uranium log can be implemented with the equation 


$$
\operatorname{TOC}_{U}=\frac{U-U_{0}}{U_{100}-U_{0}}
$$

where $T O C_{U}$ is $T O C$ estimated from the uranium $\log , U_{100}$ is the hypothetical uranium reading in $100 \% T O C$, and $U_{0}$ is the uranium reading in $0 \%$ TOC (wet shale).

Passey's $\Delta \log R$ method (Passey et al., 1990) is the most widely used empirical formula for estimation of TOC. It overlays resistivity and porosity logs (calculated with either compressional slowness, bulk density, or neutron porosity logs) in a non-organic rich shale (baseline). The degree of separation between resistivity and porosity logs in organic-rich shale $(\Delta \log R)$ can be calculated with the formula

$$
\Delta \log R_{\text {sonic }}=\log _{10}\left(\frac{R}{R_{\text {baseline }}}\right)+0.02\left(\Delta t-\Delta t_{\text {baseline }}\right) \text {, }
$$

where $\Delta \log R_{\text {sonic }}$ quantifies the degree of separation between resistivity and sonic logs, $R$ is apparent resistivity, $R_{\text {baseline }}$ is the baseline resistivity, $\Delta t$ is compressional slowness, and $\Delta t_{\text {baseline }}$ is the baseline compressional slowness. Similarly, $\Delta \log R$ can be calculated using bulk density or neutron porosity logs with the formulas

$$
\Delta \log R_{\text {density }}=\log _{10}\left(\frac{R}{R_{\text {baseline }}}\right)-2.5\left(\rho_{b}-\rho_{\text {baseline }}\right),
$$

and

$$
\Delta \log R_{\text {neutron }}=\log _{10}\left(\frac{R}{R_{\text {baseline }}}\right)+4.0\left(\phi_{N}-\phi_{N, \text { baseline }}\right),
$$

respectively, 
where $\Delta \log R_{\text {density }}$ quantifies the degree of separation between resistivity and bulk density $\operatorname{logs}, \Delta \log R_{\text {neutron }}$ quantifies the degree of separation between resistivity and neutron porosity logs, $\rho_{b}$ is bulk density, $\rho_{\text {baseline }}$ is the baseline bulk density, $\phi_{N}$ is neutron porosity, and $\phi_{N, \text { baseline }}$ is the baseline neutron porosity.

The $\Delta \log R$ method requires calibration with maturity of organic matter. For that purpose, it uses the Level of Organic Metamorphism ( $L O M)$ which can be determined by plotting TOC and $S_{2}$ values obtained from RockEval pyrolysis. As described in Chapter 3, the $L O M$ for all of the field examples studied in this thesis was determined to be greater than 10.5; hence we use the $L O M$ calibration limit of 10.4 in all cases (Passey et al., 2010). The equation to transform $\triangle \log R$ to $L O M$ is given by

$$
T O C=\Delta \log R \times 10^{(2.297-0.1688 L O M)},
$$

where $T O C$ is the estimated total organic carbon, $\triangle \log R$ is calculated from equations A.3, A.4, or A.5, and $L O M$ is the level of organic metamorphism determined from the TOC vs. $S_{2}$ cross-plot.

The main technical difficulty encountered when using the $\Delta \log R$ method is the determination of baseline values. For instance, the wet-shale baseline interval is usually not available and when it is available a slight adjustment is normally required to obtain a good match with core data. When measured TOC from core samples is available, however, baseline values can be calibrated and used in nearby wells. 

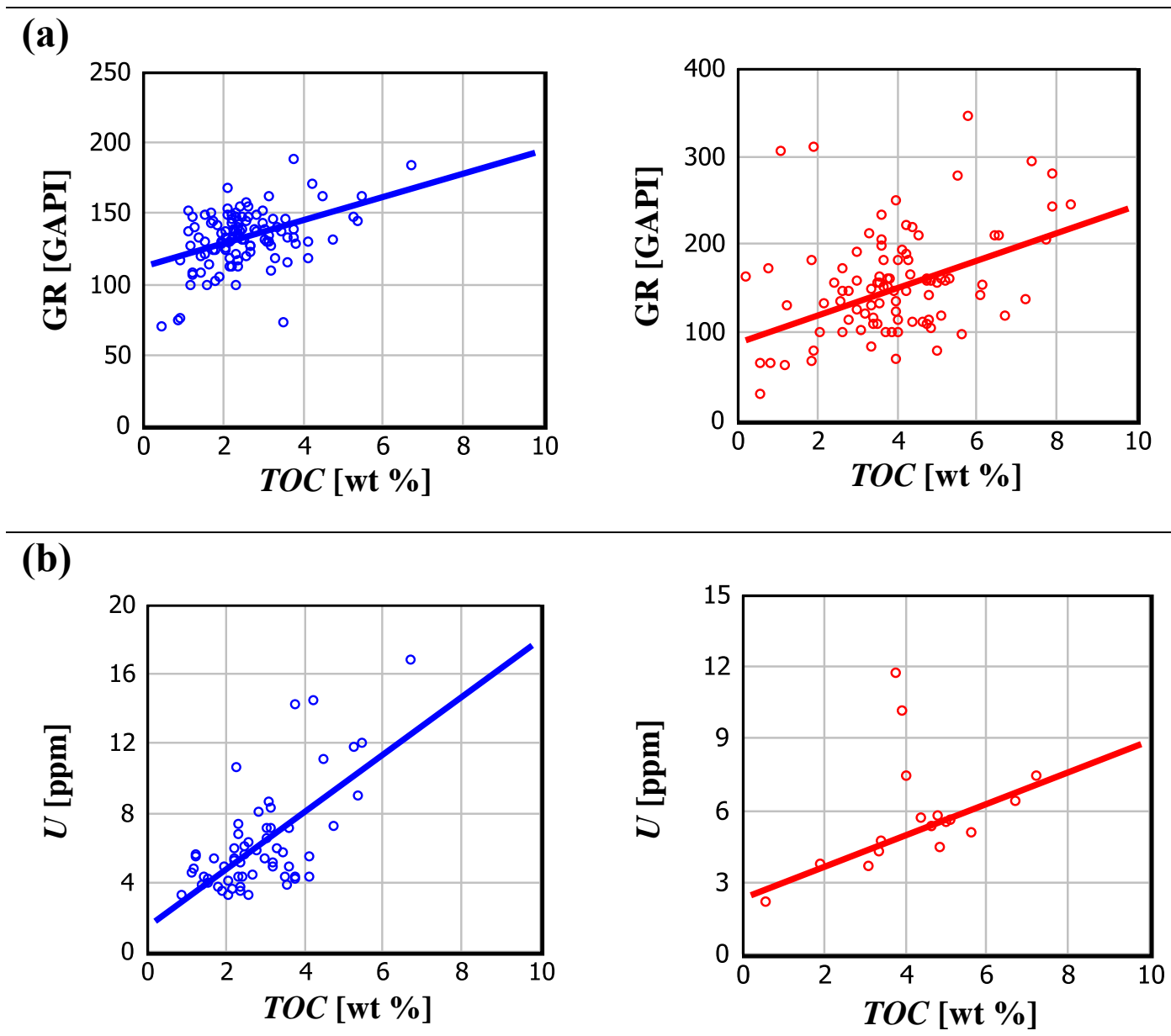

Figure A.1: Correlation of core Total Organic Carbon (TOC) in weight percent to (a) gamma-ray log, and (b) uranium log in the Haynesville (to the left), and Barnett shales (to the right). 


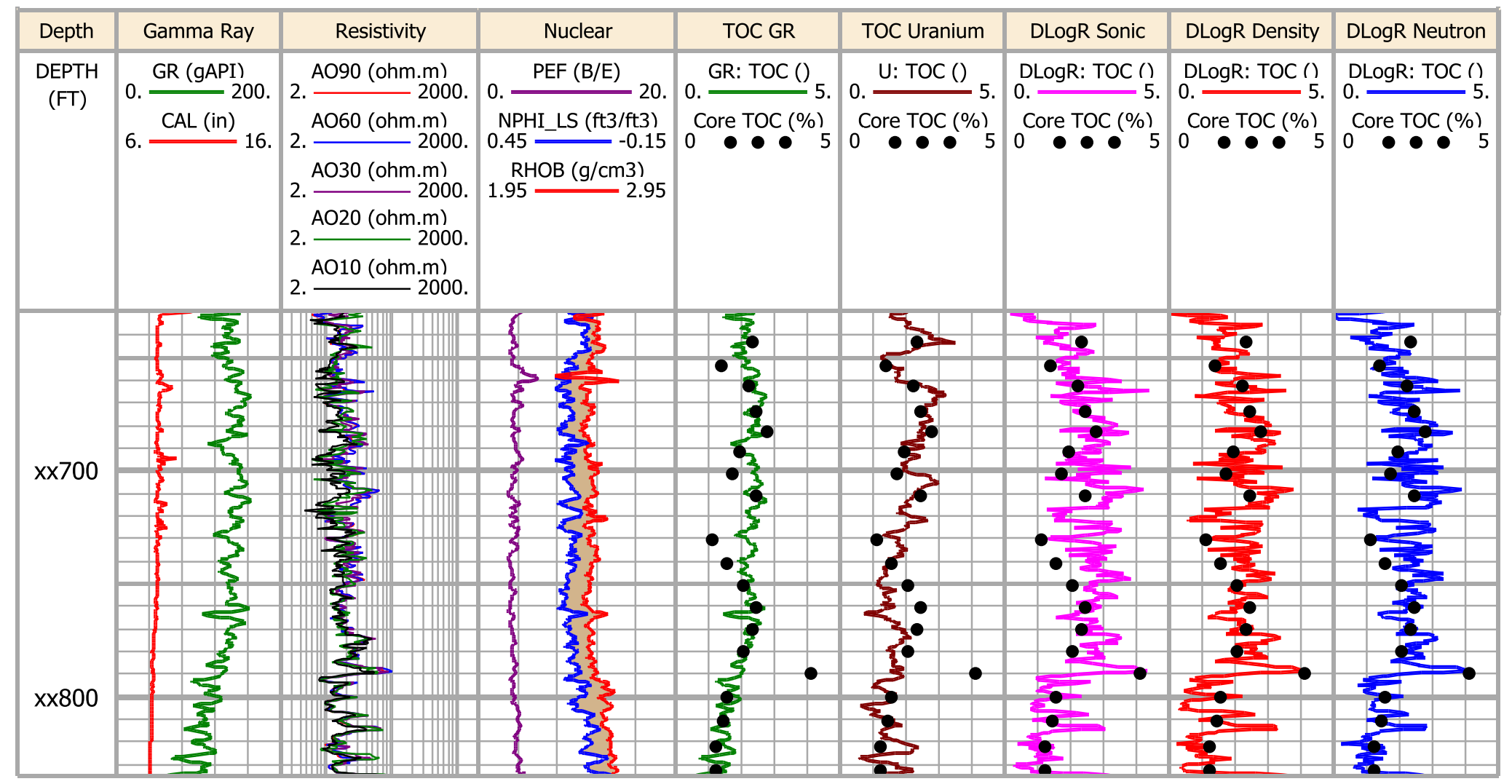

Figure A.2: Comparison of various TOC estimation methods in well H1. Track 1: Relative depth. Track 2: Gamma-ray and caliper logs. Track 3: Array-induction apparent resistivity logs. Track 4: PEF, bulk density, and neutron (limestone matrix) porosity logs. Track 5: TOC from core and estimated from gamma-ray log. Track 6: TOC from core and estimated from uranium log. Track 7: TOC from core and $\triangle \log R$ estimation using the sonic $\log$. Track 8: $T O C$ from core and $\triangle \log R$ estimation using the bulk density log. Track 9: TOC from core and $\triangle \log R$ estimation using the neutron porosity $\log$. 


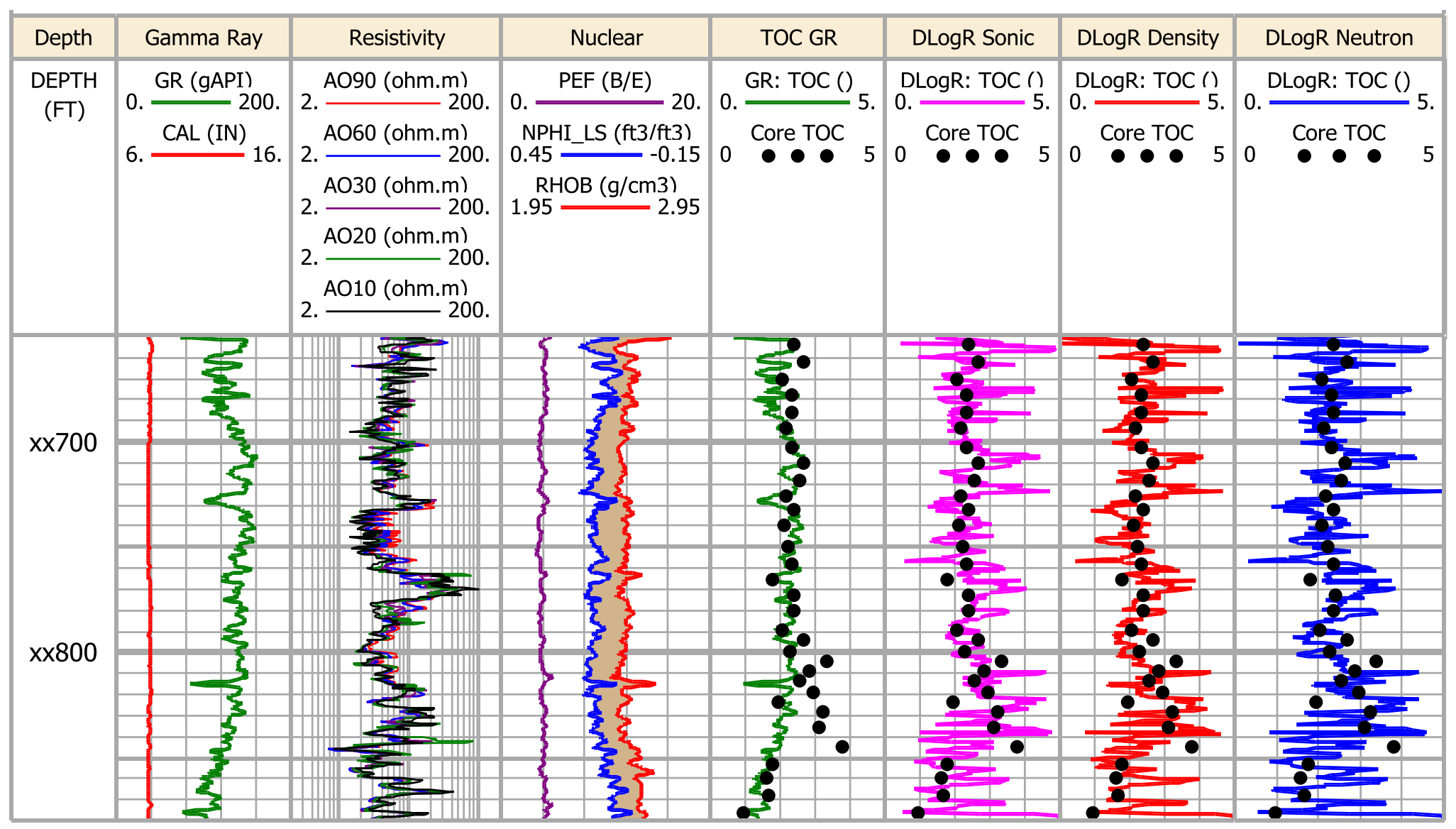

Figure A.3: Comparison of various TOC estimation methods in well H2. Track 1: Relative depth. Track 2: Gamma-ray and caliper logs. Track 3: Array-induction apparent resistivity logs. Track 4: PEF, bulk density, and neutron (limestone matrix) porosity logs. Track 5: TOC from core and estimated from gamma-ray log. Track 6: TOC from core and $\triangle \log R$ estimation using the sonic $\log$. Track 7: TOC from core and $\triangle \log R$ estimation using the bulk density log. Track 8: TOC from core and $\triangle \log R$ estimation using the neutron porosity log. 


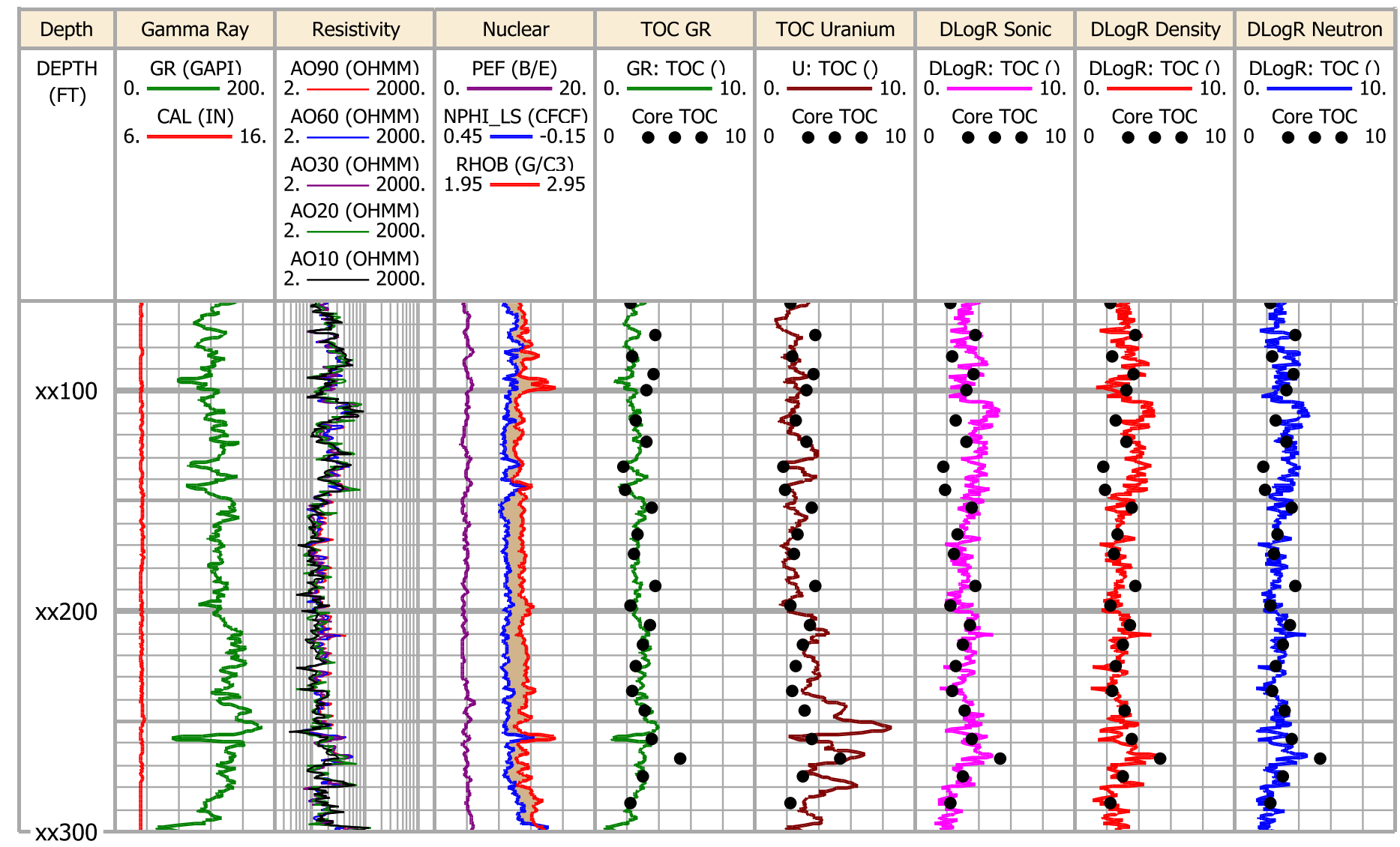

Figure A.4: Comparison of various TOC estimation methods in well H3. Track 1: Relative depth. Track 2: Gamma-ray and caliper logs. Track 3: Array-induction apparent resistivity logs. Track 4: PEF, bulk density, and neutron (limestone matrix) porosity logs. Track 5: TOC from core and estimated from gamma-ray log. Track 6: TOC from core and estimated from uranium $\log$. Track 7: TOC from core and $\triangle \log R$ estimation using the sonic $\log$. Track 8: $T O C$ from core and $\triangle \log R$ estimation using the bulk density log. Track 9: TOC from core and $\triangle \log R$ estimation using the neutron porosity log. 


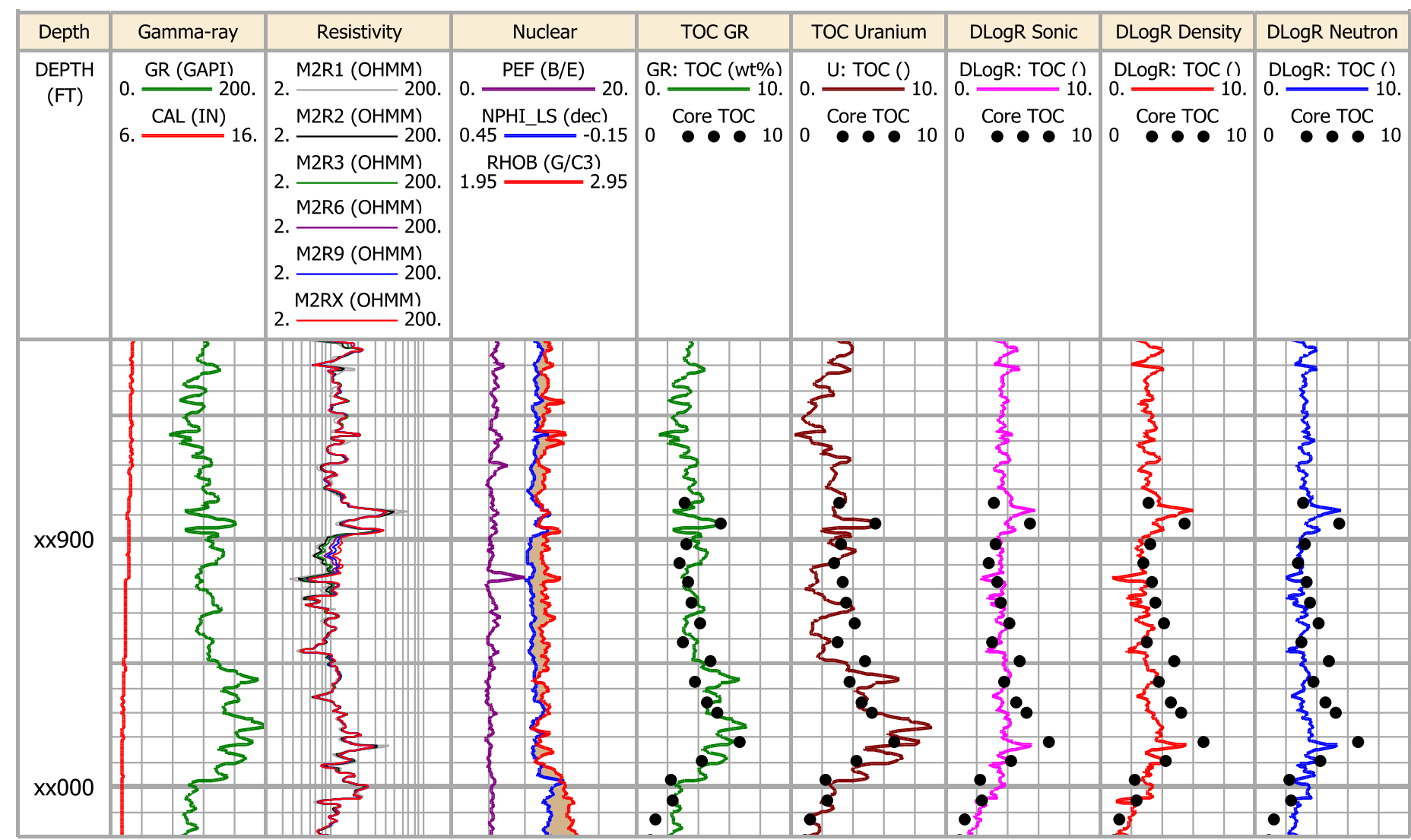

Figure A.5: Comparison of various TOC estimation methods in well H4. Track 1: Relative depth. Track 2: Gamma-ray and caliper logs. Track 3: Array-induction apparent resistivity logs. Track 4: PEF, bulk density, and neutron (limestone matrix) porosity logs. Track 5: TOC from core and estimated from gamma-ray log. Track 6: TOC from core and estimated from uranium $\log$. Track 7: TOC from core and $\triangle \log R$ estimation using the sonic $\log$. Track 8: $T O C$ from core and $\triangle \log R$ estimation using the bulk density log. Track 9: TOC from core and $\triangle \log R$ estimation using the neutron porosity log. 


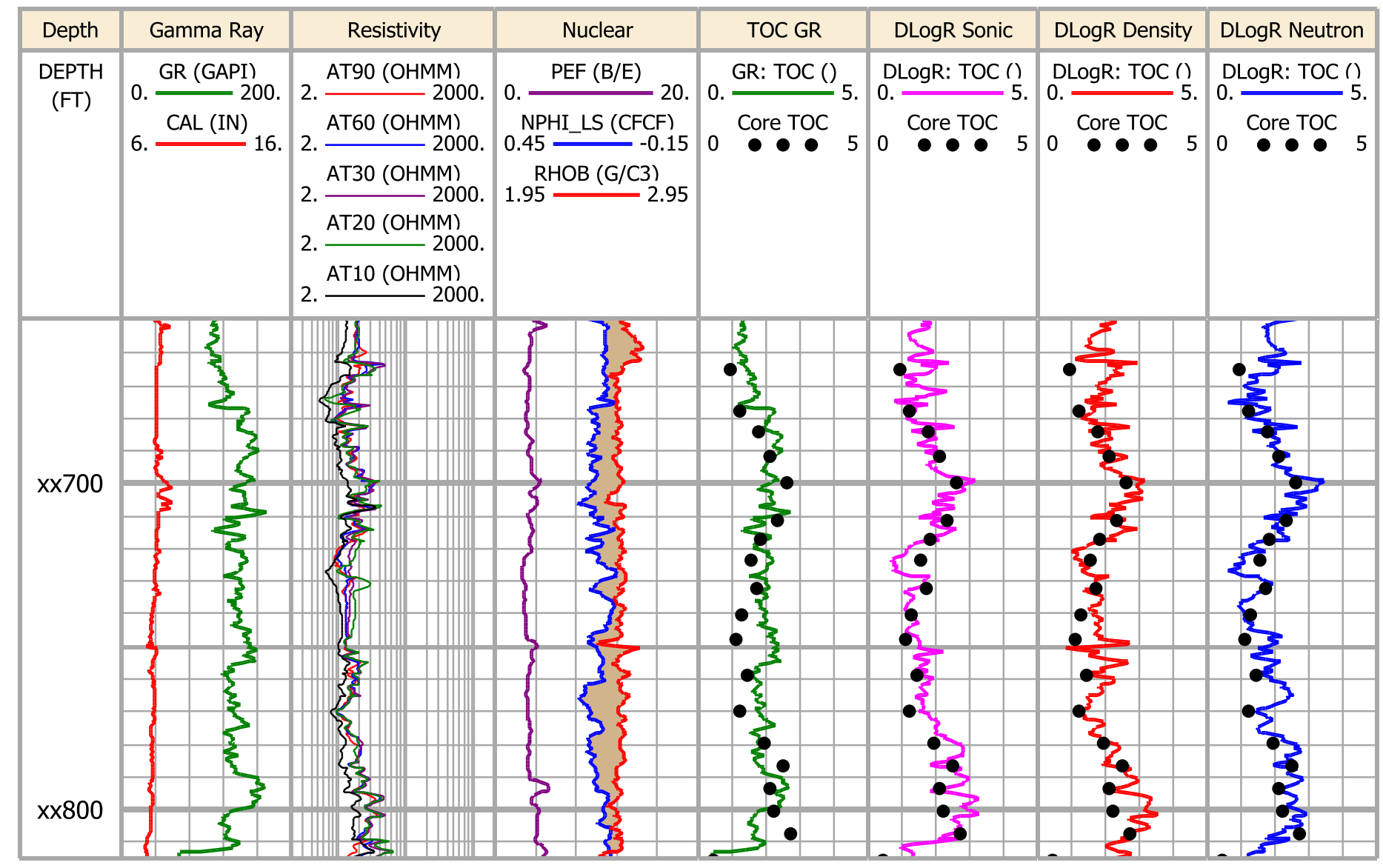

Figure A.6: Comparison of various TOC estimation methods in well H5. Track 1: Relative depth. Track 2: Gamma-ray and caliper logs. Track 3: Array-induction apparent resistivity logs. Track 4: PEF, bulk density, and neutron (limestone matrix) porosity logs. Track 5: TOC from core and estimated from gamma-ray log. Track 6: TOC from core and $\Delta \log R$ estimation using the sonic $\log$. Track 7: TOC from core and $\Delta \log R$ estimation using the bulk density $\log$. Track 8: TOC from core and $\triangle \log R$ estimation using the neutron porosity log. 


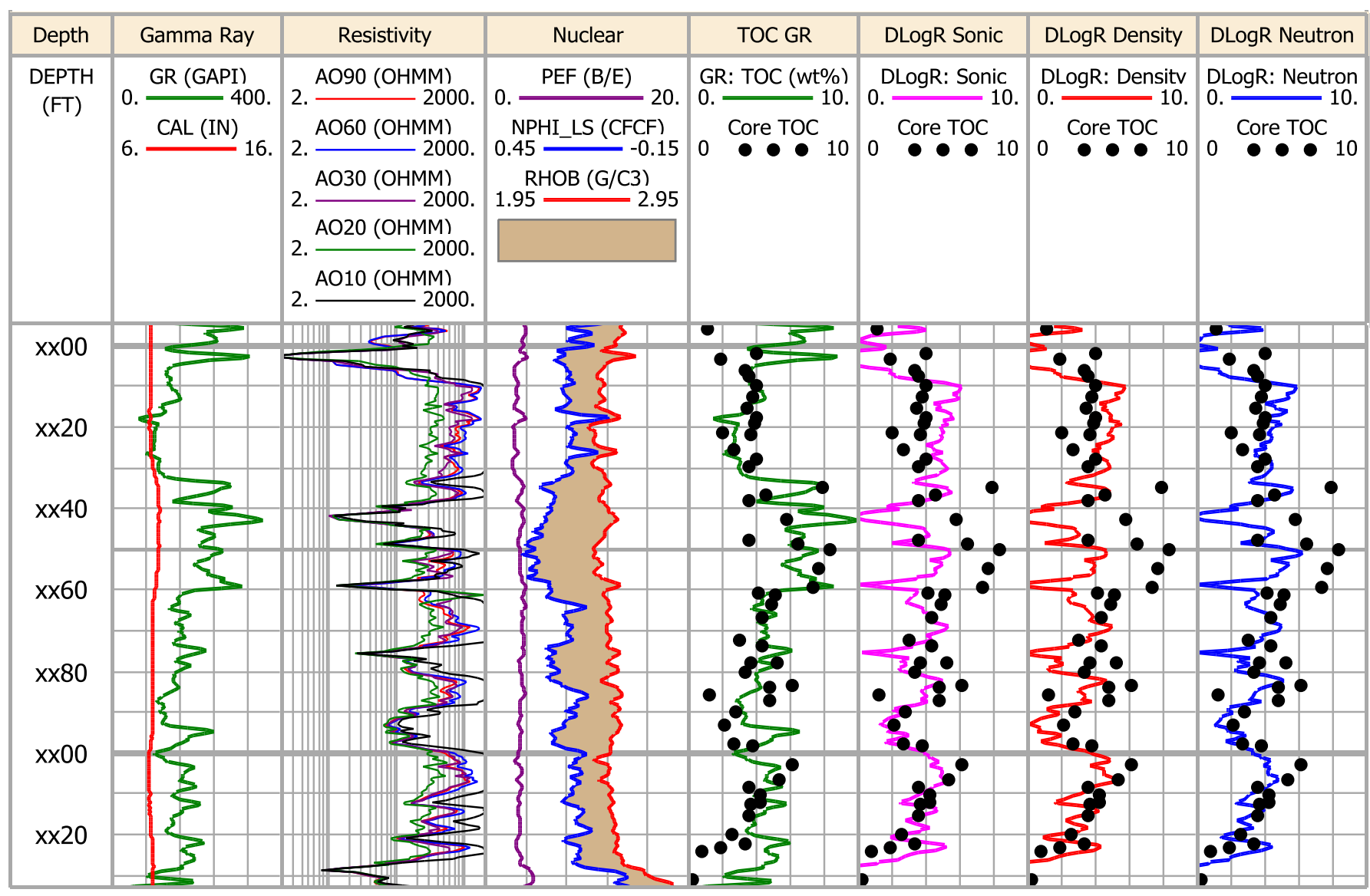

Figure A.7: Comparison of various TOC estimation methods in well B1. Track 1: Relative depth. Track 2: Gamma-ray and caliper logs. Track 3: Array-induction apparent resistivity logs. Track 4: PEF, bulk density, and neutron (limestone matrix) porosity logs. Track 5: TOC from core and estimated from gamma-ray log. Track 6: TOC from core and $\triangle \log R$ estimation using the sonic $\log$. Track 7: TOC from core and $\triangle \log R$ estimation using the bulk density log. Track 8: TOC from core and $\triangle \log R$ estimation using the neutron porosity $\log$. 


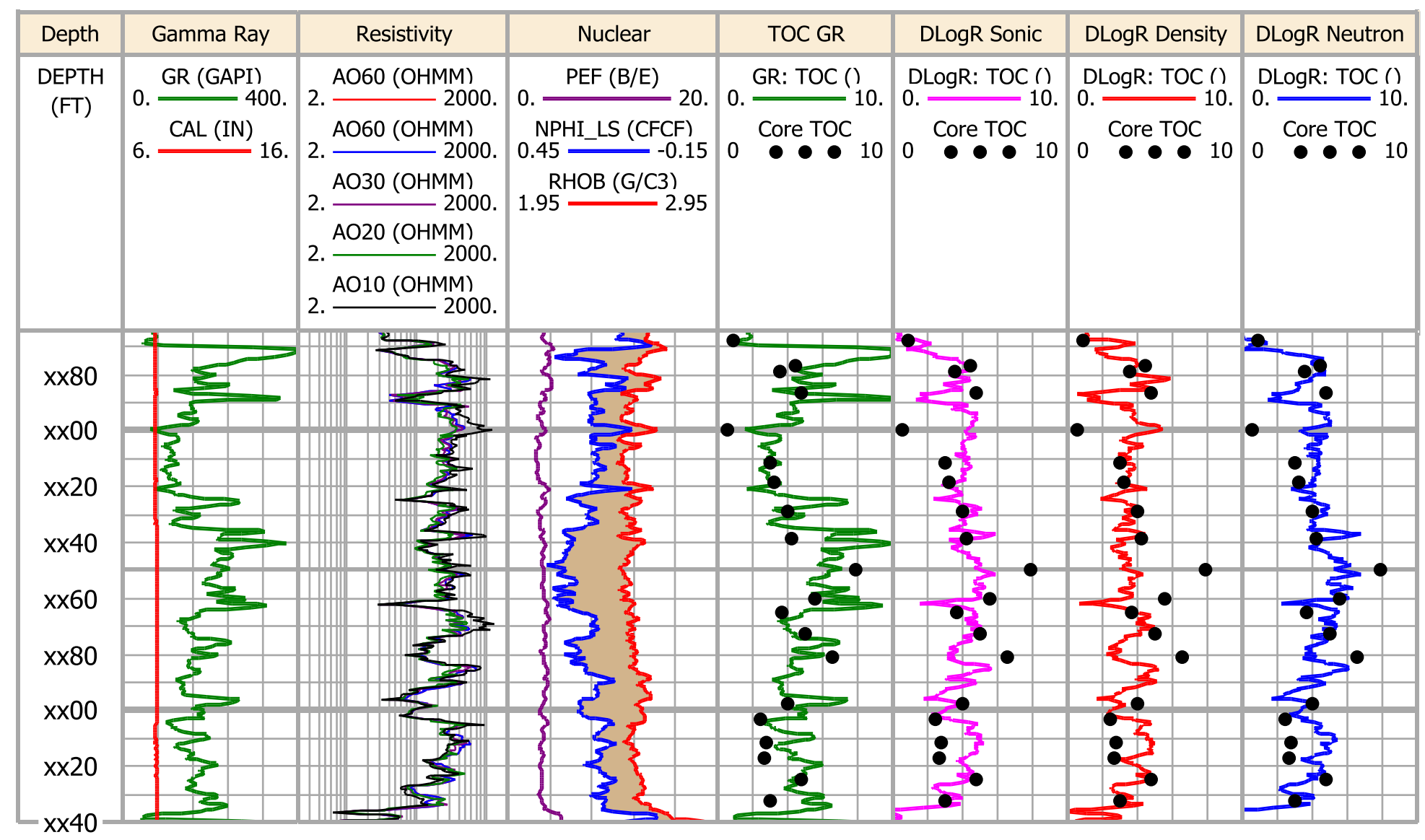

Figure A.8: Comparison of various TOC estimation methods in well B2. Track 1: Relative depth. Track 2: Gamma-ray and caliper logs. Track 3: Array-induction apparent resistivity logs. Track 4: PEF, bulk density, and neutron (limestone matrix) porosity logs. Track 5: TOC from core and estimated from gamma-ray log. Track 6: TOC from core and $\Delta \log R$ estimation using the sonic log. Track 7: TOC from core and $\Delta \log R$ estimation using the bulk density log. Track 8: TOC from core and $\Delta \log R$ estimation using the neutron porosity $\log$. 


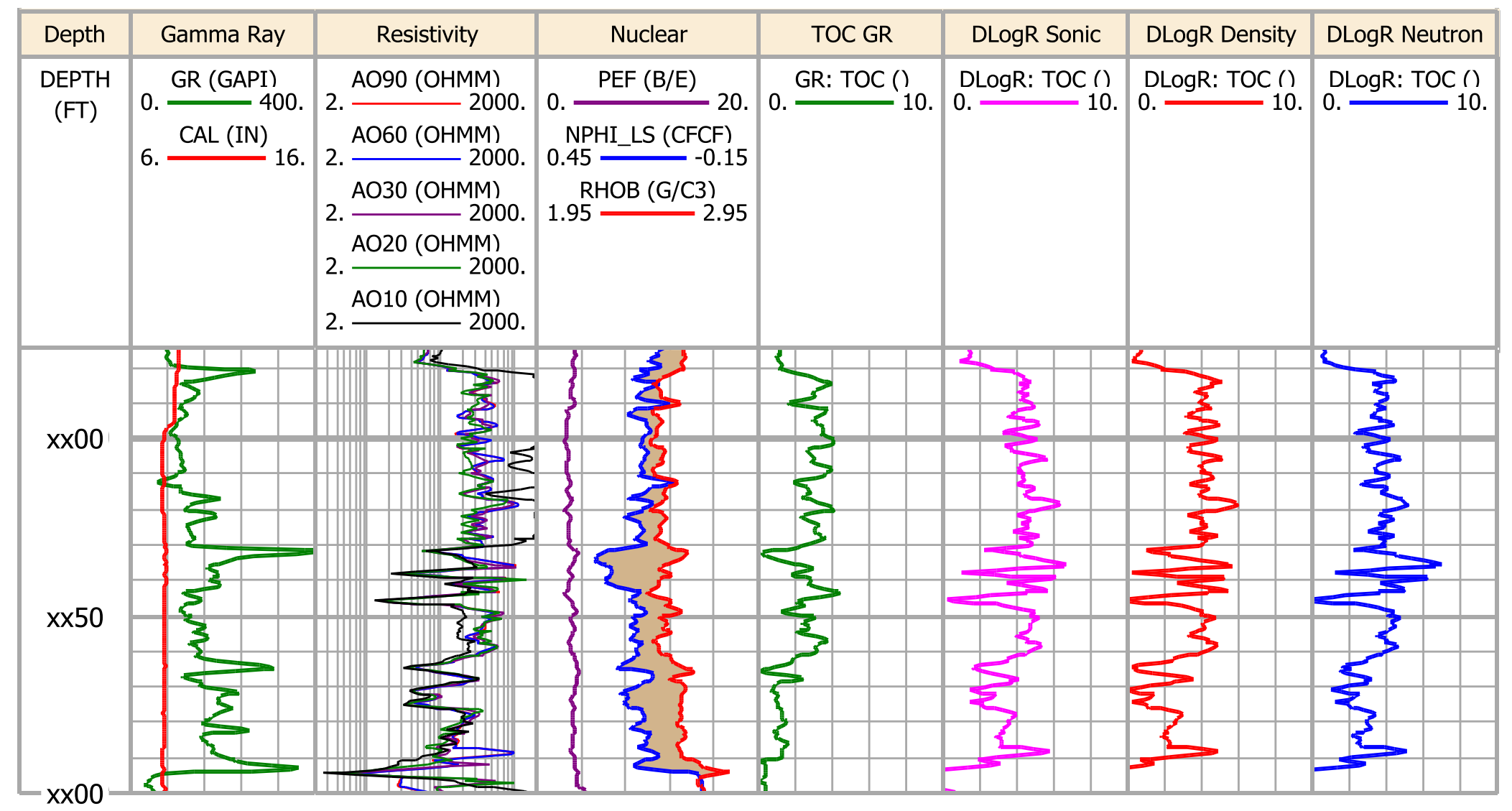

Figure A.9: Comparison of various TOC estimation methods in well B3. Track 1: Relative depth. Track 2: Gamma-ray and caliper logs. Track 3: Array-induction apparent resistivity logs. Track 4: PEF, bulk density, and neutron (limestone matrix) porosity logs. Track 5: TOC estimated from gamma-ray log. Track 6: TOC from $\triangle \log R$ estimation using the sonic log. Track 7: TOC from $\triangle \log R$ estimation using the bulk density log. Track 8: TOC from $\Delta \log R$ estimation using the neutron porosity log. 


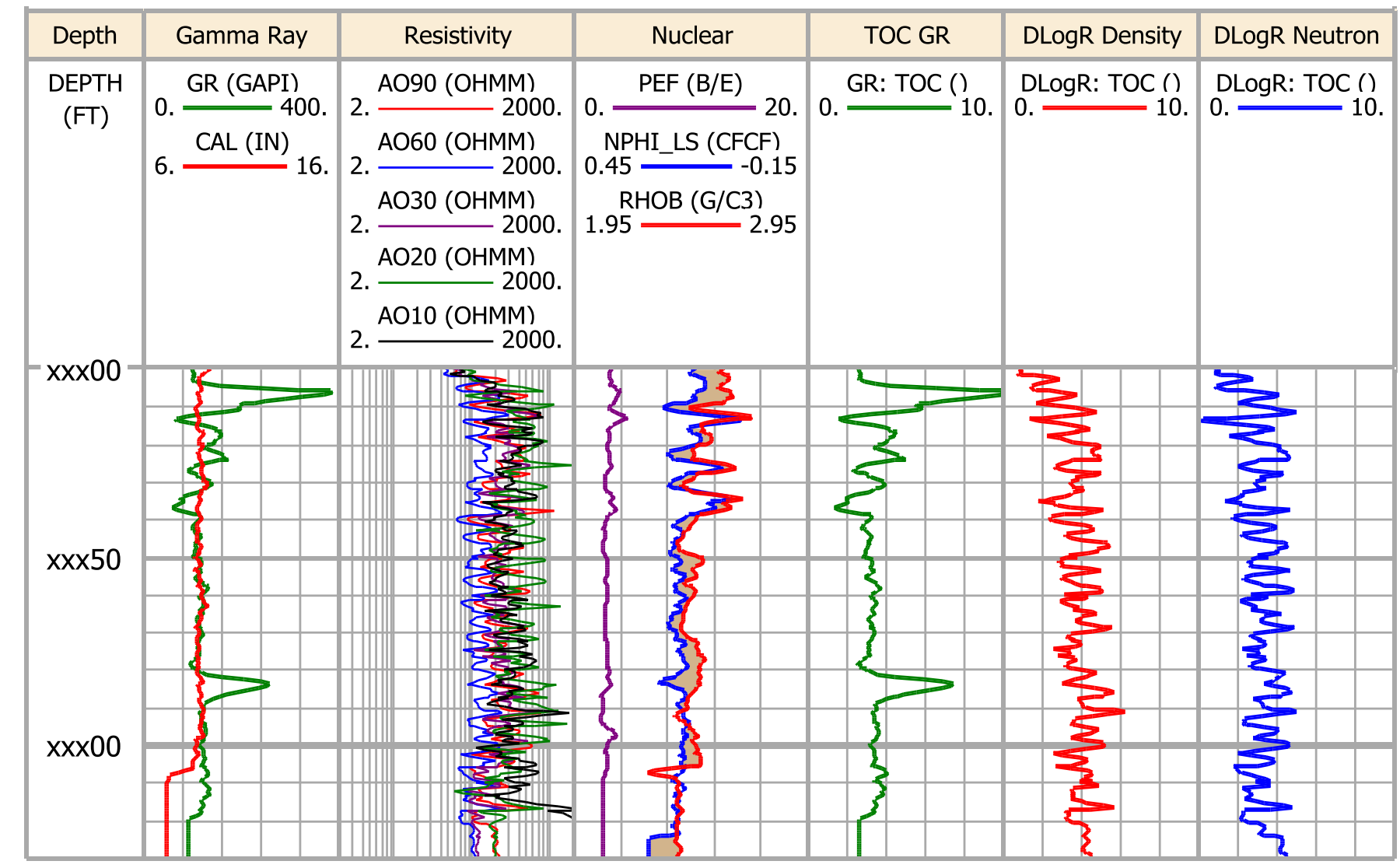

Figure A.10: Comparison of various TOC estimation methods in well B4. Track 1: Relative depth. Track 2: Gamma-ray and caliper logs. Track 3: Array-induction apparent resistivity logs. Track 4: PEF, bulk density, and neutron (limestone matrix) porosity logs. Track 5: TOC estimated from gamma-ray log. Track 6: TOC from $\triangle \log R$ estimation using the bulk density log. Track 7: TOC from $\triangle \log R$ estimation using the neutron porosity log. 


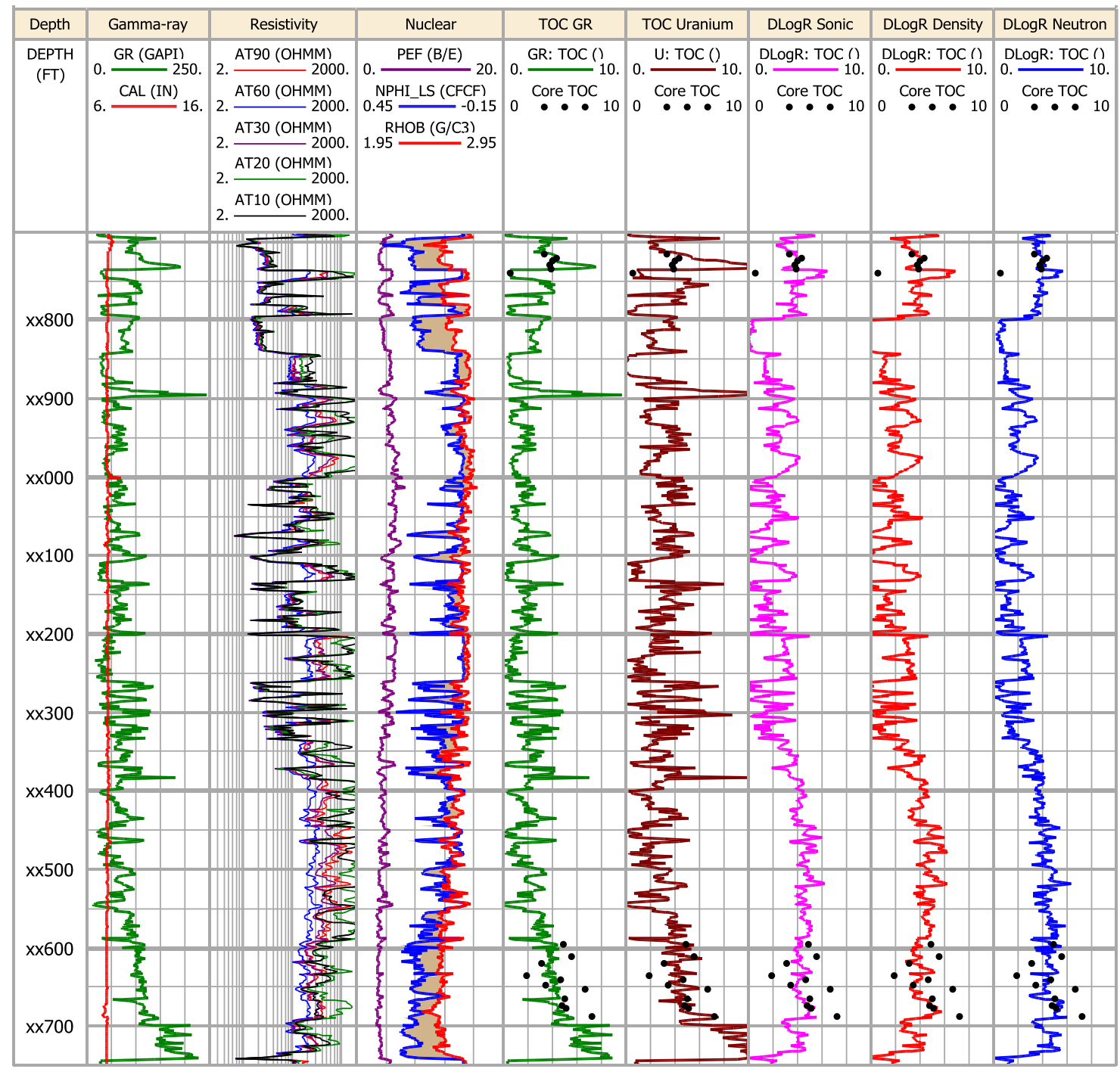

Figure A.11: Comparison of various TOC estimation methods in well B5. Track 1: Relative depth. Track 2: Gamma-ray and caliper logs. Track 3: Arrayinduction apparent resistivity logs. Track 4: PEF, bulk density, and neutron (limestone matrix) porosity logs. Track 5: TOC from core and estimated from gamma-ray log. Track 6: TOC from core and estimated from uranium log. Track 7: TOC from core and $\triangle \log R$ estimation using the sonic $\log$. Track 8: TOC from core and $\triangle \log R$ estimation using the bulk density log. Track 9: TOC from core and $\triangle \log R$ estimation using the neutron porosity $\log$. 


\section{Appendix B: Geochemical Analysis of Kerogen from RockEval Pyrolysis}

Figure B.1 shows the reconstruction of Hydrogen Index (HI)/Oxygen Index (OI) diagram (Espitalie et al., 1977), often referred to as the Pseudo-Van Krevelen plot, from core measurements studied in Haynesville and Barnett shales. Nearly all the points are

plotted close to the origin of the diagram, whereby it is difficult to identify the type of kerogen solely from RockEval data. Much of the existing literature associates gasproducing shales with kerogen type III, gas-prone kerogen. This inference is usually incorrect. Most gas shales contain overmature oil-prone (Type II) kerogen (Passey et al., 2010). Any kerogen types (I, II, or III) will cluster toward the origin when they are in an overmature stage; other tests such as visual kerogen analysis or pyrolysis-gas chromatography are necessary to properly evaluate kerogen type (Dembicki, 2009). In addition, kerogen is usually present in mixed kerogen types wherein the mixing can mask the type of kerogen in the Pseudo-Van Krevelen plot (Dembicki, 2009). 
(a)

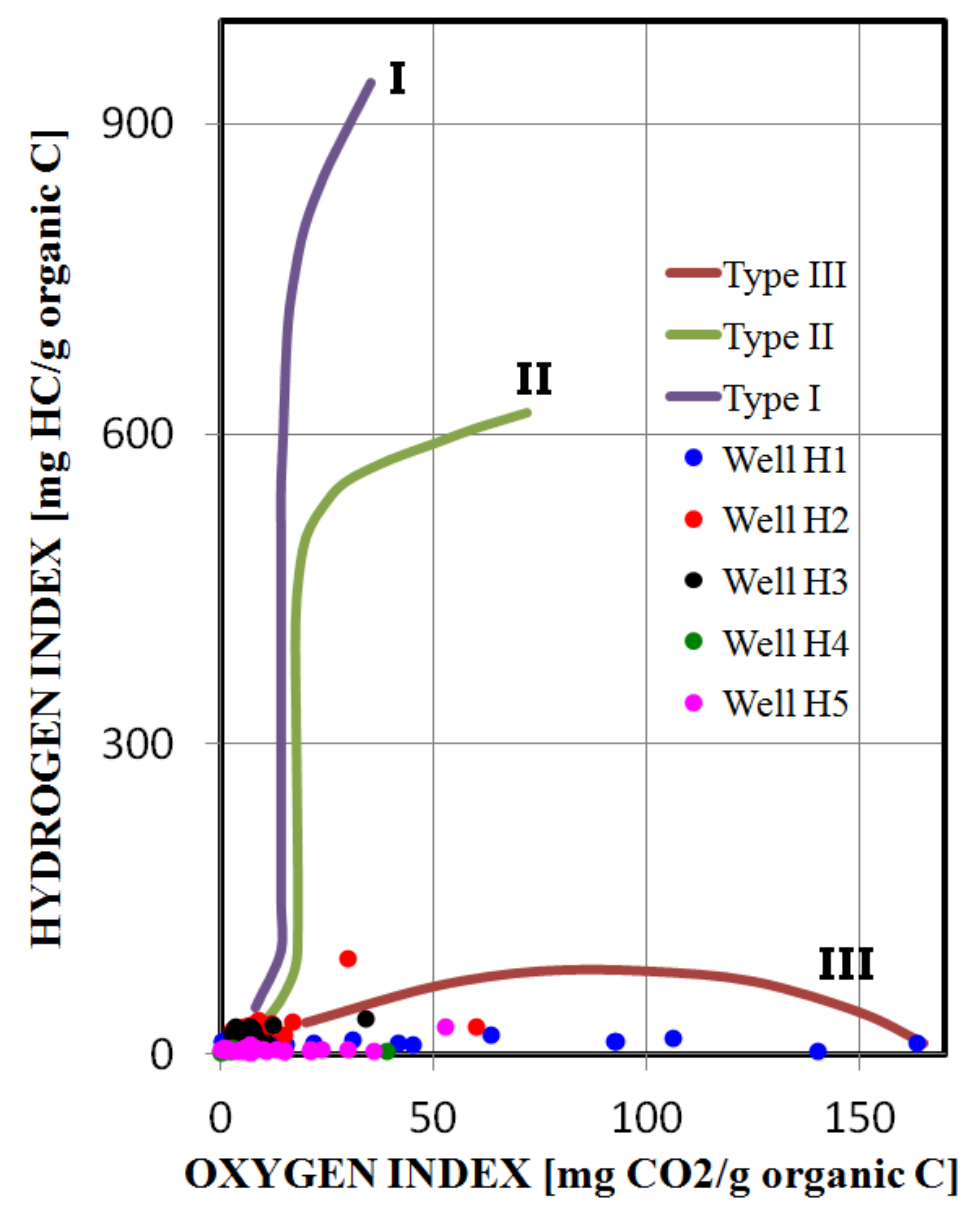

(b)

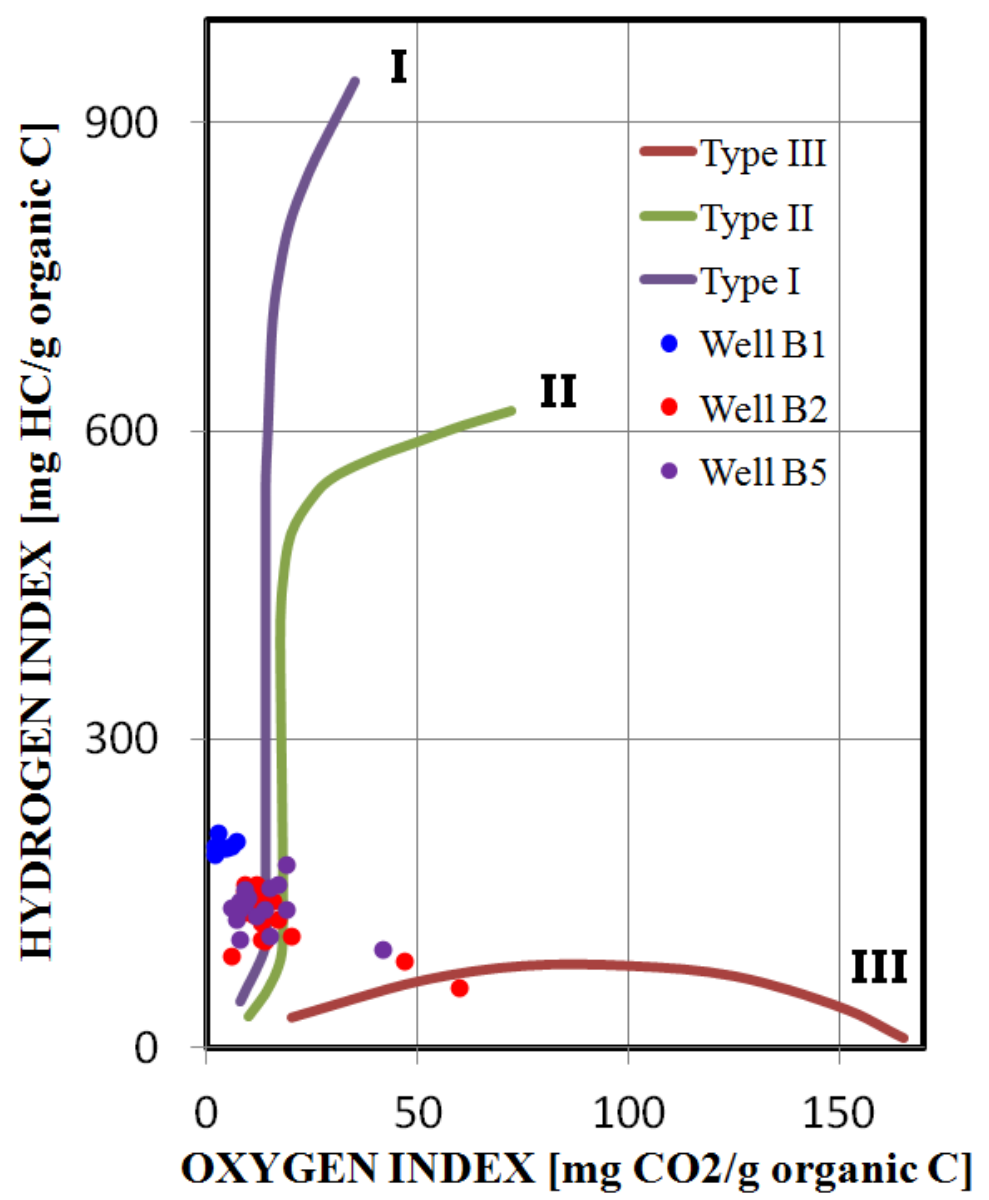

Figure B.1: Pseudo-Van Krevelen diagram constructed from RockEval measurements of core samples for: (a) Haynesville, and (b) Barnett shales. Figure is adapted from Espitalie et al. (1977) 


\section{Nomenclature}

\author{
$a$ \\ $C_{k}$ \\ $G R_{0}$ \\ $G R_{100}$ \\ K \\ $L_{m}$ \\ $L O M$ \\ $m$ \\ $n$ \\ $R_{\text {clay }}$ \\ $R_{o}$ \\ $R_{n c}$ \\ $R_{t}$ \\ $R_{w}$ \\ $S_{g}$ \\ $S_{o}$ \\ $S_{\text {wnc }}$ \\ $S_{w t}$ \\ $S_{1}$ \\ $S_{2}$ \\ Th : Thorium log, [ppm] \\ $T_{\max } \quad: \quad$ Temperature corresponding to the $S_{2}$ peak from the RockEval \\ pyrolysis measurement, $\left[{ }^{\circ} \mathrm{C}\right]$ \\ TOC : Total Organic Carbon, [wt\%] \\ : Archie's Winsauer factor, [ ] \\ : Carbon weight fraction in kerogen, [ ] \\ : Estimated gamma-ray log reading in $0 \%$ TOC formation, [GAPI] \\ : Hypothetical gamma-ray log reading in $100 \%$ TOC formation, [GAPI] \\ : Potassium log, [\%] \\ : Neutron migration length, [cm] \\ : Level of organic metamorphism, [ ] \\ : Archie's porosity exponent, [ ] \\ : Archie's saturation exponent, [ ] \\ : Clay resistivity, [Ohm-m] \\ : A measure of maturity from the Vitrinite reflectance, [\%] \\ : Non-clay resistivity, [Ohm-m] \\ : True formation resisitivity, [Ohm-m] \\ : Connate water resistivity, [Ohm-m] \\ : Gas saturation, [ ] \\ : Oil saturation, [ ] \\ : Non-clay water saturation, [ ] \\ : Total water saturation, [ ] \\ : First peak of the RockEval pyrolysis measurement, [milligram of \\ hydrocarbon per gram of rock] \\ : Second peak of the RockEval pyrolysis measurement, [milligram of \\ hydrocarbon per gram of rock]
}




\begin{tabular}{|c|c|c|}
\hline$T O C_{G R}$ & & Estimated TOC from the gamma-ray log [wt $\%]$ \\
\hline$T O C_{U}$ & & Estimated TOC from the uranium $\log [\mathrm{wt} \%]$ \\
\hline$U$ & & Uranium curve of the spectral gamma-ray logs, $[\mathrm{ppm}]$ \\
\hline$U_{\text {maa }}$ & & Apparent matrix volumetric photoelectric factor, [b/cc] \\
\hline$U_{0}$ & & Estimated uranium log reading in $0 \%$ TOC formation, [GAPI] \\
\hline$U_{100}$ & & Hypothetical uranium log reading in $100 \%$ TOC formation, [GAPI] \\
\hline$V_{\text {ankerite }}$ & & Volumetric concentration of ankerite, [ ] \\
\hline$V_{\text {calcite }}$ & & Volumetric concentration of calcite, [ ] \\
\hline$V_{C A R}$ & & Volumetric concentration of the carbonate mineral group, [ ] \\
\hline$V_{\text {chlorite }}$ & & Volumetric concentration of chlorite, [ ] \\
\hline$V_{C L A}$ & & Volumetric concentration of the clay mineral group, [ ] \\
\hline$V_{\text {clay }}$ & & Volumetric concentration of clay, [ ] \\
\hline$V_{\text {dolomite }}$ & & Volumetric concentration of dolomite, [ ] \\
\hline$V_{\text {fluorapatite }}$ & & Volumetric concentration of fluorapatite, [ ] \\
\hline$V_{H C}$ & & Volumetric concentration of hydrocarbon, [ ] \\
\hline$V_{H C-k e r o g e n}$ & $\cdot$ & Volumetric concentration of hydrocarbon in matrix pores, [ ] \\
\hline$V_{H C \text {-matrix }}$ & & Volumetric concentration of hydrocarbon in kerogen pores, [ ] \\
\hline$V_{\text {illite }}$ & & Volumetric concentration of illite, [ ] \\
\hline$V_{\text {kaolinite }}$ & & Volumetric concentration of kaolinite, [ ] \\
\hline$V_{\text {kerogen }}$ & & Volumetric concentration of kerogen, [ ] \\
\hline$V_{k \text {-feldspar }}$ & & Volumetric concentration of potassium feldspar, [ ] \\
\hline$V_{\text {mix }}$ & & Volumetric concentration of mixed layer illite/smectite, [ ] \\
\hline$V_{n c}$ & & Volumetric concentration of non-clay minerals, [ ] \\
\hline$V_{\text {pyrite }}$ & & Volumetric concentration of pyrite, [ ] \\
\hline$V_{p \text {-feldspar }}$ & & Volumetric concentration of plagioclase feldspar, [ ] \\
\hline$V_{Q F}$ & & Volumetric concentration of the quartz and feldspar mineral group, [ ] \\
\hline$V_{\text {quartz }}$ & & Volumetric concentration of quartz, [ ] \\
\hline$V_{W}$ & & Volumetric concentration of water, [ ] \\
\hline$V_{W-\text { clay }}$ & & Volumetric concentration of clay-bound water, [ ] \\
\hline
\end{tabular}




\begin{tabular}{|c|c|}
\hline$V_{W-\text { matrix }}$ & Volumetric concentration of water in matrix pores, [ ] \\
\hline$W_{\text {ankerite }}$ & Weight concentration of ankerite, [] \\
\hline$W_{\text {calcite }}$ & Weight concentration of calcite, [ ] \\
\hline$W_{C A R}$ & Weight concentration of the carbonate mineral group, [ ] \\
\hline$W_{\text {chlorite }}$ & Weight concentration of chlorite, [ ] \\
\hline$W_{C L A}$ & Weight concentration of the clay mineral group, [ ] \\
\hline$W_{\text {clay }}$ & Weight concentration of clay, [ ] \\
\hline$W_{\text {dolomite }}$ & Weight concentration of dolomite, [] \\
\hline$W_{\text {fluorapatite }}$ & Weight concentration of fluorapatite, [ ] \\
\hline$W_{\text {illite }}$ & Weight concentration of illite, [ ] \\
\hline$W_{\text {kaolinite }}$ & Weight concentration of kaolinite, [] \\
\hline$W_{\text {kerogen }}$ & Weight concentration of kerogen, [ ] \\
\hline$W_{k \text {-feldspar }}$ & Weight concentration of potassium feldspar, [ ] \\
\hline$W_{m i x}$ & Weight concentration of mixed layer illite/smectite, [ ] \\
\hline$W_{\text {pyrite }}$ & Weight concentration of pyrite, [ ] \\
\hline$W_{p \text {-feldspar }}$ & Weight concentration of plagioclase feldspar, [ ] \\
\hline$W_{Q F}$ & Weight concentration of the quartz and feldspar group, [ ] \\
\hline$W_{Q F M}$ & Weight concentration of the quartz, feldspar, and mica group, [ ] \\
\hline$W_{\text {quartz }}$ & Weight concentration of quartz, [ ] \\
\hline$\Delta \log R_{\text {density }}$ & $\begin{array}{l}\text { Quantification of the degree of separation between bulk density and } \\
\text { resistivity logs for Passey's method, [ ] }\end{array}$ \\
\hline$\Delta \log R_{\text {neutron }}$ & $\begin{array}{l}\text { Quantification of the degree of separation between neutron porosity } \\
\text { and resistivity logs for Passey's method, [ ] }\end{array}$ \\
\hline$\Delta \log R_{\text {sonic }}$ & $\begin{array}{l}\text { Quantification of the degree of separation between sonic slowness and } \\
\text { resistivity for Passey's method, [ ] }\end{array}$ \\
\hline$\Delta t$ & Compressional slowness from sonic $\log ,[\mu \mathrm{s} / \mathrm{ft}]$ \\
\hline$\Delta t_{\text {baseline }}$ & Baseline compressional slowness, $[\mu \mathrm{s} / \mathrm{ft}]$ \\
\hline$\phi_{\text {clay }}$ & Clay porosity, [ ] \\
\hline
\end{tabular}




$\begin{array}{lll}\phi_{N} & : & \text { Neutron porosity, [] } \\ \phi_{N, \text { baseline }} & : & \text { Baseline neutron porosity, [] } \\ \phi_{n c} & : & \text { Non-clay porosity, [ ] } \\ \phi_{t} & : & \text { Total porosity, [ ] } \\ \rho_{b} & : & \text { Bulk density, [g/cc] } \\ \rho_{\text {baseline }} & : & \text { Baseline bulk density, [g/cc] } \\ \rho_{\text {clay }} & : & \text { Clay density, [g/cc] } \\ \rho_{f} & : & \text { Fluid density, [g/cc] } \\ \rho_{g} & : & \text { Grain density, [g/cc] } \\ \rho_{H C} & : & \text { Hydrocarbon density, [g/cc] } \\ \rho_{\text {kerogen }} & : & \text { Kerogen density, [g/cc] } \\ \rho_{\text {ma }} & : & \text { Matrix density, [g/cc] } \\ \rho_{\text {maa }} & : & \text { Apparent grain density, [g/cc] } \\ \rho_{W} & : & \text { Water density, [g/cc] }\end{array}$




\section{Acronyms}

\begin{tabular}{|c|c|c|}
\hline AAPG & $:$ & American Association of Petroleum Geologists \\
\hline AIT & $:$ & Schlumberger Array-Induction Tool \\
\hline $\mathrm{C} / \mathrm{O}$ & : & Carbon/Oxygen Logging \\
\hline CAR & : & Carbonate mineral group \\
\hline CLA & : & Clay mineral group \\
\hline CSF & $:$ & Common Stratigraphic Framework \\
\hline DLIS & : & Digital Log Interchange Standard \\
\hline EIA & $:$ & U.S. Energy Information Administration \\
\hline FIB & : & Focused Ion Beam \\
\hline FTIR & : & Fourier Transform Infrared Spectroscopy \\
\hline GAPI & : & American Petroleum Institute Gamma-ray Units \\
\hline GR & : & Natural Gamma-ray Log \\
\hline GRI & : & Gas Research Institute \\
\hline $\mathrm{HI}$ & : & Hydrogen Index \\
\hline HST & $:$ & Highstand System Tract \\
\hline LAS & $:$ & Log ASCII Standard \\
\hline LST & : & Lowstand System Tract \\
\hline MFS & : & Maximum Flooding Surface \\
\hline $\mathrm{N}$ & $:$ & North \\
\hline NCS & : & Neutron-capture Gamma-ray Spectroscopy Log \\
\hline $\mathrm{NE}$ & $:$ & Northeast \\
\hline NGL & : & Natural Gas Liquid \\
\hline OI & : & Oxygen Index \\
\hline PEF & : & Photoelectric Factor Log \\
\hline ppm & : & Parts per million \\
\hline QFM & : & $\begin{array}{l}\text { Quartz, Feldspar, and Mica mineral group } \\
\qquad 106\end{array}$ \\
\hline
\end{tabular}




$\begin{array}{lll}\text { S } & : & \text { South } \\ \text { SEM } & : & \text { Scanning Electron Microscope } \\ \text { SNUPAR } & : & \text { Schlumberger Nuclear Parameter code } \\ \text { SW } & : & \text { Southwest } \\ \text { tcf } & : & \text { Trillion cubic feet } \\ \text { TST } & : & \text { Transgressive System Tract } \\ \text { UTAPWeLS } & : & \text { University of Texas at Austin's Petrophysical and Well Log Simulator } \\ \text { XRD } & : & \text { X-Ray Diffraction } \\ \text { XRF } & : & \text { X-Ray Fluorescence }\end{array}$




\section{References}

Britt, L., and Schoeffler, J., 2009, The geomechanics of a shale play: What makes a shale prospective!, SPE Eastern Regional Meeting, Charleston, West Virginia, USA, September 23-25.

Bruner, K. R., and Smosna, R., 2011, A Comparative Study of the Mississipian Barnett Shale, Forth Worth Basin, and Devonian Marcellus Shale, Appalachian Basin, DOE Report DOE/NETL-2011/1478.

Buller, D., and Dix, M. C., 2009, Petrophysical evaluation of the Haynesville shale in northwest Louisiana and northeast Texas, Gulf Coast Association of Geological Societies Transactions, v. 59, pp. 127-143.

Dembicki, H., 2009, Three common source rock evaluation errors made by geologists during prospect or play appraisals, AAPG Bulletin, v. 93, no. 3, pp. 341-356.

Dicker, A. I., and Smits, R. M., 1988, A practical approach for determining permeability from laboratory pressure-pulse decay measurements, SPE International Meeting on Petroleum Engineering, Tianjin, China, November 1-4.

Ellis, D. V., and Singer, J. M., 2007, Well Logging for Earth Scientists, Springer.

Espitalie, J., Madec, M., Tissot, B., Mennig, J., and Leplat, P., 1977, Source rock characterization method for petroleum exploration, 9th Annual Offshore Technology Conference, Houston, Texas, May 2-5.

Fertl, W. H., 1979, Gamma ray spectral data assists in complex formation evaluation, SPWLA 6th European Symposium, London, England, March 26-27.

Fertl, W. H., and Chilingar, G., 1988, Total organic carbon content determined from well logs, SPE Formation Evaluation, v. 3, no. 2, pp. 407-419.

Fertl, W. H., and Rieke, H. H., 1980, Gamma-ray spectral evaluation techniques identify fractured shale reservoirs and source-rock characteristics, Journal of Petroleum Technology, v. 32, no. 11, pp. 2053-2062.

Guidry, F. K., Luffel, D. L., and Olszewskl, A. J., 1990, Devonian shale formation evaluation model based on logs, new core analysis methods, and production tests, SPWLA 31st Annual Logging Symposium, June 24-27.

Hammes, U., 2012, Personal communication. 
Hammes, U., and Frébourg, G., 2012, Haynesville and Bossier mudrocks: a facies and sequence stratigraphic investigation, east Texas and Louisiana, USA, Marine and Petroleum Geology, v. 31, no. 1, pp. 8-26.

Hammes, U., Hamlin, H. S., and Ewing, T. E., 2011, Geologic analysis of the upper Jurassic Haynesville shale in east Texas and west Louisiana, AAPG Bulletin, v. 95, no. 10, pp. 1643-1666.

Heidari, Z., Torres-Verdín, C., and Preeg, W. E., 2012, Improved estimation of mineral and fluid volumetric concentrations from well logs in thinly bedded and invaded formations, Geophysics, v. 77, no. 3, pp. WA79-WA98.

Herron, S. L., 1987, A total organic carbon log for source rock evaluation, The Log Analyst, v. 28, no. 6, pp. 520-527.

Herron, S. L., and Le Tendre, L., 1990, Wireline source-rock evaluation in the Paris basin, AAPG Studies in Geology, v. 30, pp. 57-72.

Jarvie, D. M., Hill, R. J., Ruble, T. E., and Pollastro, R. M., 2007, Unconventional shalegas systems: The Mississippian Barnett shale of north-central Texas as one model for thermogenic shale-gas assessment, AAPG Bulletin, v. 91, no. 4, pp. 475-499.

Jones, S. C., 1997, A technique for faster pulse-decay permeability measurements in tight rocks, SPE Formation Evaluation, v. 12, no. 1, pp. 19-26.

King, G., 2010, Thirty years of gas shale fracturing: What have we learned?, SPE Annual Technical Conference and Exhibition, Florence, Italy, September 19-22.

Loucks, R. G., Reed, R. M., Ruppel, S. C., and Jarvie, D. M., 2009, Morphology, genesis, and distribution of nanometer-scale pores in siliceous mudstones of Mississipian Barnett shale, Journal of Sedimentary Research, v. 79, no. 11-12, pp. 848-861.

Loucks, R. G., and Ruppel, S. C., 2007, Mississippian Barnett shale: Lithofacies and depositional setting of a deep-water shale-gas succession in the Fort Worth basin, Texas, AAPG Bulletin, v. 91, no. 4, pp. 579-601.

Luffel, D. L., and Guidry, F. K., 1989, Core-Analysis Results: Comprehensive Study Wells, Devonian Shale, Topical Report GRI-89/0151.

Luffel, D. L., and Guidry, F. K., 1992, New core analysis methods for measuring reservoir rock properties of Devonian shale, Journal of Petroleum Technology, v. 44, no. 11, pp. 1184-1190. 
Luffel, D. L., Hopkins, C. W., and P.D., S., 1993, Matrix permeability measurement of gas productive shales, SPE Annual Technical Conference and Exhibition, Houston, Texas, October 3-6.

Lüning, S., and Kolonic, S., 2003, Uranium spectral gamma-ray response as proxy for organic richness in black shales: Applicability and limitations, Journal of Petroleum Geology, v. 26, no. 2, pp. 153-174.

Mba, K., and Prasad, M., 2010, Mineralogy and its contribution to anisotropy and kerogen stiffness variations with maturity in the Bakken shales, 2010 SEG Annual Meeting, Denver, Colorado, October 17-22.

McKeon, D. C., and Scott, H. D., 1989, SNUPAR-a nuclear parameter code for nuclear geophysics applications, IEEE Transactions on Nuclear Science, v. 36, no. 1, pp. 1215-1219.

Montgomery, S. L., Jarvie, D. M., Bowker, K. A., and Pollastro, R. M., 2005, Mississippian Barnett shale, Fort Worth basin, north-central Texas: Gas-shale play with multi-trillion cubic foot potential, AAPG Bulletin, v. 89, no. 2, pp. 155175.

Papazis, P. K., 2005, Petrographic Characterization of the Barnett Shale, Forth Worth Basin, Texas, Master's Thesis, The University of Texas at Austin.

Parker, M., Buller, D., Petre, J., and Dreher, D., 2009, Haynesville shale-Petrophysical evaluation, SPE Rocky Mountain Petroleum Technology Conference, Denver, Colorado, April 14-16.

Passey, Q. R., Bohacs, K., Esch, W., Klimentidis, R. E., and Sinha, S., 2010, From oilprone source rock to gas-producing shale reservoir - Geologic and petrophysical characterization of unconventional shale-gas reservoirs, International Oil and Gas Conference and Exhibition in China, Beijing, China, June 8-10.

Passey, Q. R., Creaney, S., Kulla, J. B., Moretti, F. J., and Stroud, J. D., 1990, A practical model for organic richness from porosity and resistivity logs, AAPG Bulletin, v. 74, no. 12 , pp. $1777-1794$.

Pollastro, R. M., Jarvie, D. M., Hill, R. J., and Adams, C. W., 2007, Geologic framework of the Mississippian Barnett shale, Barnett-Paleozoic total petroleum system, bend arch-Fort Worth basin, Texas, AAPG Bulletin, v. 91, no. 4, pp. 405-436.

Popielski, A. C., 2011, Rock Classification from Conventional Well Logs in Hydrocarbon-Bearing Shale, Master's Thesis, The University of Texas at Austin. 
Poupon, A., Loy, M. E., and Tixier, M. P., 1954, A contribution to electrical log interpretation in shaly sands, Journal of Petroleum Technology, v. 6, no. 6, pp. $27-34$.

Quirein, J., Witkowsky, J., Truax, J., Galford, J., Spain, D., and Odumosu, T., 2010, Integrating core data and wireline geochemical data for formation evaluation and characterization of shale gas reservoirs, SPE Annual Technical Conference and Exhibition, Florence, Italy, September 19-22.

Ramirez, T., Klein, J., Bonnie, R., and Howard, J., 2011, Comparative study of formation evaluation methods for unconventional shale gas reservoirs: Application to the Haynesville shale (Texas), SPE North American Unconventional Gas Conference and Exhibition, The Woodlands, Texas, June 14-16.

Schlumberger, 2009, Log Interpretation Chart, Schlumberger, Sugar Land, Texas.

Schmoker, J. W., 1979, Determination of organic content of Appalachian Devonian shales from formation-density logs, AAPG Bulletin, v. 63, no. 9, pp. 1504-1509.

Schmoker, J. W., 1981, Determination of organic-matter content of Appalachian Devonian shales from gamma-ray logs, AAPG Bulletin, v. 65, no. 7, pp. 12851298.

Slatt, R., 2011, Important geological properties of unconventional resource shales, Central European Journal of Geosciences, v. 3, no. 4, pp. 435-448.

Sondergeld, C., Newsham, K., Comisky, J., Rice, M., and Rai, C., 2010, Petrophysical considerations in eevaluating and producing shale gas resources, $S P E$

Unconventional Gas Conference, Pittsburgh, Pennsylvania, February 23-25.

U.S. Energy Information Administration, 2011, Review of Emerging Resources: U.S. Shale Gas and Shale Oil Plays.

Voss, B., Torres-Verdin, C., Gandhi, A., Alabi, G., and Lemkecher, M., 2009, Common Stratigraphic Framework to simulate well logs and to cross-validate static and dynamic petrophysical interpretations, SPWLA 50th Annual Logging Sympsium, The Woodlands, Texas, June 21-24.

Wang, F. P., and Reed, R. M., 2009, Pore networks and fluid flow in gas shales, SPE Annual Technical Conference and Exhibition, New Orleans, Louisiana, October 4-7.

Wignall, P. B., 1994, Black Shales, Clarendon Press, Oxford and New York. 
Zhang, S., and Klimentidis, R. E., 2011, Porosity and permeability analysis on nanoscale FIB-SEM 3D imaging of shale rock, International Symposium of the Society of Core Analysts, Austin, Texas, September 18-21. 